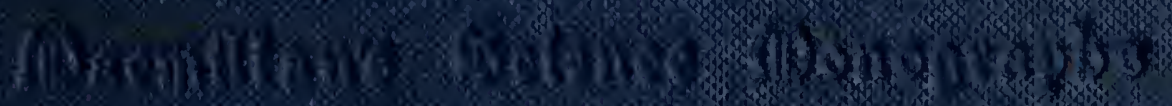

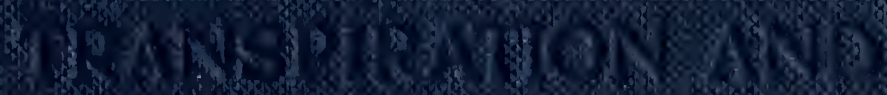

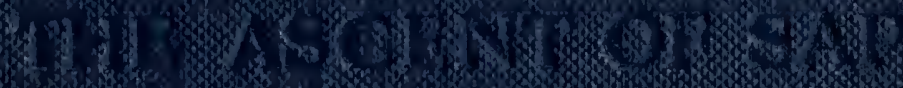

$$
\begin{aligned}
& \text { 11. } 121.12125 \\
& \text { 1 } 12161 \times 01
\end{aligned}
$$





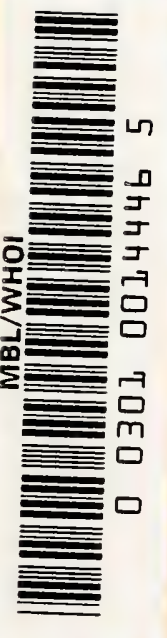



SIDachíllan's Ðcícnce IIDonograpbs

TRANSPIRATION AND THE ASCENT OF SAP IN PLANTS 


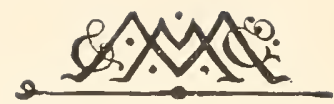

MACMILLAN AND CO., LIMITED

LONDON . BOMBAY . CALCUTTA

MELBOURNE

THE MACMILLAN COMPANY

NEIW YORK . BOSTON . CHICAGO

DALLAS . SAN FRANCISCO

THE MACMILLAN CO. OF CANADA, LTD

TOKONTO 


\section{TRANSPIRATION AND THE ASCENT OF SAP IN PLANTS}

HENRY H. DIXON, Sc.D., F.R.S.

University Professor of Botany in Trinity College, Dublin : Director of Trinity Collige Botanic Gardens

MACMILLAN AND CO., LIMITED ST. MARTIN'S STREET, LONDON 
COPYRIGHT

$$
5=26
$$




\section{PREFACE}

The Ascent of Sap is a problem of old standing. As was the case with several other biological problems, a peculiar alternation may be observed in the hypotheses formed to explain the phenomena. At first the process of the ascent of water in trees was, almost without serious thought, assigned to the vital activities of the plant, and, in general with other vital processes, put outside the domain of physical investigation. Later, advances in physics and chemistry, introducing rationality into observation, emboldened hardy spirits to assign the whole process to various physical forces or to combinations of them. Doubtless these philosopher's somewhat transgressed legitimate deduction, and their daring met its punishment in the overthrow of their successive physical theories. It was then again the turn of the Vitalists, and during the latter part of the last century they enjoyed their heyday of dogma. However, the leaven of rationality still worked on in even their theories, and several physiologists must have felt what Strasburger stated, that the physical forces developed in, and the physical configuration exhibited by, the water tracts would supply a complete explanation when properly understood. In the present monograph, an account is given of a 
physical explanation of the rise of water in trees. This theory rests on the knowledge of a property of liquids, which, although discovered in the middle of the last century, was little recognised and seldom referred to in physical literature. It now appears that a full appreciation of this property is essential for the realisation of the manner in which water is raised in plants and of the meaning of the structure of trees as a mechanism for lifting water.

In the formation of the theory and in much of the earlier work carried out to test its validity and to illustrate its applicability, Dr. J. Joly and the author worked in collaboration. The work on the cryoscopy. of sap was carried out with the help of Mr. W. R. G. Atkins, to whom the author is further indebted for his help in reading the proofs and for his useful criticisms. Prof. R. A. Gregory - the editor of this series of monographs-has also kindly supplied several valuable emendations and suggestions.

Henry H. Dixon.

SCHOOL of BotaNy,

Trinity College, Dublis.

1914. 


\section{CONTENTS}

\section{CHAPTER I}

PASE

TIIE NATURE OF TRANSPIRATION .

\section{CHAPTER II}

ASCEN" OF SAP IN STEMS. CRITICISM OF PIYSICAL THEORIES

\section{CHAPTER III}

ASCENT OF SAP IN STEMS. CRITICISII OF VITAL THEORIES . . . 47

\section{CHAPTER IV}

COHESION THEORY OF THE ASCENT OF SAI' IN STEMS

\section{CHAPTER V}

TENSILE STRENGTH OF THE SAP OF TREEN .

\section{CHAPTER VI}

ESTIMLATE OF TIIE TENSION REQUIRED TO RAINE TIIE SAl'.

CHAPTER VII

\section{CHAPTER VIII}

THE THERMO-ELECTRIC METHOD OF CRYOSCOPY 
viii

\section{CONTENTS}

\section{CHAPTER IX}

PAGE:

METHODS OF EXTRACTING S.AP FOR CRYUSOPIC "BSERVATIONS * $\quad 175$

CHAPTER X

OSHOTIC PRESSURES IN PLANTS . . . . . . . . . 19

\section{CHAPTER XI}

ENERGY AVAILABLE FOR RAISINA THE SAP . . . . . 201

INDEX . . . . . . . 21: 


\title{
TRANSPIRATION AND THE ASCENT OF SAP IN PLANTS.
}

\author{
CHAPTER I \\ THE NATURE OF TRANSPIRATION
}

Transpiration and evaporation.-Comparison of the transpiration from the upper side and of that from the under side of hypostomatous leaves has shown that transpiration is principally effected through the stomata. The total area of the stomata, however, bears but a very small proportion to that of the whole leaf. For example, in a leaf of Catalpa bignonioides it is but 0.9 per cent. of the total leaf surface. In a leaf of Helianthus annus the area of the stomata appears to be about 3 per cent. of the whole leaf surface.

Many years ago, Unger showed that under similar conditions the amount of water evaporated from a free surface was $2 \cdot 8$ to $13 \cdot 8$ times that transpired from an equal leaf surface. If we take the lower limit, this means that $35 \mathrm{sq} . \mathrm{cm}$. of water surface will give off as much water vapour as $100 \mathrm{sq}$. cm. of leaf surface under similar conditions. Of this $100 \mathrm{sq}$. cm. as much as $3 \mathrm{sq}$. cm. may be represented as stomata. So we arrive at the surprising result that the combined area of the stomata is at least ten times as efficient in giving off water vapour as a free water surface of equal area. 
Diffusion through stomata.-The beautiful researches of Brown and Escombe on diffusion through perforated septa have satisfactorily cleared up this difficulty. They showed experimentally that the amount of vapour which diffuses through a perforation in a septum does not diminish proportionally as the cross section diminishes, but only in proportion as its diameter decreases. This result, which is at first sight by no means obvious, has been mathematically explained by both Stephan and Larmor. Brown and Escombe quote both writers; but as their methods may not be easily followed by all botanists the following simple explanation may be of interest.

When diffusion, undisturbed by convection currents, is taking place from a perforation which is kept filled with water vapour, or from a surface of water, into a space less rich in water vapour, it is evident that after a time a certain gradient of concentration will establish itself over the aperture. The concentration will be greatest near the perforation and less more remote from it, whilst shells of uniform concentration will be found over-arching the perforation. At a hittle distance from the aperture, say when the diameter of the shells is about four times that of the perforation, these shells will be approximately hemispheres.

To possess any given concentration $\rho$ a shell must have an area bearing a definite proportion to the area of the perforation; because the supply maintaining its concentration is derived from the water molecules leaving the aperture, and the number of these will be proportional to its area.

Let $R$ and $A$ denote the radius and area respectively of the shell having a concentration $\rho$, and $r$ and $a$ the radius and area of the perforation. Let $\rho_{1}$ indicate the concentration of water vapour in the perforation.

$$
A=k a \text { or } R^{2}=h r^{2} \text {. }
$$


The flow into the shell $=$ the gradient $\times$ area $=\frac{\rho_{1}-\rho}{R} \times A$

$$
\frac{\rho_{1}-\rho}{R} \times 1=\frac{\rho_{1}-\rho}{r^{\prime} k} l_{i} \pi r^{2}=\left(\rho_{1}-\rho\right) 、 \sqrt{\prime} i \pi r
$$

Therefore the flow from the aperture is proportional to its radius and not to its area.

Under the "static" conditions to which these calculations apply, the shape of the stomata also contributes to their efficiency. It will easily be understood that separated as they are from one another by distances relatively great compared with their diameters, the diffusion of water vapour from adjacent stomata will not interfere. Consequently the rate of diffusion at the margins will be greater than over the middle of the apertures. Therefore, an opening having the longest margin relatively to its area will be the most efficient; and the slit-like form of the stomata is seen to be particularly advantageous.

The consideration that the margins are the most effective parts of the stomata in diffusion suggests another way of looking at the "diameter law." It is evident that for very small holes the marginal region bears a very large relation to the whole opening. For circular apertures the area decreases as the square of the radius while the margin is reduced only as the radius. In the case of slit-like apertures the whole opening may be regarded as marginal. But it is this marginal region which is most effective; and therefore we should expect the amount of water vapour diffusing through such an aperture to be approximately proportional to the margin (and therefore to the diameter) rather than to the area of the aperture.

The diffusion of water vapour from the intercellular spaces of the leaves through the stomata has been thus explained on simple physical principles. It remains to be seen how the supply of water to these spaces is to be accounted for.

Functions of evaporation, osmosis, and im- 
bibition in transpiration.- The leaf trachea containing the rising sap are separated from the intercellular spaces by a layer of one or more thin-walled cells. The thin wall, which is formed of cellulose, is permeable to water and dissolved substances; at the same time it is tough and of considerable tensile strength. It is lined by a layer of viscid protoplasm which in turn surrounds, and is completely filled by, a solution-the vacuole. The latter contains various carbohydrates and electrolytes in solution, and round it the protoplasmic layer forms a fairly perfect semi-permeable membrane. It is evident that, when sufficient water is available, the solutes in the vacuole will exert an osmotic pressure on the protoplasm which will be forced outwards against the wall and distend the latter. Ultimately, the tensile stress in the wall will balance the osmotic pressure of the solutes of the vacuole and equilibrium will be established and the cells will be tense and rigid. The walls of the trachere are also quite permeable, but they are more rigid than those of the cells and they are further prevented from collapsing by the presence of the internal supports in the form of rings and spirals. The trachere do not enclose a semi-permeable membrane of protoplasm.

We may now consider how this mechanism will act in the transference of water. The imbibitional or capillary forces of the cell-walls in contact with the intercellular spaces of the leaf will draw off water from their vacuoles through the protoplasm until the concentration of solutes in the vacuole is such that the vapour pressure of water in it is equal to that obtaining in the cell-wall. Supposing now that the vapour pressure of the water menisci in the réseau of the cell-wall is greater than that obtaining in the intercellular space, water will leave the wall and the menisci will retreat into it. This will cause their curvature to increase and will raise their capillary forces so that they will endeavour to extract water from the solution in the 
vacuole. A concentration of the vacuole results, and consequently the osmotic pull on the water in the trache⿰ is increased. Hence it follows that a transference of water from the tracheæ will take place so long as the vapour pressure of water in the trachere is greater than that in the intercellular spaces of the leaf.

With such a mechanism before our minds we can easily realise that the whole process of transpiration may be purely physical and one into which vital actions (viz., actions connected with living substance the intermediate steps of which are little understood) need not enter.

These considerations also explain several observations otherwise difficult of interpretation. When colouring materials (e.g., eosin) or other substances, poisonous or non-poisonous (e.g., copper sulphate, picric acid, tartaric acid, sodium bicarbonate, ferricyanide of potassium, etc.) are supplied in watery solution to the cut surface of a transpiring branch, it is found that the rate of transpiration continues without much diminution till the solution can be detected in the leaves, but then suddenly falls off. This may be seen either by direct measurement of the water drawn up, or by the fact that the leaves of these branches usually remain fresh until the arrival of the solution in them, but then rapidly lose their turgor, flag, and finally become dry and crisp. These observations are easily explained if we may assume that at first the solution is drawn up in the conduits under the tension set up through the osmotic forces of the cells of the leaves, but afterwards, when the upper portion of comparatively pure water has been eliminated from the plant by transpiration, the solution comes into contact with the living cells and modifies or destroys their osmotic properties. The latter soon lose their turgor, and the leaf droops.

That the loss of turgescence will necessarily be attended by a diminution of the amount of water evaporated from the leaf will appear evident when it is considered that: 
First the transpiring surface of the evaporating cells will be diminished owing to the contraction of the cells when they cease to be turgescent. Secondly, the diffusion of the water-vapour from the inner tissues of the leaf will be hindered by the collapse of the intercellular passages caused by the drooping of the leaf; and, finally, the evaporating films which on the surface of the wall of the turgid cell may be supposed to be but slightly concave, will under the new conditions tend, by retreating inwards into the substance of the cell-walls, to form a series of more concave menisci from which, as is known, evaporation will proceed more slowly. However, as the walls of these cells are imbibed with water, and a continuous column of water extends back from the outer evaporating walls down through the conduits into the plant hanging from the surface film formed on the outside of the evaporating cellwall, a slow movement upwards will take place of the solution in the conduits even after the loss of turgor by the osmotic cells. The supply is in most cases inadequate to prevent the drying of the leaf.

To the evaporation at the surface film formed on the cell-walls must also be referred the ascent of water in pieces of dead wood which have been soaked and injected with water, as described by Strasburger; for in this case, of course, the intervention of osmotic forces is excluded. It is to be noticed that in this experiment also the wood dries downwards from above.

From the foregoing considerations it seems quite feasible to explain the process of transpiration as a purely physical one in which the intervention of living matter, as such, is not necessary; for we might substitute a dead osmotic cell in the plant for the living one without having reason to expect a difference in the action of the mechanism. This being so, it appears highly probable that transpiration is often a purely physical phenomenon.

However, we must not shut our eyes to the fact that 
several observations seem to support the view that under normal conditions some sort of vital action intervenes.

Transpiration of living and dead leaves.-It was noted above that when the leaves of a branch are killed, not only is the flow of water upwards greatly reduced, from causes which have been already explained, but ultimately the leaves dry up and finally fail entirely to raise water in the branch. It is true that in this case, not only are vital actions removed, but also one of the most important features of the mechanism, viz., the semipermeable membrane, is destroyed by the coagulation of the protoplasm. It is evident, however, that after this the capillary forces of the cell-wall of the leaf-cells alone are unable to continue to raise the water under the new conditions, and this would suggest that unaided they may be insufficient in the living leaf.

This line of reasoning would indicate that the protoplasm may not only act as a semi-permeable membrane by allowing water to pass through to a region of diminished pressure, but it may also actively secrete water, or a solution, on its outer surface. Such glandular action of protoplasm is well known, and examples from the coenocytic fungi may serve as illustration. In Phycomyces, Pilobolus, and Mucor, water which is absorbed by the submerged part of the coenocyte is expelled on its aerial surface. The same process may be witnessed in the nectaries and all the glands of higher plants.

In these cases there is some reason to believe that the liquid exuded is not pure water; and hence it seems probable that the protoplasm first secretes soluble substances on its outer surface and that these act osmotically when concentrated by evaporation, on the vacuoles within and draw water from the cells. Where the process is very rapid, as, for example, the expulsion of water from the cells of the pulvinus of Mimosa in response to a stimulus such a sequence of events can scarcely be imagined. The 
extremely rapid action seems only explicable by assuming some sudden change in the permeability of the protoplasm.

Secretion of water.-The active secretion of water by cells is particularly well illustrated by the water glands in the tips of the leaves of Colocasia contiquorum. As is well known, when this aroid is under suitable conditions of moist soil, saturated atmosphere, and favourable temperature, a succession of drops (often as many as two per second) may be seen issuing from its leaf tip. A similar exudation of fluid may be often observed on the leaves of grass-seedlings when surrounded with a saturated atmosphere.

It is evident that this exudation of fluid would be easily explicable on purely physical processes if the fluid contained any considerable quantity of dissolved substances. Then the external solutes might be assumed by virtue of their osmotic pressure to extract water from within and so keep up the supplies on the outside of the cell. The presence of dissolved substances may be sometimes demonstrated in the exudations of the fungi by evaporating drops of the fluid on polished glass. How far these dissolved substances are crystalloids, and so competent to act osmotically, remains to be determined. At the same time, it should be noted that, even admitting there are sufficient crystalloidal solutes on the surface of the cell to account for the exudation, it seems we must assume a secretory action in the protoplasm to bring these crystalloids out of the cells and expose them on the outer surface, and this action must be a continued one as the exudation will constantly be carrying off its solutes.

If, however, the fluid exuded is pure water, or contains practically no dissolved crystalloids, it is evident that osmosis cannot account for the process, for the osmotic action of the solutes within the vacuoles cannot cause the elimination of water on the outside of the cells. In this, 
energy is being expended, and the energy apparently must be supplied by the metabolism of the protoplasm.

Fortunately the quantities exuded from the leaf tips of Colocasia are quite large enough to allow us carefully to test the purity of the water. With this intent some 10 c.c. were collected from the leaves of this plant during one night; and, by means of the thermo-electric method of cryoscopy, which will be described later, were tested with regard to their freezing-point. It was found not to differ sensibly from that of distilled water. The electrical conductivity was also determined for the sample, and it was found to be less than that of tap water. These tests show that osmotically we may regard the exudation as pure water, and, consequently, the process must be one of secretion involving the intervention of living protoplasm and the expenditure of stored energy.

In the case of Colocasia the dripping ceases when the leaves are surrounded with an unsaturated atmosphere. Evidently the secretion is no more than able to keep pace with the demand of evaporation, but at the same time it seems reasonable to assume that the water has been largely supplied for evaporation by a secretory process. It seems also reasonable to suppose that when evaporation is accelerated beyond the capacities of protoplasm for secretion the cell-walls will dry and the capillary forces of the menisci in their substance will lend their aid in separating the solvent from the solutions in the vacuoles.

How far can we transfer the glandular functions of the leaf tip of Colocasia to the mesophyll cells of the transpiring leaves? An answer to this question has been sought by different ways.

Transpiration into various gases.-If the cells of the mesophyll secrete pure water on their outer side we should be justified in expecting that this secretion, in common with other vital actions, would be inhibited when the protoplasm was anssthetised, or would be 
reduced when its activities were depressed. Starting from this idea an endeavour was made to test the effect on transpiration of an application of chloroform vapour, ether vapour, and carbon dioxide gas. Although each of these three agents, when they were brought round the transpiring leaves, led to a marked falling off in the amount transpired, consideration showed that their actions are so manifold that the effect observed cannot with certainty be attributed entirely to their direct action in checking the vital actions of the protoplasm. At the same time, experiments were made to test the effect of an increased supply of oxygen on transpiration; the marked acceleration pro-

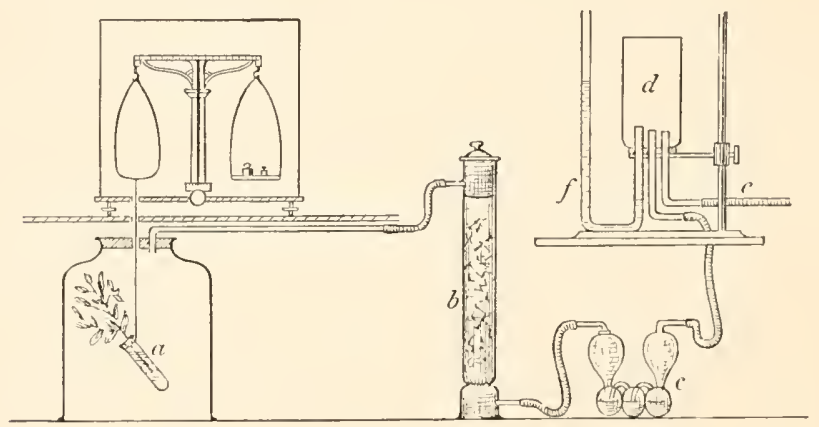

FIG. 1.

duced by this gas possibly is due to its stimulating effect on the secretion, but in any case is of considerable interest in this discussion.

The method of experiment was as follows: The rate of transpiration of a branch enclosed in a large receiver, and supplied with a constant current of dried air, was observed. This rate was then compared with the rate of transpiration, when a similar current of some other dried gas, or dried air, carrying with it some anssthetising vapour, was passed through the receiver.

The rate of transpiration was estimated, either by the motion of an index moving in a capillary tube sealed 
hermetically to the cut end of the branch, or by directly weighing the amount of water transpired. In the latter case, which was found to be the more satisfactory, the branch, inserted through a caoutchouc cork into a testtube containing water, was hung from one arm of a balance. The arrangement is shown in Fig. 1. In this figure $b$ is a 'tower' containing calcium chloride, and $c$ is a sulphuric acid bulb for drying the gas supplied. Before passing through the drying materials, the gas entering at $e$ is led into an inverted flask $d$, which is provided, in addition to the tubes of entry and exit, with a $U$-tube, $f$, filled with oil. The supply of gas is adjusted until the oil in the longer arm of the tube $f$ is brought to a certain level. By this means the pressure, and consequently the flow, of gas through the apparatus, can be adjusted and compared. When vapours are to be supplied, the liquid from which the vapour is derived is placed in a sulphuric acid bulb, like that in the figure, but inserted in the train between the air supply and the flask $d$. In each case the supply was passed into the apparatus from a cylinder containing the compressed gas.

The chamber containing the branch was exposed only to a very feeble light so that the stomata were closed throughout the experiments.

The first experiments made were with the index method of estimating the rate of transpiration. A modification of the apparatus, as figured, which is readily understood, was then used, and the branch, sealed hermetically to a capillary tube containing the index, was inserted from below into the receiver.

With these arrangements there soon appeared to be a marked difference in the rate of transpiration in oxygen and carbon dioxide. Thus, to quote the mean of a number of observations with a branch of Cytisus laburmum in carbon dioxide the index moved $1 \mathrm{~cm}$. in 38 sec.; with the same branch in oxygen it moved $1 \mathrm{~cm}$. in 28 sec. 
When the rate of transpiration in air was compared with that in oxygen, it was found that when a branch was surrounded with the latter gas, transpiration was slightly more rapid. The index for the branch in air moved $1 \mathrm{~cm}$. in $36 \mathrm{sec}$; for the same branch in oxygen it moved I cm. in 33 sec.

If, while a current of air was passing through the receiver, a piece of cotton wool soaked in chloroform was introduced, a much more marked difference in the rate of transpiration became apparent in a short time. Thus the index was traversing $10 \mathrm{~cm}$. in $50.8 \mathrm{sec}$. before chloroform was introduced. Thirty minutes later the index took 516 sec. to traverse the same distance. The chloroform was then removed, and the air current maintained for 60 minutes. At the end of this time the index moved $10 \mathrm{~cm}$. in $120 \mathrm{sec}$. This result is the mean of a number of experiments made with a small branch of Acer macrophyllum.

With another branch in air the motion of the index was $10 \mathrm{~cm}$. in $127 \mathrm{sec}$. When surrounded with chloroform vapour for 45 minutes the index took 642 sec. to traverse the same distance.

A similar diminution in the rate of transpiration is observed when the branch is surrounded by ether vapour. 'Thus, with a branch of Acer macrophyllum in air, the index moved $10 \mathrm{~cm}$. in 205 sec.; with the same in ether vapour it moved $10 \mathrm{~cm}$. in $265 \mathrm{sec}$.

'These experiments indicate a large difference in the rate of transpiration in the different gases. The figures given here will serve only as examples of the results of such experiments, for, although they were the means of a number of observations, the latter are made so precarious by various circumstances, that they can only be taken as indicating a difference, and not as giving a measure of it. 'The sticking of the index in the capillary tube, and the opening of the receiver to introduce the anasthetics, bring 
in errors, which render the method unsuited to exact observation.

In order to eliminate these sources of inexactness, recourse was made to the arrangements shown in the figure. The results obtained by this method are displayed in the following table. The difficulties of keeping the flow ${ }^{1}$ of gas exactly constant through the apparatus, and other experimental errors, lead to variations between the individual observations often amounting to 10 per cent.; but by multiplying these observations, an approximation to the actual alteration in the rate of transpiration has been obtained. The numbers here given are the means of a large number of observations. In each case, the branches experimented on were from a bush of Syringa vulgaris, except in the experiments where effect of ether vapour was observed. In these, branches of Cytisus laburnum were used.

If the amount transpired in air be taken as 100, the amounts transpired in the other gases are as follows. These figures may be said to denote the specific transpiration for the gases :-

Table 1.

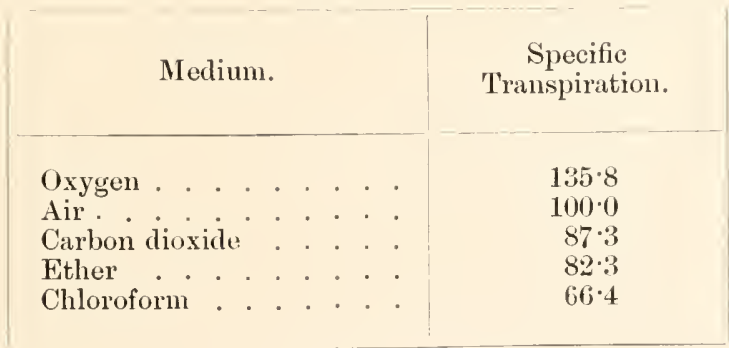

The first source of error affecting these experiments, and one which it seems hard to eliminate, arises from the fact that the effects of the different gases may be more or less rapid. Thus it is very certain that the light gases

1 It is to be observed the rate of flow of the different gases will be different, even if the pressure be the same. 
will diffuse into the intercellular spaces more quickly than the heavy gases, and so come into contact with evaporating cells more quickly. Besides this, it seems probable that the poisoning and anæsthetic effects of one may be more rapid than those of another. The observations, on which the numbers given above are based, were commenced in each case after the branch had been surrounded by the gas for five minutes, and were discontinued before any lethal effects could be observed in the leaves; for such, if arising, would cause the osmotic pressures obtaining in the leaf-cells to become diminished, by rendering the protoplasmic membranes permeable. These effects were usually visible within 45 minutes after starting the experiment. It is possible that the denser vapour could not, within this time, diffuse into all the intercellular spaces of the leaves.

An error arising from this possibility is most unsatisfactory, as it seems extremely difficult to make proper allowance for it. It seems impossible, at present, to decide how soon the surrounding gas will come into contact with the evaporating cells, and, also, when the anæsthetising or stimulating action will cease, and the lethal effects will begin, if, indeed, there is any sharp line of distinction.

Next we come to an error which can, in some degree, be eliminated. It is known that the rate of diffusion of a gas will be influenced by the nature of the gas occupying the space into which it is diffusing. Thus water-vapour will diffuse more slowly into carbon dioxide gas than into oxygen. This difference depends on the relative sizes of the molecules of the gases into which the water-vapour has to diffuse. For the same pressure and temperature, there will be the same number of molecules of these gases in the surrounding space; but if their sizes are different, it is plain that the water-molecules will less readily diffuse into the space occupied by the gas composed of the larger molecules. 
In order to form some idea of this effect, I suspended a shallow dish containing water in the receiver, previously occupied by the transpiring branch; and in connection with the train of apparatus previously described, successive weighings gave approximately the loss of water by evaporation from this dish. During the experiment a stream of gas, dried as before described, was kept up through the apparatus. The rate of evaporation, when this current was composed of air, oxygen, carbon dioxide, and largely of ether and chloroform, was observed.

Again denoting the loss of weight of a vessel of water in air as 100, the loss in the other gases was found to be as follows :-

Table 2.

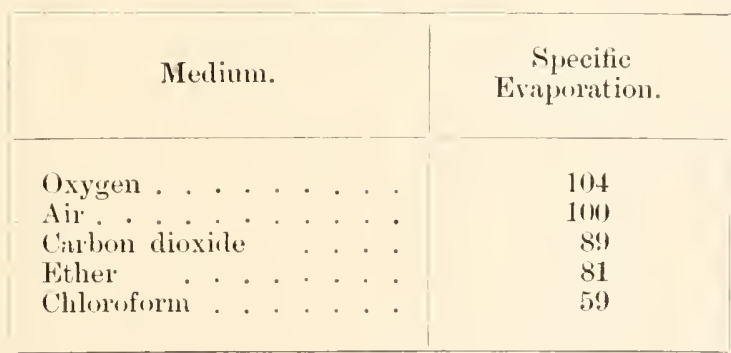

From these observations it would appear that the rate of transpiration is diminished when the leaves are surrounded by carbon dioxide, ether vapour, or chloroform, much in the same degree as the rate of evaporation would be diminished by the presence of these gases; and this diminution is in the inverse order of their densities. In the case of oxygen, however, the rate of transpiration is increased much more than the rate of evaporation would be from a liquid surface.

It must be understood that these numbers only apply to the first effects of carbon dioxide, ether, and chloroform; for when these gases begin to exercise a lethal action on the cells, the rate of transpiration is very 
markedly diminished, presumably owing to the reduction of the osmotic pressure in the cells.

The experiments both on transpiration and evaporation are exposed to two common errors-e.g., a certain amount of gas will be dissolved in each case by the liquid present, and this will reduce the loss of weight, and so diminish the rate in both cases. Again, this solution of the gas in the liquid will alter the surface tension, and so modify the rate of loss.

With regard to oxygen the case is different. The increase in the percentage of this gas, or even possibly some impurity carried with it, increases the rate of transpiration much more than that of evaporation ; and so furnishes experimental evidence in favour of the view that water is brought forward to the seat of evaporation by secretion.

With the other gases there is practically no difference between the specific transpiration and specific evaporation. The logical conclusion from this seems to be that these gases were without perceptible effect on the vital actions of the leaf-cells, so far as transpiration is concerned, during the experiment.

Thus the problem as to how far secretory actions, taking place in the leaf-cells at the expense of the stored energy of organic compounds, accelerate transpiration is not decided by these experiments; but I think it will appear that their evidence, although by no means unequivocal, favours the view that such actions have some function in the elimination of water from the transpiring cells.

Although these experiments cannot be regarded as quantitatively exact, I think they are not without their bearing on plant physiology.

It is a matter of frequent observation that many plants which are natives of arid regions secrete a relatively large amount of ethereal oils. It has been urged that the rapours of these ethereal oils form a sereen which arrest the heat radiations, and thus the leaves of the plant are kept cooler than they otherwise would be. It might, however, be said against this theory that such an absorptive screen in contact with the leaves (and it would eridently be most effective at the surface of the leaves) would rather tend to raise their temperature. lie that as it may, it seems that the 
action of vapours in checking eviporation, emphasised by this research, attords a simpler explanation of the function of these oily secretions. When the vapour of the ethereal oils is liberated from the leaf-tissues, it will surround the leaves, and fill the intercellular spaces. In these positions we might expect that it will exert a retarding action on transpiration and evaporation, in accordance with the experiments quoted above. I have only been able to make a few experiments on the matter, but these indicate the surmise griven here is correct. I found that the vapour given off from chopped-up leaves of Artemisia absinthium reduced the rate of transpiration very considerably. Thus, if we denote the rate of transpiration of a branch of Syringa vulguris, in a current of dry air, by 100 , this rate will be reduced to about 87 if we allow the aircurrent to pass over chopped leaves of this Artemisia, and so carry some of the vapour given off by these leaves round the transpiring branch. 'The air is, of course, dried after passing over the leaves. In a similar mamner I found that the same vapour recluced the rate of transpiration of a branch of Cystisus laburnum from 100 to 93 . In these experiments the temperature lay between $16^{\circ}$ and $17^{\circ} \mathrm{C}$. At higher temperatures, it is possible that the effects would be more marked.

Information as to the nature of the forces effective in bringing forward the water to the seat of evaporation was also sought by examining the possibility of transpiration into a saturated space.

Transpiration into saturated spaces.-In normal circumstances transpiration is effected under conditions favourable to evaporation. The transpiring surfaces are at such a temperature that the vapour pressure in the surrounding space is less than at the surface of the transpiring cells. To maintain this temperature, the leaves of the plant are free to receive light and heat radiations, and heat may be conducted into them, as evaporation tends to lower their temperature below that of their surroundings. This inflow of energy from the external world must, in ordinary circumstances, be taking place during transpiration. In addition to these sources of energy, the cells of the leaves may do work at the expense of the potential energy of the store materials they possess. This stored energy, which is, of course, ultimately derived from the radiant energy entering the plant, is the only remaining source of energy available for the leaves. 
If, when the radiated energy is cut off, and the conditions are such that water tends to condense on the leaves from the surrounding space, the cells of the leaves still continue to draw up water in the capillaries, then the work done must be at the expense of the stored energy ; and, if this work is no longer continued, when the leaves are killed, we may fairly ascribe it to vital actions pumping or drawing up water from the conduits of the plant.

It may be pointed out that this energy could only be made available when the store materials can obtain the requisite oxygen from the plant's surroundings, or from its own substance, and so, in common with other vital actions, it would cease when oxygen is not available.

Supposing, then, we find that the upward motion of the transpiration current continues when radiated energy is cut off, and when the leaves are surrounded by a space saturated with water vapour, we are driven to conclude that the traction exerted on the ascending water is exerted by a vital action, and we can no longer assume that simple physical processes, exactly corresponding to the actual inflow of energy, at the moment, can account for the elevation of water in such a case. On the other hand, the converse will be true if no elevation of water occurs in the plant when it is submitted to the conditions described.

To put this matter to an experimental test, the following arrangements are made:-A small branch about $30 \mathrm{~cm}$. long is cut and set in water in a cool, dark cupboard. From this it is transferred, still standing in water, to a glass receiver. The internal walls of the receiver are kept wet. After remaining one hour under the receiver, and still screened from light, it is assumed that any reduced gas pressure existing in the water conduits has become equalised to that of the atmosphere, and that, consequently, the external pressure exerted at the base of the branch has ceased to move the water upwards. An open beaker, containing water at $100^{\circ} \mathrm{C}$., is now intro- 
duced under the receiver, and the branch is transferred from the water to a watery solution of eosin. A wooden screen is set to cut off the direct radiation of the beaker from the branch. These arrangements are made in a dull light, and, when complete, the whole is set in total darkness.

As soon as the beaker containing the hot water is introduced under the receiver, the space inchuded will immediately be filled with cloud and water vapour. Water is freely deposited on the walls of the receiver and on the surfaces of the leaves of the plant. The space is completely saturated, and remains so, as it continues to fall in temperature, owing to the gradual cooling of the whole; and, as the water is always at a higher temperature than the leaves, a constant distillation goes on from the beaker to the leaves. The arrangements are shown in Fig. 2.

When these arrangements have been made, the apparatus is left for one hour.

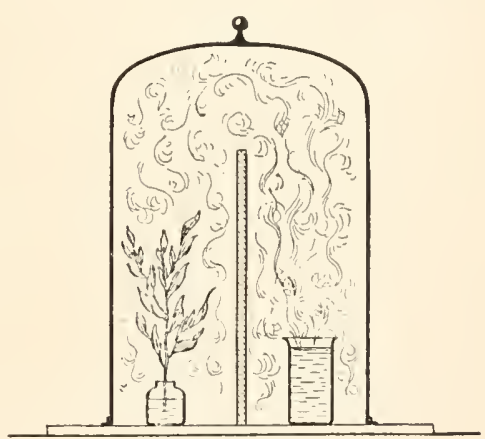

FIg. 2. At the end of this time, it will be found that the eosin solution has been drawn up very markedly into the plant, thus showing that the elevation of the water in the conduits may be effected by vital action. For in this experiment the immediate energy relations of the plant to its surroundings camnot account for the rise. I have performed this experiment, obtaining the same result, with Chrysanthemum sinense, C. lacustre, Myrtus communis, Eucalyptus globulus, Escallonia macrantha.

As we should expect, it was found that, when dead leaves and branches were set in this saturated chamber, no rise of the eosin was observed, although simultaneously eosin 
was drawn up into living specimens placed side by side with the dead ones. The dead branches which I used had been killed by chloroform vapour, or by immersion for some minutes in water at $90^{\circ} \mathrm{C}$.

In these experiments when the coloured fluid was drawn up only into the capillaries of the stem, the pumping action raising it may have been exerted either by the cells bordering the conduits in the stem, or by those in a similar position in the leaves. But when the veins of the leaves become injected, it is evident, since no cells interrupt the continuity of the water-conducting capillaries, that some of the cells exerting the traction in the fluid must be situated in the leaves.

This fact may be demonstrated more directly by experiments in which the ascent of watery eosin in a branch stripped of its leaves is compared with that in a similar branch provided with leaves, when both are placed in the saturated chamber. It will be found-I have performed the experiment with Chrysanthemum sinense, Escallonia macrantha, Cheiranthus cheiri-that the leafy branch will draw up the eosin rapidly, while in similar circumstances the colouring matter will rise but slightly-a few cms. per hour-in the branch deprived of its leaves. The rise observed may be easily explained by the supposition that, in the green parts of the young branches and the buds, the cells probably act like those of the leaves, and draw up water; or, again, the action of the cells bordering the capillaries of the stem-wood-parenchyma and medullary rays-may be responsible for the elevation observed. In any case the rise is but shight, $3-5 \mathrm{~cm}$. in the stripped branches, compared with $20-30 \mathrm{~cm}$. in the leafy branches during the same time.

That the elevating force is chiefly located in the leaves may also be shown by the fact that large leaves detached from the stem are capable of quickly injecting the finest veins at their apices when set upright in watery eosin in 
the saturated chamber. For this purpose I used the leaves of Eucalyptus globulus, and found that their apical veins were injected often after standing only $30 \mathrm{~min}$. in eosin, when surrounded with a saturated atmosphere. 'T'he eosin, to do this, had risen $20 \mathrm{~cm}$. in the leaf above the level of the solution in which the leaf stood. In this case it is evident that the cells of the leaf must have been solely responsible for the observed elevation.

But the directed pumping actions which cause the elevation of the coloured fluid in these cases, although mostly confined to the leaf, do not appear to be restricted to any special cells forming water-glands on the surface of the leaf. It seems most probable that most or all of the cells bordering on the vascular capillaries, both in leaf and stem, are able to exert a tractional force on the water in the conduits, and are able to expel water, when thus drawn in, on their outer surfaces. It may be, however, that the cells of the water-glands of plants are more highly specialised for this function, and hence the exudation of drops on leaves of plants in a moist atmosphere takes place over these glands or hydathodes, as Haberlandt prefers to call them.

The following observation shows that the elevation of the water is not solely due to the functioning of these water-glands, even in plants possessed of these structures. The leaves of Escallonia macrantha, Chrysanthemum sinense, and Chrysanthemum lacustre have water stomata on the margin of the leaf; but if these glands are removed by cutting away the whole margin with a scissors, it will be found that water will be drawn up into these leaves through the stem almost as quickly as into leaves which are left intact.

Another observation which shows that the traction is exerted by cells of the leaf, which are not visibly differentiated, may be made on Cheiranthus cheiri. The leaves of this plant, so far as I can make out, have no specialised 
water-glands. However, the extreme apex often withers away in the older leaves, as if some substance had been exuded there from the leaf. In case this tip be the seat of a water-gland, it was removed from all the leaves of a branch which was set in the saturated chamber. After a suitable time it was found that the coloured fluid had risen into all the veins of the leaves, and it was seen in the ultimate blind terminations of the vascular bundles. In Cheiranthus cheiri these terminations are surrounded by cells undifferentiated from the other cells of the mesophyll of the leaf. The coloured fluid must have been drawn into the terminal portions of the veins by these cells, and not by any specialised water-glands. We may conclude that the similar cells along the conduits have the same function.

It was usually found at the end of all the experiments conducted in the saturated chamber that the surfaces of the leaves had a copious deposit of water upon them, and so it seemed probable that water was actually extruded from the cells of the leaf even after water had begun to condense on them from the surroundings.

The actual presence of free liquid on the surface of the leaves apparently did not markedly diminish the rate of rise of the coloured fluid in the branch, and so, if the branch was immersed in water before commencing the experiment, it was found that the eosin mounted notwithstanding into the dripping leaves.

In these cases, the pumping cells, being surrounded by water, must possess a directed action, which enables them to draw the water in on one side from a liquid supply, and to expel the water on the other into free liquid.

This directed action may be more strikingly demonstrated by the following experiment:-A branch is fixed water-tight into the lower narrow opening of a glass receiver, so that its upper part and leaves project into the interior, while its base extends beyond the cork in the 
neck, and is supplied with a solution of eosin (see Fig. 3). If the receiver be filled with water, so that the leaves of the branch are completely submerged, it will be found that, notwithstanding the presence of the water in contact with the leaves, and the hydrostatic pressure due to its depth, the eosin will mount rapidly into the branch.

In some of my experiments the pressure of the water was sufficient to drive liquid back into the intercellular spaces of the leaves of the branch. So

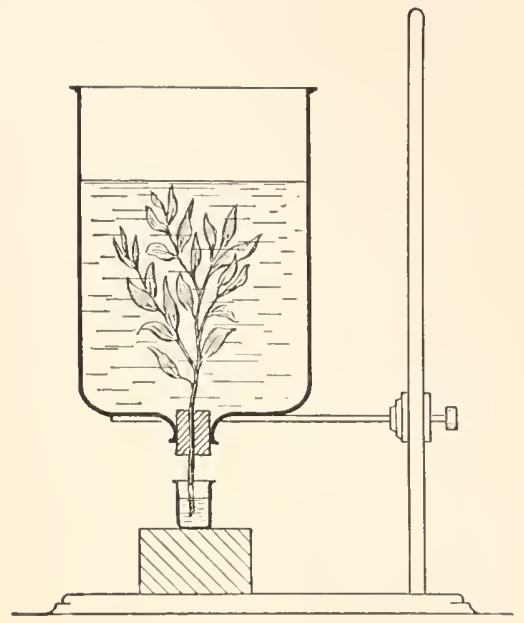

FIG. 3. that it appears that the pumping action can raise water against a considerable external hydrostatic pressure.

In carrying out this experiment, of course, care must be taken that the gas-pressure in the branch has become equalised with that of the atmosphere. With this precaution, however, the result seems conclusive, i.e., that secretory actions, and not evaporation, cause the rise of the eosin into the branch.

It will be found that, if the water in the receiver is warm $\left(25^{\circ}-30^{\circ} \mathrm{C}.\right)$, and if the apparatus is placed in a strong light, the ascent of the eosin will be rapid; if, on the other hand, the water is cold (below $12^{\circ} \mathrm{C}$.) and the light is not strong, the eosin will rise but slowly in the branch. If the apparatus is placed in darkness, the eosin will rise but little or not at all.

It seems probable that the increased rate is, in part, due to the quickening of the vital processes caused by the rise in temperature when the water surrounding the leaves is warm. 
The stimulating action of the light is indirect, and probably is effective by the increased supply of oxygen set free by assimilation. The upward movement of the eosin is most rapid when bubbles of oxygen are being evolved in quantity at the surface of the leaves. This observation, then, constitutes another proof that the lifting action is due to a vital process, and decreases when the supply of oxygen is diminished. In this respect the action resembles other vital phenomena, such as growth, irritability, etc. The fact that a small rise does take place in the dark is explained by the presence of oxygen in the water, and also of that derived by intra-molecular respiration.

The combination of this oxygen will of course lead to a minute rise in temperature which will favour a distillation of water from the leaves. This effect, however, would probably be so small that it could not account for the rapid rise of water in plants in a saturated space, as has been just described.

Over short periods osmosis may, however, be adequate to draw up water into leaves even though they are surrounded by a saturated space; but this seems only possible if we start with the leaf-cells incompletely distended. Until they are fully turgid they will absorb water on every side, and naturally some of this will come from the trachere, while some may at the same time be derived from water in contact with their outer surfaces.

Summary.-From what has been here detailed, I think we may with great confidence assert that the elevation of the sap, when plants are situated in saturated places, is effected by directed actions taking place in the living cells of the leaves. Simple osmotic and evaporative forces cannot be continually effective in raising the water in the conduits in these circumstances. With regard to the elevation of water, when the leaves are surrounded by an unsaturated atmosphere, we cannot as yet be dogmatic. But the fact that, 
when the leaves of plants are killed, they dry up and are unable to furnish themselves with sufficient water from an unlimited supply at the base of their stem, argues that surface tension and evaporation forces at their surfaces are in themselves inadequate. And, when we couple with this, the observations on the directed vital actions taking place in the leaf-cells when they are surrounded with a saturated atmosphere, I think we may, with great probability, assume that these directed vital actions are responsible to a great extent for the raising of water in plants even in unsaturated spaces. In any case the present evidence shows that directed vital actions are capable of replacing and supplementing the more simple physical actions, e.g., evaporation, capillarity, and osmosis.

When, however, the pressure of water vapour is further reduced and evaporation is so rapid that secretion cannot keep the supply equal to the demand, then it must be supposed that capillarity (imbibition) and evaporation draw the water to the surface of the cells. Whether this state of affairs can be prolonged indefinitely without injury to the leaves is not at present known.

\section{Literature.}

Brown, H. T., and Escombe, F., "Static Diffusion of Gases and Liquids in Relation to the Assimilation of Carbon and Translocation in Plants," Phil. Trans. Roy. Soc. London, vol. 193, B., p. 223.

Dixon, H. H., "Note on the Rôle of Osmosis in Transpiration," Proc. Roy. Irish Acad., vol. iv, ser. 3, p. 61, and Notes from the Botanical School of Trinity College, Dublin, vol. i, p. 35 .

Id. "On the Effects of Stimulative and Anresthetic Gases on Transpiration," Proc. Rom. Irish Acad., vol. iv, ser. 3, p. 618, and Notes from the Botunical School of Trinity Coltege, Dublin, vol. i, ए. 97.

Id., "Transpiration into a Saturated Atmosphere," Proc. Roy. Irish Acad., vol. iv, ser. 3, p. 626, and Notes firom the Botanicul School of Trinity College, Dublin, vol. i, p. 106.

Id., "On the Physics of the 'Transpiration Current," Notes from the Botanical School of Trinity Cotlege, Dublin, vol. i, 1. 57.

Id., "A Transpiration Model," Proc. Roy. Dullin Soc., 1903, vol. x (N. S.), p. 114, and Notes from the Botanical School of Trimity College, Dublin, vol. i, p. 217. 


\section{TRANSPIRATION AND ASCENT OF SAP сн. I}

Id., "Note on the Supply of Water to the Leaves on a dead Brancli," Proc. Roy. Lublin Soc., 1905, vol, xi.(N. S.), p. 7.

Id., "Transpiration and the Ascent of Sap," Progressus Rei Botanicae, Bd. iii. s. 1.

Dixon, H. H., and Joly, J., "The Path of the Transpiration Current," Ann. of Bot., 1895, p. 403.

Henslow, (x., "Origin of Plant Structures."

Joly, J., "Contribution to a Discussion on the Ascent of Water in Trees," Brit. Assoc. Report, 1896 and Ann. of Bot., 1896, vol. x, p. 647.

Strasburger, E., "Ueber den Bau und Verrichtungen der Leitungsbahnen in den Pflanzen" (Jena), 1891.

Unger, F., "Neue Untersuchungen uiber die Transpiration der Pflanzen," Sitzungsb. d. Wien. Akad., 1861, Bd. 44, p. 362, and Bot. Ztg., 1872 , p. 62. 


\section{CHAP'TER II}

ASCENT OF SAP IN S'TEMS. CRITICISM OF PHYSICAL THEORIES

Early writers.-Since the ringing experiment of Hales $(\mathbf{1 7 2 7})^{1}$ and the experiments of Magnol and De la Baisse, who about the same time supplied cut branches of plants with coloured fluids and thus mapped out the conducting tracts, physiologists have been agreed that the upward movement of water from the roots takes place in the woody tissues of plants. In contrast to this unanimity concerning the path of the upward current are the very divergent views which are held as to the nature of the process by which the water is raised.

Of the views of the earlier writers it is hard to obtain a clear conception; their point of view was so utterly different from that of the present day. Much of their work is vitiated by the fact that they constrained themselves to see in plants a circulation of fluids similar to the circulation of the blood of animals. Little attention was paid to the forces causing this circulation.

It is true that Christian Wolff (1723) believed that the forces involved were the expansion of air and capillarity;

1 It is remarkable that this elassic experiment was not devised by Hales to traee the upward path of the water current, but to prove that there is no cireulation of sap in trees comparable to that of the blood of animals. Indeed, from Hales's own account, it appears that he thought the upward movement of water was slightly interfered with by the ringing. 
and Hales, a little later, attributed the rise of water in the vessels to capillarity. These forces have ever since been called in again and again to play their part in the various theories formed to account for the "circulation of juices," or as it is called in more recent times, the Ascent of Sap in Plants.

Gas pressure theory.-Direct descendants of these theories were the air-pressure and the gas-pressure theories of Böhm and Hartig, and these, like their predecessors, were soon rendered untenable by quantitative examination.

Jamin's chain.-Nor did the comparison of the distribution of the water and gas in the plant to a Jamin's chain avail to save these doomed hypotheses, for it was early recognised that any support rendered to the water columns by this configuration must at the same time act as a resistance to upward motion.

A recent attempt to rehabilitate the Jamin's chain hypothesis, or rather a modification of it, was not more happy. It was suggested that the peculiar intermixture of air and water in the conducting tracts brought into play obscure physical forces which lead to the elevation of the water. It has been shown, however, that the experiments upon which the view was based, were completely vitiated by the neglect of a property of plaster of Paris which enables it to continue to absorb water long after it has set. This absorption gave rise to an upward movement of water in the experiment, which was erroneously believed to demonstrate that the "suction" of less than one atmosphere applied to the top of a continuous column of water suspended in a porous substance with air bubbles intermingled could still operate as a suction more than 12 metres lower down.

Boehm's views. - It will be understood that all that was needed to refute the foregoing theories was a clear statement of the theories themselves and a quantitative estimate of the forces they asserted were adequate to 
lift the water columns in trees. Such a clear statement is, however, not possible in the case of Böhm's final theory to account for the ascent of sap. Orving to his contradictory expressions and obscurity in description it will always remain impossible clearly to understand what his hypothesis was. He assigned a part to the capillary forces of the trachese and to atmospheric pressure. The latter he conceived as driving the water from the trachex into the leaf-cells, and also he saw no difficulty in the height of the water columms owing to the cohesion of water; but without doubt he was quite astray as to the conditions under which cohesion could act.

Function of the tracheal walls.-With Sach's imbibition hypothesis, a new factor was introduced into the discussion on the ascent of sap. The assumed mobility of water in the tracheal walls was directly negatived by the experiments of Elfving and Vesque, who showed that only negligible amounts of water passed upwards when the lumina of the tracher were plugged with cacaobutter. It was objected to Elfving's experiments that cacaobutter was of too greasy a nature, and might enter the wall, so gelatine was substituted by Errera and Strasburger. It might fairly be urged, however, that there is less danger of a greasy substance entering the water-saturated wall than of a substance miscible in water such as gelatine, which, even if entering the wall in minute quantities, might be very injurious to its transmitting properties.

Penetration of gelatine into walls.-In this connection experiments were made to test the possibility of gelatine permeating the cell walls. A few of these may be quoted. They all agreed in showing the passage of warm dilute gelatine through the cell-walls-possibly in some cases through the closing membranes of the pits only - and consequently suggest the probability that it would alter the capability of the wall for transmitting 
water. A length of $10 \mathrm{~cm}$., straight and free from side branches, was cut from a branch of Taxus baccata, the mean diameter being $2 \cdot 5 \mathrm{~cm}$. This was deprived of its bark, and affixed by an india-rubber ring at one end to a glass tube communicating with an air-pump; a little water in the

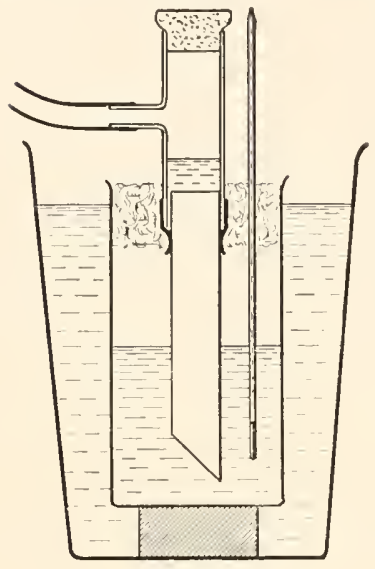

FIt. 4. tube covered the upper end of the wood. (Fig. 4 shows the arrangements.) On exhausting the tube, bubbles rose from the surface of the wood. These could be stopped by simply immersing the lower end in mercury. Hence it was concluded that continuous airpassages existed in this piece of wood, which should be stopped before any tests could be made as to its permeability by gelatine. Accordingly the lower end was dipped in melted paraffin at about $70^{\circ} \mathrm{C}$., the melting point of the paraffin being $56^{\circ}$, and the whole length of the stick jacketed by water which was maintained at $70^{\circ}$ for 45 minutes, a vacuum being preserved in the tube attached to its upper end during this time. Finally the stick was cooled slowly from above downwards by lowering the water-bath to allow of the contraction of the paraffin being made good by supply from below. When all was cold, the end was pared to expose lumina free from paraffin. The stick now drew up water freely, 3 or 4 c.c. in 15 minutes, but allowed neither air nor mercury to pass up. The water pumped through was next tested by a solution of tannin, but remained perfectly clear. We conclude therefore that no direct air-passages remain open, and that nothing is yielded by the wood of the yew giving an obscuring reaction with tannin.

Some gelatine which had been cut up into fine threads and soaked in repeatedly changed water for two days 
was now melted and diluted till it set weakly at $13^{\circ}$. At a temperature of $30^{\circ}$ to $40^{\circ}$ this was supplied to the lowel end of the yew, the latter as before being kept warm throughout its entire length by a water-jacket which was never raised above $40^{\circ}$. At the expiration of four hours the liquid within the vacuous tube had risen by about 5 c.c. The experiment was then stopped, and the contents of the tube tested with tannin. There was an opalescent precipitate. Comparison with the solution below showed that much of the gelatine had been held back by the wood.

Starting the experiment a second time with the same piece of yew, it transmitted 3.5 c.c. in four hours; the liquid drawn up affording this time a much denser precipitate. A final test showed the wood to be still impervious to air when a vacuum was maintained in the tube.

A similar experiment with the wood of Pinus austriaca gave a like result. It was observable that if the dilute gelatine was not raised some few degrees above its meltingpoint-i.e., till the solution almost ceases to be opalescent -its passage was much less marked; indeed in some experiments only traces were transmitted through the wood. This appears to be due to the fact that in solutions presenting an opalescent or milky appearance, the gelatine is probably still in the solid or gelatinous state; the heterogeneous distribution and difference of refractive index giving rise to the milky colour. In all cases a considerable quantity of the gelatine is held back. One quantitative experiment on Taxus gave the percentage of gelatine in the transmitted liquid as only half that in the original solution.

In one experiment the gelatine was stained with Kleinenberg's hæmatoxylin. The solution was made of such strength as to set at about $20^{\circ}$, and was supplied at $40^{\circ}$ to the wood of Taxus brecata. It passed out colourless into the glass tube, about 1 c.c. in two hours, the length of the wood traversed being $2.5 \mathrm{~cm}$, and its cross-section 2.2 sq. cm. This wood had not been treated with paraffin, 
as it revealed no direct air-passages upon trial. As the hrematoxylin does not stain wood, this experiment points to a mechanical separation from the gelatine owing to the passage of the latter through membranes or walls. It is possible, however, that some of the stain was taken up by the cellulose walls of the medullary rays and the tori of the pit membranes.

Microscopical examination of branches choked with gelatine mixed with Indian ink, after the manner of Errera and Strasburger, showed that the closing membranes of the pit had exerted a straining action, accumulating Indian ink upon the one side, so that the pits were picked out very sharply as black objects. This filtering action is suggestive of the passage of the medium carrying the precipitate; and although, so far as this observation is concerned, there might have been filtration of the gelatine from the water in which it was dissolved, still, taken in conjunction with the other observations, we think it supports the view led to by those observations, i.e., that dilute melted gelatine can pass through the substance of the closing membranes, and, if so, is very probably capable of penetrating into the cell-wall, or otherwise we must suppose perforations to exist in the pit-membrane or its torus.

\section{Effects of paraffin and gelatine compared.-} The effect of using paraffin wax of low melting-point as the material for choking the lumina was also tried and compared with that of gelatine. Four similar branches of lime, Tilia europaea, were cut (May 9), and put standing for twenty minutes in water at $50^{\circ} \mathrm{C}$., immersed to a deptl of about $20 \mathrm{~cm}$. These were called A, B, C, D.

A was preserved in water at $50^{\circ}$.

$\mathrm{B}$ was transferred to melted paraffin at $50^{\circ}$ (meltingpoint $48^{\circ}$ ).

C was transferred to gelatine coloured with Indian ink at $50^{\circ}$. 
D was transferred to gelatine coloured with haematoxylin at $50^{\circ}$.

Each was immersed to a depth of $20 \mathrm{~cm}$. and placed in bright light, the air temperature being $16^{\circ}$. At the expiration of forty minutes all were transferred to water at $13^{\circ}$. Then the end of each was thinly pared, and at 5.30 p.m. all were left finally standing in water at $13^{\circ}$. At 6.30 all were fresh. At $11 \mathrm{a} . \mathrm{m}$. on the $10 \mathrm{th}$, i.e., after $15 \frac{1}{2}$ hours,

A was still quite fresh,

B ,, very much flagged,

C ,, less flagged than B,

D , , , , , B, but more flagged than C.

All were now transferred to a strong solution of saffranine, and put in full sunshine for $1 \frac{1}{4}$ hours, when they were washed and sections made for microscopical examination. So far as C and D were concerned, it is only necessary to observe that they revealed that only some of the lumina were actually stopped with gelatine. The walls of many of the gelatine-filled vessels were found stained with saffranine, which attained to $26 \mathrm{~cm}$. in $\mathrm{C}$, and to $5 \mathrm{~cm}$. in D. 'The gelatine in the lumina had become coloured with the stain.

Transverse sections of B close to the base showed all lumina choked with paraffin, while the walls between were deeply stained with the saffranine.

In polarised light with crossed Nicols the appearance was very striking, the crystalline paraffin showing out strongly. Transverse sections, $2 \mathrm{~cm}$. from the end, showed the large vessels still filled with paraffin. In some places neighbouring vessels apparently quite filled with paraffin had the intervening walls deeply stained; at this level, however, where the vessels were filled with paraffin the staining was not quite so dark as elsewhere, though the colour was still strong. The paraffin finally attained a height of $12 \mathrm{~cm}$. in one or two vessels. In no case was there any visible appearance of shrinkage of the paraffin from the wall, although in some sections, as might be expected, the action of the 
razor was to compress it from the cell-wall upon the one side over the section.

Similar experiments were made on elm and lime, with the added precaution of removing the paraffin or gelatine at the ends without cutting or removing any of the wood. This was effected by careful use of the razor, the object being to avoid as far as possible laying open the lumina of conduits the terminal walls of which might lie upon the surface of the section. In the case of elm and lime agam, sections taken about half a millimetre from the end showed areas over which the filling with paraffin was complete, and yet deep staining of the intervening walls. Longitudinal sections near the end confirmed this appearance; the lumina seemed quite filled. In these cases the removal of the branches from the hot paraffin was effected gradually, to secure, so far as possible, that solidification and shrinkage should proceed slowly from above downwards, and thus guard against shrinkage leading to the withdrawal of the paraffin out of contact with the wall. Again, the branches of lime treated for comparison with gelatine revealed areas in the cross-sections completely injected with gelatine and having the walls deeply stained. Thus we see that both in those experiments in which the lumina were choked with paraffin and in those in which the lumina were choked with gelatine there was at least a feeble upward motion of the solution of saffranine in the walls. Lime branches treated with paraffin, in some places close to the cut surface, showed the penetration of this into the protoplasm-filled cells, permeating their contents. High up, only the larger vessels were filled with paraffin.

The result of these experiments may be summed up as follows :- -

The stoppage of the lumina and the freedom of the cellwall is preserved by the use of paraffin, and, possibly, by th at of gelatine. 
The flagging of the leaves appears to be the more rapid the more completely the closing of the lumina has been effected.

When the lumen is closed an upward passage of liquid is still maintained in the wall, but this is probably much too feeble to meet the wants of the leaves.

Paraffin casts of tracheæ.- Owing to its extreme mobility the penetration of the paraffin is very complete in these experiments. Thus it was found easy by its means to demonstrate the continuity of the tracheal elements forming the vessels in lime, sycamore, and elm. For this

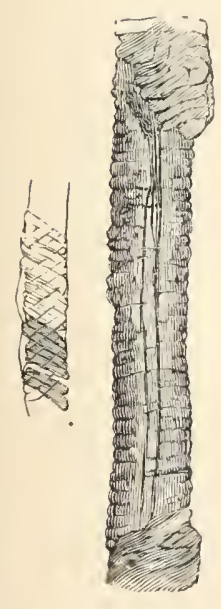

Fiเ. อ.-Tilia MICROPHYLL.

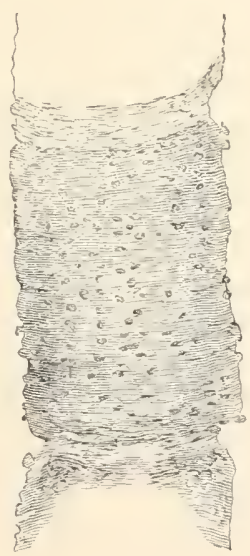

Paraffin Casts of Vessels.

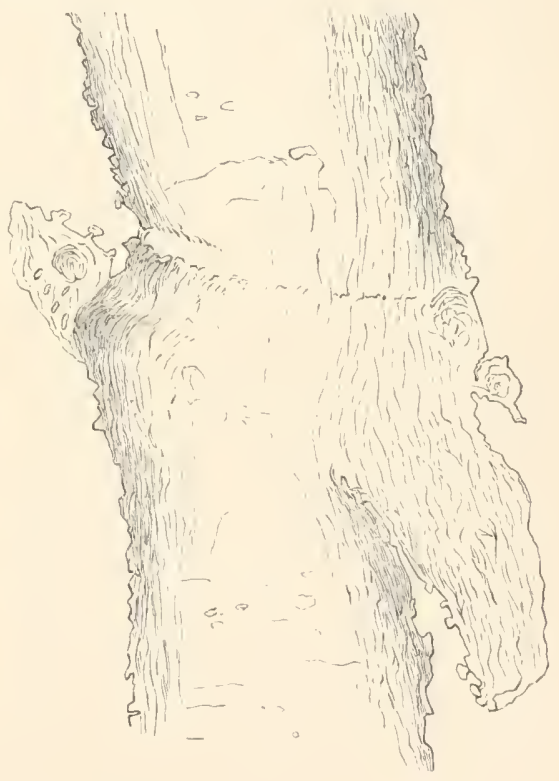

Fis: 6.-TiLis MICROPHYLLA.

Fit. 7 .-

Tlumes CAMPESTRIS.

lengths of $35 \mathrm{~cm}$. were used and the wood of the branches injected as described above was removed with sulphuric acid. It is necessary to anchor the branch by a leaden weight in a deep vessel of the acid. A single night suffices in many cases to remove the wood and leave the paraffin 
casts of the vessels streaming upwards from below like a sheaf of fine white threads. The examination of these threads under the microscope reveals many features of interest. Figs. 5, 6 and 7 represent portions of some of these casts.

Some further experiments were made bearing upon the ascent of water in the wall. All confirm the fact that an appreciable quantity of water ascends in branches most carefully choked with paraffin.

Thus, while flagging will inevitably overtake a paraffined branch left furnished with the same number of leaves as it bore upon the tree, yet if the greater number of these are removed, the remaining leaves will generally hold out fairly well. This experiment was tried with a control paraffined branch upon which all the leaves were left standing.

If after injection we remove part of the branch at a fork and, keeping the one part which is attached to the paraffined extremity in water, insert the extremity of the other through a cork into a dry vessel, the latter will flag much the more rapidly. Still more direct is the following : a paraffin-injected branch of Titire microphylla, with nine leaves, was put standing, from 4.15 p.m., May 11, till noon on the 12th, in a vessel of water which had been carefully weighed and so closely corked round the stem as to preclude possibility of loss by evaporation at its surface. In this period of nearly twenty hours the branch drew up 1.005 grammes of water. 'This same branch, after it had flagged, and had been put out into breeze and intermittent sunshine from noon till 3.30 p.m., drew up $0 \cdot 161$ gramme.

Again, of two paraffin-injected lime branches, one scraped to free the surface and placed in water, the other left closed with its cap of solid paraffin ; the latter flagged much more quickly, although it bore a smaller number of leaves. In two days the second was, indeed, dry and shrivelled, while the former had preserved much of the freshness of its leaves. 
Generation of gas in the lumen.--Bearing on this same point - the partial passage of water through the walls - the following experiments were carried out, in which it was sought to replace the paraffin or gelatine by a gas developed in the plant. Thus a cut branch first supplied from a solution of tartaric acid and subsequently from a solution of sodium bicarbonate will have carbon dioxide evolved in the lumina of its conducting tissues in consequence of the interaction of these substances.

A preliminary experiment upon a lime branch (Tilire microphylla) which had stood for two hours in a solution of tartaric acid, and then one hour in sodium bicarbonate, before finally being transferred to pure water, showed rapid flagging of its leaves and soft shoots as the result. But as this was possibly a direct consequence of the action of the reagents, and not of the evolved gas, a more careful experiment was carried out upon five branches of elm cut from the same tree, with similar precautions, and, as far as possible, of like dimensions.

$\mathrm{A}$ and $\mathrm{B}$ were placed in sodium bicarbonate solution.

$\mathrm{C}$ and D were placed in tartaric acid solution.

E was placed in a solution of a mixture of tartaric acid and sodium bicarbonate which had ceased effervescing.

After $1 \frac{1}{2}$ hours $\mathrm{A}$ and $\mathrm{C}$ were interchanged in the solutions; thus, in these two only was carbon dioxide developed. $B$ served as a control regarding the effects of sodium bicarbonate alone, D, as a control for tartaric acid, E, for the effect of the mixed solution without development of gas. In five hours $\mathrm{A}$ and $\mathrm{C}$ were very much, and about equally, flagged, while the rest remained fresh. Next morning, however, all had drooped, showing that prolonged treatment with either or both of these substances is injurious in any case. It was evident, also, that the stoppage of the lumina by the gas had greatly accelerated the flagging.

It was not probable that the check upon aeration of the tissues involved in all of the foregoing experiments 
wherein the lumen is choked, could account for so rapid a flagging of the soft parts. However, to set this doubt at rest, we inserted branches in water which had been boiled and cooled in racuo, and coated with oil after the insertion of the branch. These, however, remained perfectly fresh; indeed, they seemed in no way affected.

Lumen blocked with ice.-In order to investigate this subject more fully, an additional series of experiments was devised and carried out upon the passage of water through the wood of Taxus at low and at high temperatures. For it was very certain that in the one case the formation of ice, and, in the other, the formation of steam, would occur in the lumen before occurring in the wall, rendering the former non-conducting without the introduction of any foreign substance.

It was necessary to determine first of all the freezingpoint of water in the lumen by direct microscopic observation. To effect this a special form of cold stage was used, the construction of which will be easily understood from Fig. 8. In this stage the object under examination is

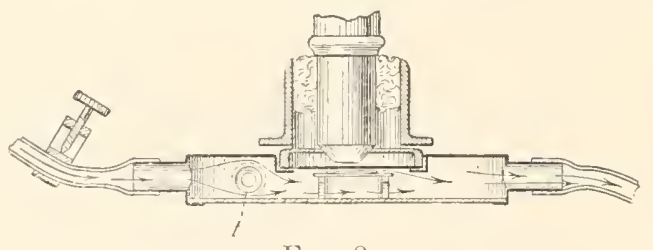

FIt: 8 .

completely surrounded by the cooling liquid, which also flows round the bulb of the thermometer, $t$. The temperature is, therefore, accurately known. The bottom of the cell is of glass; a ring screwing out upon the top serves to permit the lifting of a cover-glass acting as a water-tight window, this being luted on the edge with a little white lead. The object is luted between two coverglasses, and carried upon an open support within. It is necessary to protect the upper window from moisture pre- 
cipitated from the atmosphere; this is done by the loose metal ring surrounding the object-glass, and packed round with a little cotton wool. The thermometer enters by a tubulure in front; its bulb appears in cross-section at $t$ in the figure. The regulation of the temperature is very simply effected by retarding or accelerating the current of cold liquid (brine) by means of the pinch-cock.

The section of the wood to be examined is cut, and with the addition of as little water as possible, is luted up between the cover-glasses, so that it is surrounded by air, but contains water within its substance. The close proximity of the section to the upper window, some 1.5 millimetres, allows of considerable magnification.

The cold cell, after the introduction into it of the section sealed up between the cover-glasses, is placed on the stage of a microscope, and then, by the arrangement already described, the temperature is caused to fall gradually, while the water within the section is carefully observed.

The phenomena attending freezing were perfectly definite, the clear liquid in the lumina assuming the aspect of solid paraffin. In two experiments in which the reduction of temperature was effected very gradually, the freezingpoint was found to lie between $-10^{\circ}$ and $-11^{\circ}$. Freezing spread with great rapidity all over the field in both wide and narrow lumina. Air-bubbles present exhibited immediate reduction of volume, and often distortions of shape, and it was important to observe that an exudation of sap occurred upon bare cell-walls, which, appearing in drops, instantly turned to rough-shaped ice-crystals.

1 Of course, this is not the true freezing-point of the liyuid in the wood, but the temperature which it attains by supercooling before solidification takes plice. It thaws consequently at a higher temperature, which again is not the true freezing point, but one which approximates to the eutectic point. It is evident that much variation may be expected in the temperature at which crystallisation occurs in the supereooled liquid.

The true freezing-point of the sap in the trachese of other plants is much higher than either of these temperatures, and there is no reasoln to believe that the sap of 'Taxus is peculiar in this respect (see page 45). 
Thawing occurred at a higher temperature than freezing, no signs of melting being exhibited till $-4^{\circ}$ or $-5^{\circ}$ was reached. This specimen of wood was removed from a branch which had been standing some days in water. A freshly cut branch of Taxus afforded $-14.5^{\circ}$ as the freezingpoint.

Owing to the pressure-effect of the ice upon the wall, visibly shown by the forcible expression of drops, there appeared some doubt whether this method would afford any result of value. However, the experiments were persisted in, and a length of $22 \mathrm{~cm}$. by $6 \mathrm{~mm}$. in diameter of a yew-twig, carefully washed, was attached to the apparatus shown in Fig. 9, in which the passage of liquid

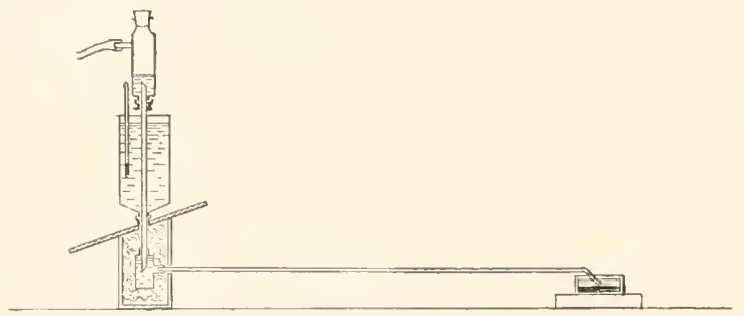

FI1: 9.

through the vertically placed stick (due to a diminished air-pressure in the vessel above) is shown by the movement of mercury in the horizontal capillary tube. The rate of transmission of water was observed while the temperature of the jacket was varied. The general results were as follows:-

In cooling, the current had almost ceased at $-7^{\circ}$ and, completely at $-11^{\circ}$; in warming, it recommences feebly at $-5^{\circ}$. It was impossible to fix upon any temperature as the actual freezing temperature in the lumina from the observations, but as all current had ceased at $-11^{\circ}$, at which temperature the water in the walls was almost certainly not frozen, we must conclude that these observations reveal no current in the walls, even of the feeblest 
intensity, for the method of observation is very delicate. However, the method is beset by the doubt involved in the evident ice-pressure upon the walls. The large increase in the viscosity of water at the lower temperatures would also greatly reduce or stop the flow.

Lumen blocked with vapour.-Experiments in which the wood of Taxus was exposed to high temperatures - above $100^{\circ}$ - appear to show that water, carrying a dye in solution, can be drawn through the wood when this is at a temperature so high as $125^{\circ}$, and very certainly filled with water-vapour everywhere in its lumina.

Fig. 10 shows and explains the arrangement of the experiment. The vessel into which the branch dips contains mercury heated from beneath. A glass tube surrounds the branch, the space between branch and glass being filled with mercury. To resist the pressure of the vapour evolved from the surface of the wood at this temperature, it was necessary

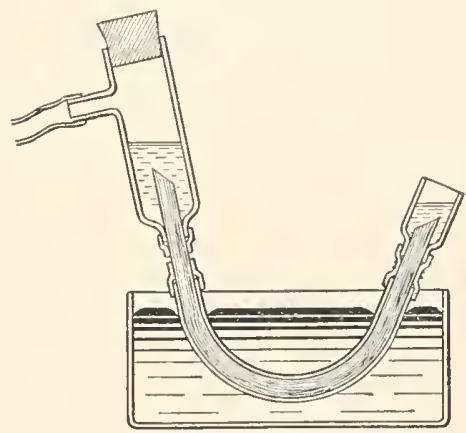

FIเ. 10. to bind the stick into the tube with air-tight rubber rings overlaid with wire. The following experiment was made :

A small branch of Taxus baccata, $24 \mathrm{~cm}$. long, having a woody cylinder of $5-6 \mathrm{~mm}$. in diameter, and composed of nine annual rings, was jacketed with mercury at $125^{\circ}-130^{\circ}$ for eight minutes, while its basal end was attached to an air-pump so that the atmospheric pressure forced through water supplied to the distal end of the branch. The water was then replaced by a strong solution of eosin, and the whole, still kept at $125^{\circ}-$ $130^{\circ}$, was left for two hours. Then the experiment was 
stopped. The eosin being first removed, the surface to which it had been applied was pared and dried. The branch was then detached from the air-pump and allowed to cool. On mieroscopic examination it was found that the eosin-solution had passed $22 \mathrm{~cm}$. up the wood, and at this height was seen in cross-section as two irregular patches occupying quadrants in the seventh and eighth rings. The walls of these were uniformly coloured. At the level of the mercury jacket, and throughout the $7 \mathrm{~cm}$., where the branch was immersed in mercury, the colouring was most intense in the limiting membranes. At the end where the eosin was applied, the walls were scarcely coloured, except those adjoining the medullary rays and immediately round the bordered pits.

Small transmission in the walls. - The simplest interpretation of these results is that the coloured water moved in the wall, while the lumen was occupied with vapour; the intenser coloration of the limiting membrane is strongly in support of this view, for it is very probable that for some distance from its surface the wall was so far choked with rapour as to impede the motion of a liquid.

These experiments then, so far as they go, are in perfect agreement with the previous set in which the lumina are choked by the introduction of foreign substances (cacaobutter, gelatine, air, in the experiments of other authors, or by paraffin and carbon dioxide in our own); and they show that the freedom of the lumina is necessary for the rapid transmission of water, but that a slow current may pass through the walls even when the lumina are completely blocked.

Negligible amounts transmitted as vapour.'There appeared the possibility that the flagging of the branches having closed lumina might be due to the stoppage of them as vapour-conduits, and not as water-conduits; that is, the experiments were not yet conclusive as to the 
actual function of the lumina, although showing clearly that their freedom is essential to preserve the turgescence of the leaves. The well-known phenomenon of the equilibrium vapour-pressure varying with the curvature of the meniscus suggested the possibility that a transport of vapour of considerable importance might occur in the conduits, the menisci high up in the trees possessing a lower equilibrium vapour-pressure than the menisci lower down. By successive condensations beneath and evaporations above the pit-membranes, this current might be maintained throughout the conduits unoccupied by liquid water.

This idea led to experiments in which cut branches were fed entirely upon water-vapour in the following manner:The branch had its cut extremity fixed in a short glass vessel containing water at the bottom; and the cut surface of the wood (which was cut at an acute angle in order to expose a larger surface) was raised some 5 or $7 \mathrm{~cm}$. above the surface of the water. A side tubulure to the vessel enabled a vacuum to be maintained within by means of a Sprengel pump. The vacuum was so complete that ebullition occurred upon placing the hand round the lower part of the vessel. Such experiments were made upon elm and lime, using control branches, some of which were simply left with their cut surfaces exposed to the air, others with their ends sealed into tubes containing air, but no liquid water. In no case was any result obtained going to show that the vapour-fed branch possessed any advantage over the others.

It appears then that the movement upwards of water in the form of vapour through the lumina is insignificant, and the imbibition theory cannot recerve effective help from this direction.

It is needless now to go into the many arguments which overthrew the imbibition hypothesis. It is enough to say that the ingenuity of the theory, and the reputation of 
its elaborator and defender, made it survive an incredibly long time, despite the accumulation of crushing evidence from structure, and of clear inference from experiment.

Osmotic hypothesis. - Various writers have endeavoured to explain the rise of the transpiration stream by appealing to the action of osmotic phenomena. In almost all the vital theories the hypothetical pumping actions of the cells are supposed to be effected by osmosis. Consequently, the osmotic hypothesis, so far as the osmotic actions in question are supposed to be manifested in connection with the cells of the wood, has been discussed with those theories. It is, in fact, hard to see how osmotic pressures can be generated in the conducting tracts apart from these cells. In the cells only are to be found semipermeable or approximately semipermeable membranes. Larmor's suggestion that an upward movement is determined by a gradient of concentration in the solutions contained in the trachex from below upwards, could only apply to an ideal state of things, and is negatived by the facts: (1) The membranes of the tracher are freely permeable to dissolved substances; (2) no such differences in concentration are found; (3) the resistance to flow upwards and downwards is the same.

With regard to the second objection enumerated above, some recent experiments on the concentration of the sap in the roots and in the stem at various levels are of particular interest.

It has been found possible to extract the sap from the wood of roots and stems of transpiring trees by centrifuging short lengths cut from these organs. Considerable quantities of the sap, quite unaltered, may be obtained in this manner, and the molecular concentration of the solutes in them accurately measured by means of cryoscopic and electrical conductivity determinations. In each case it has been found that the concentration of the sap is sensibly less 
above than in the lower parts of the tree. The record of a few measurements will illustrate this. Under $\Delta$ in Table 3 is given the depression of the freezing-point, which is proportional to the concentration of the total dissolved contents of the sap; while under $\mathrm{C}$ is recorded the conductivities expressed as reciprocals of the resistances measured in ohms. These give a measure of the content of electrolytes.

TABLE 3.

Showing the concentrations of Woop-sap in Steus ayb Roots.

\begin{tabular}{|c|c|c|}
\hline & $\Delta$. & $\mathrm{C} \times 10 .{ }^{6}$ \\
\hline 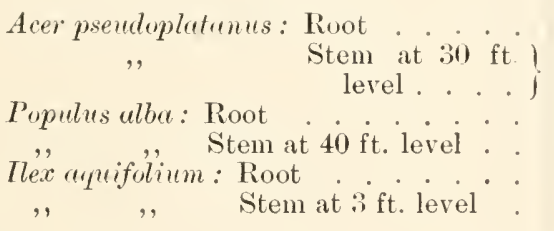 & $\begin{array}{l}0.070^{\circ} \mathrm{C} \\
0.049^{\circ} \\
0.072^{\circ} \\
0.047^{\circ} \\
0.099^{\circ} \\
0.082^{\circ}\end{array}$ & $\begin{array}{l}693 \\
410 \\
518 \\
339 \\
- \\
-\end{array}$ \\
\hline
\end{tabular}

\section{Literature.}

Boehm, J., "Ueber die Ursache des Saftsteigens in den Pflanzen," Sitzungsb. d. Alacd. d. Wiss. in Wien, 1863, Bd. 47 .

Id., "Wird das Saftsteigen in den Ptlanzen durch Diffusion, Capillärität oder durch Luftdruck bewirkt"? Sitzungsb. d. Aliad. d. Wiss in Wein, 1864, Bd. 50.

Id., "Les causes de l'ascension de la sève," Ann. des Sciences Nut. Bot., 1878, vi, 6 .

Id., "Ueber die Ursache der Wasserbewegung und der geringen Luftteusion in transpirirenden Ptlanzen," Bot. Zt.y., 1881, s. 801.

Id, "De la cause de mouvement de l'eau et de la faible pression de l'air daus les plantes," Ann. des Sciences Nut. But., 1881, vi, 12.

Copeland, E. B., "The Rise of the Transpiration Stream," Bot. Cruzette, 1902, pp. 161 and 260.

Dixon, H. H., "The Cohesion Theory of the Ascent of Sap," Proc. Roy. Dublin Soc., 1903, vol. 10 (N. S.) p. 48, and Notes from the Botanical School of Trinity College, Dublin, vol. i, p. 203.

Id., "Transpiration and the Ascent of Sap," Progressus Rei. Bot., 1909, Bd. III, s. 1.

Dixon, H. H. and Joly, J., "The Path of the Transpiration Current," Ann. of Bot., 1895, ix, p. 403.

Elfving, F., "Ueber die Wasserleitung im Holz," l'ot. Zty., 1882, s. 707. 


\section{TRANSPIRATION AND ASCENT OF SAP cн. II}

Errera, L., "Une expérience sur l'iscension de la sève chez les plantes," Compt. rend. de lu Soc. Roy. de Bot. de Belgique, 1S86, Bull. xxv, 2, 1. 28.

Hales, S., "Vegetable Staticlis," London, 1769.

Hartig, R., "Ueber die Vertheilung der organischen Substanzes, des Wrassers und des Luftraumes in den Bäumen, und ïber die Lrsache der Wasserbewegung in transpirirenden Pflanzen," Untersuchumgen d. Forst. Bot. Tnst. München, II. Berlin, 1882.

Id., "Die Gasdrucktheorie," (Berlin) 1883.

Id., "Die Wasserbewegung in den Pflinzen," Bot. Zty., 188:, Bd. 41, s. 250 .

Id., "Holzuntersuchungen," Berlin, 1901.

Larmor, J., "Note on the Mechanics of the Ascent of Sap in Trees," Proc. Roy. Soc., London, 1905, vol. 76 B, 1. 460.

ron Sachs, J., "Lectures on the Physiology of Plants," translated by H. Marshall WVard, Oxford, 1887.

Strasburger, E., "Ueber den Bau und Verrichtungen der Leitungsbahnen in den Pflanzen," Jena, 1891.

Tesque, V., "Recherches sur le mourement de la sève ascendante," Ann. des Sciences Nut. Bot., 1814, sér. vi, 19, p. 188. 


\section{CHAPTER III}

ASCENT OF SAP IN STEMS. CRITICISM OF VITAL THEORIES

WiтH the overthrow of the imbibition hypothesis, and the establishment of the fact that the major part of the transpiration current moves in the lumen of the vessels and tracheids, the pendulum of opinion among botanists swung over to the vital theory of the ascent of sap.

Godlewski.-Thus in 1884 Godlewski formulated a view which won many supporters, and, with modifications, still seems to appeal to some. He assumed a periodic change in the permeability of the osmotic membranes of the parenchymatous cells contained within the wood in order to bring about a pumping action which would account for the raising of water in the trachex of the stem. Thus, supposing a cell of a medullary ray in contact with eight trachexfour on each side-to draw water into itself and to increase its turgor so that its protoplasmic membrane is considerably stretched, and assuming the osmotic pressure of the cell and the resistance to filtration of the membrane opposite to one tracheæ to be periodically and suddenly diminished owing to a chemical change, then it is evident that the contractility of the protoplasm will cause water to escape through the most permeable spot of the membrane, viz., into the trachea opposite to which filtration is most easy. Once in the tracheæ, Godlewski 
assumed it to move mowards until it was drawn into a medullary ray cell lying at a higher level in the stem. The reason given for the motion upwards in the tracheic rather than downwards in obedience to the gravitational force, is because the air pressure in the tracher above is less than in those at lower levels. For this difference of pressure in the air bubbles in the stem Godlewski relies on Hartig's results. Hartig had, indeed, previously shown that the percentage of air in the higher parts of stems is less than that in the lower, but this does not necessarily involve a lower pressure. Godlewski claimed for his hypothesis that it explained the relations of the tracher to the parenchymatous tissues, the radial position of the bordered pits, which facilitates a staircase motion of the water upwards in the stem, and the radial intercellular spaces along the medullary rays, which afford the aeration necessary for the respiratory liberation of energy in these cells.

Janse supported Godlewski in a general way, and was one of the first to point out that, if the lower part of a branch be killed, the leaves above fade, as a rule, within a few days. This result is obtained even when the branch remains attached to its supporting stem. Janse, at first, assumed that this wilting is due to the interference with the vital sap-raising functions of the wood parenchyma, and the consequent failure in the water supply. He also conceived that the pumping action of the medullary rays is polarised, water being regularly absorbed on one side and expelled on the other.

Westermaier, who stated his views about the same time as Godlewski, also maintained the water-raising function of the cells in the wood. But, while Godlewski believed the major part of the motion to take place in the tracheal tubes, Westermaier considered the upward passage to be effected in the wood parenchyma, while the vessels and tracheids acted as water reservoirs rather than as conducting pipes. Godlewski contrasts his view and Wester- 
maier's by stating that he holds the wood parenchyma cells to correspond to the piston, and the tracheie to the tube of a pump, while the latter holds that the cells act as tube and piston, and the trachere are the reservoirs. Furthermore, Westermaier assumes that the water is held by capillarity in the traches in the form of short columns of water alternating with columns of air.

It is evident that Godlewski and Westermaier saw the difficulty of assuming that the water, once set free from the cells, would move upwards rather than downwards. Godlewski supposed that the difference in air pressure above and below decided its movement. Westermaier believed it is held by capillary forces in the trachea at the level to which it is raised by the cells.

According to the first assumption, however, we are reduced to the theory that the whole upward motion is due to a difference of air pressure above and below. Inasmuch as this difference is never so great as one atmosphere, a rise of more than about 10 metres cannot be accounted for.

Neither could Westermaier's hypothesis be followed, inasmuch as it was known that the major part of the motion of water upwards takes place in the trachere and not in the living cells, which, as a matter of fact, offer a great resistance to the passage of water. It was also rendered invalid owing to the fact that water is free to stream past the bubbles, and that they do not offer support for the water in the wood, but only increased resistance to its downward motion. This was made evident by the "drop experiment" ascribed to Sachs and Hartig, and also by Schwendener's observation, that the bleeding sap does not carry the bubbles with it from the trachee. Westermaier's hypothesis also, as has been often pointed out, is quite inapplicable to Conifers, for in their wood there is no vertical connection of cells placing the medullary rays of various levels in communication with one another.

Boucherie's experiment.-One of the most 
remarkable features in the discussion of the problem of the ascent of sap is that long before these vital hypotheses were conceived, they had received decisive experimental refutation. Boucherie, in 1840, while experimenting on methods of injecting timber for various technical ends, found that if a tree were cut across at the base and supplied with a poisonous fluid, it not only drew this fluid up to its highest leaves, but afterwards would draw up a second solution when the latter was supplied.

It is strange how the bearing of Boucherie's experiments appears to have escaped the notice of botanists completely, and it may be noted that Biot, when commenting on Boucherie's work, seems to find no special interest in it in connection with the problem of the elevation of the water of the transpiration current, but occupies himself with other questions. Boucherie's experiments did not wait long for confirmation. A few years afterwards J. Schultz injected trees in the same manner, but his results were also overlooked by botanists.

It appears, however, to have remained for Strasburger to point out the full significance of these experiments, and to confirm them with many more of his own, carried out with all possible precautions.

Strasburger further demonstrated the needlessness of the vital hypotheses by experiments in which stems more than 10.5 metres long, in a vertical position, continued to draw up water after they had been completely killed by exposure to a temperature of $90^{\circ} \mathrm{C}$.

From these results it was abundantly proved that water can rise, and has in these experiments risen, without the assistance of the living. cells of the stem; and, if forces exerted by these cells do intervene in raising the water in living plants, they are accessory to, and can only assist the purely physical forces in play which are able to perform the task unassisted. 
Evidence from structure.- The very structure of the conducting wood of trees, far from supporting Godlewski's contention that the cells assist in elevating the transpiration stream, offers the strongest evidence against it. These cells, placed as they are beside the transmitting tubes, can, by their pumping actions, in no way exert a lifting force on the stream. The water, as experiment shows, is free to move downwards as well as upwards. Nor would a polarised or unidirectional action of these cells, as hypothecated by Janse, help, owing to their relation to the tubes. In that case, these cells would regularly draw in water on one side and expel it on the other into tubes, where it is exposed both to downward forces and to resistance to upward motion. In fact, to utilise the pumping action of living cells in raising the transpiration current would require that the continuity of the conducting tracts should be here and there completely interrupted by the pumping cells; but if flow be possible in permeable tissues round these groups of cells, pumping actions on the part of the cells will be futi'e in assisting to raise water. As is well known, no such interpolation of cells cutting the continuity of the woody tissues is revealed by the most careful study of the conducting tracts. The structure of the latter tissues is, therefore, fatal alike to the earlier views of Godlewski and Westermaier, and to the less precise form under which they have been recently resuscitated by Ursprung.

Exception has been taken to the statement that the structure of the wood is against the vital hypothesis, and it has been maintained that this statement is based on ignorance of the resistance offered by the wood to the filtration of water.

Assuming the resistance to be considerable, Janse believes that a pumping action in the medullary-ray-cells is able to account for the rise of the water. This action, 
according to Janse, consists in an absorption of water on one side of the cell and a giving off of it on the other, a result which is effected, he suggests, by the harmonious action of enzymes and protoplasmic streaming. An enzyme fixes water in the cavities of the protoplasm on one side of the cell, and streaming brings it to the other side, where a reversing enzyme sets it free.

In order to get a clearer idea of the demands of this theory, it is interesting to apply to it the figures already obtained for the velocity of the transpiration current, and those for the rate of protoplasmic streaming, and at the same time to take into account the structure of stems.

Ewart has shown that the rate of upward movement during transpiration in stems of Conifers is about $7 \mathrm{~cm}$. to $10 \mathrm{~cm}$. per hour. Higher figures are sometimes given. According to Janse, this movement must be due to the difference between the actual amount raised by the medullary-ray-cells and the leakage back by filtration. The pressure under which this filtration takes place is the pressure of a head of water equal to the height of the tree. As will appear later, this head causes a flow approximately equal to the rate of the transpiration current. Therefore the pumping action of the cells must continually pass an amount of water which would, if there was no leakage, be twice that of the transpiration current. It is obvious, however, that the motion through the cells must be much more rapid than this, as they occupy but a fraction of the cross-section of the wood.

A cross section of the wood of Pinus silvestris shows that-

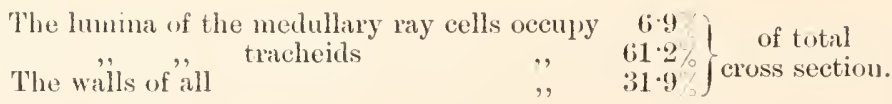

I am indebted to Mr. W. R. G. Atkins for these measurements. They were made by cutting out and 
weighing accurate camere lucida tracings on uniform paper of sections of the wood.

It follows that to produce the $7 \mathrm{~cm}$. per hour velocity observed, an actual rate of $14 \mathrm{~cm}$. per hour must be maintained, while the velocity of the water through the cells must be about nime times that, or $126 \mathrm{~cm}$. per hour, i.e., about $2 \mathrm{~cm}$. per minute. But this figure has still further to be increased, inasmuch as at most half of the cells' lumen can at any time be active in transferring the water from the lower to the upper side. The other half will, by hypothesis, be occupied by the return current of the protoplasm. Thus we must assume a motion across the cells of at least $4 \mathrm{~cm}$. per minute. This will be still an under-estimate of the velocity, for it is evident that only a portion of the total protoplasm can be occupied by water, and also only a portion of the lumen is occupied by protoplasm. Therefore, the velocity of $4 \mathrm{~cm}$. per minute must be regarded as an under-estimate of the velocity of the current in the protoplasm required by the theory. It is needless to say that such a velocity of protoplasmic streaming has never been observed. Janse himself states the streaming in the endodermis cells of Iris, which he believes to act in the same way, amounts at a temperature of $19^{\circ} \mathrm{C}$. to $300 \mu$ or $0.03 \mathrm{~cm}$. per minute. It appears, then, that this theory which attributes the lifting force of the water in the stem to the protoplasmic streaming of the medullary-ray-cells requires a rate of protoplasmic streaming at least 100 times that hitherto observed.

The adhesion of writers to the vital hypothesis since Strasburger's results were published is so remarkable that we must devote some space to examine fully the grounds for their contention.

Transmission through dead stems.-When a considerable length of a branch, still attached to an uninjured plant, is killed by surrounding it with steam or 
hot water, it is found that the leaves above the killed portion sooner or later fade and wither. The vitalists' interpretation of this observation is that, when the vital actions of the wood parenchyma and medullary-ray-cells are removed, the supply of water to the leaves above is so reduced that they fade and dry from want of water. It is significant that the discoverers of the phenomenon saw in it no support of the vital hypothesis. Weber recognises that the reduction of the water supply may be attributed to the stoppage of the tracheal tubes. Janse, although supporting Godlewski's vital theory, quickly saw that this observation, being traceable to the blocking of the supply tubes, could not be quoted in support of the vital hypothesis. Finally, Vesque sees no support in it for the vital theory. Ursprung, however, one of the most recent champions of this hypothesis, relies on the observation with great confidence to support his view, but even his observations show that, out of some twenty species in which the phenomenon was observed, in fourteen stoppages after heating in the conducting tubes were actually observed-usually above the heated region. Ursprung, in spite of this, maintains that the reduction in the water supply is not caused by stoppage because (1) the leaves may begin to die before the stoppage of the tubes is observed; (2) even when stoppages do occur, fading may be postponed; (3) fading does not occur when a piece of the wood is removed from an uninjured branch corresponding in size to the plugged portion of the heated branch.

Stoppages in the tracheæ.-It is to be noted that the failure to observe stoppages microscopically does not negative their existence. A transparent material might form quite an effective plug in the tubes, or render the transmitting pits almost impermeable, while it might be almost or quite invisible. Such a transparent substance Weber did actually detect in his experi- 
ments on Picea excelsa. This investigator's observation that the resistance of the region immediately above the killed part is enormously increased, is a piece of positive evidence in favour of stoppage which cannot be put aside. He found that the lower part (11.8 cm. long) of the heated stem, including both boundaries between the dead and the living regions, refused to transmit water under a head of $62 \mathrm{~cm}$. of mercury. Microscopic observation shows that clogging is greatest in these border regions. The permeability of the upper parts of the same stem was much greater, as was seen from the fact that the upper $16.5 \mathrm{~cm}$. supporting the faded leaves transmitted sufficient water under a head of $59 \mathrm{~cm}$. of water to render the leaves turgescent once more. In several other experiments Weber has shown that the resistance of the conducting wood is enormously increased where the uninjured part borders on the heated region. Janse confirmed and extended Weber's observations of this increase of resistance even when the temperature to which the branch was exposed was as low as $60^{\circ}-64^{\circ}$.

It is easy to show that the water traversing a piece of stem killed with heat is contammated in its passage. Thus, if distilled water is forced through a piece of a stem freshly cut from a tree, it is transmitted without sensible coloration so long as morbid changes in the stem do not take place. But if the same stem is surrounded with steam so that its cells are killed, the water which emerges is no longer colourless, but is tinged, more or less deeply, with brown. When attached to the tree the killed piece must contaminate the rising transpiration stream in the same way. The record of this contamination first appears on the walls of the tracher of the leaves, which become stained; then in their lumina, which become filled with the coloured fluid concentrated by evaporation. This substance is finally caught in the walls of the conducting tubes of the stem and forms plugs, filling their 


\section{TRANSPIRATION AND ASCENT OF SAP ch.}

lumina immediately above the killed region. Even without Weber and Janse's direct determinations it would be hard to believe that the deposit of this coloured substance in the walls and lumina of the tubes could be without effect on their efficiency in transmitting water.

From what has been said it will appear that even in those cases where no visible stoppage has been found, we have ample reason to suspect its presence. Furthermore, in many cases, both where the gum-like clogging material has been observed, and where it has not been found, the bordering living cells develop tyloses, and so more or less completely stop the flow of water in the tracheæ. The occurrence of tyloses has been recorded in a large number of cases.

Thus the fading and drying of the leaves above the killed region gives no support to the idea, that the lack of water from which the leaves suffer is due to the removal of vital forces which are required to raise the water-supply, but it rather indicates a great increase in the resistance of the stem, due in part to the stoppage of the lumina and to the clogging of the walls of the transmitting trachee. Janse's and Ursprung's observation, that the greater the length of the killed portion the more rapid the fading, is quite explicable on this view, as it is natural that a greater amount of the clogging material would be set free by the larger number of killed cells.

Contamination of the sap.-It also seems certain that some of the materials liberated into the transpiration stream by the killed cells act deleteriously on the cells in the leaf, and bring about morbid changes in them so that in many cases these cells actually lose their turgor and die even before they suffer severely from the reduction in their water supply. It actually, then, appears, as Vesque puts it, that the leaves dry because they die. ${ }^{1}$

1 Here it may be pointed out that the leaves which fade after their supporting branch has been killed by heat, fade in a different manner from 
A priori such a result seems inevitable. When the heat has killed a portion of the stem, the cells adjoining the water-tracts become permeable; and hence the dissolved substances in their vacuoles are set free into the upward current of sap in the tracher. The vacuoles contain acids, carbohydrates, and salts, so that, even in the absence of corroborative observations, we should expect the sap to be enriched with these substances Furthermore, very probably substances in the cells ordinarily not in solution would be brought into solution, and introduced into the sap by the higher temperature; possibly, too, some bodies might be precipitated from the rising sap by the higher temperature. Yet another change is to be anticipated. The heat will destroy any thermolabile substances in the sap and in the adjoining cells. Coagulation changes may also be expected.

It is not difficult to test these surmises experimentally; and, indeed, a colour-change in the sap issuing from heated stems has before now been recorded and commented upon.

The sap extracted from various trees by means of a centrifuge provided material suitable for this investigation. Short lengths of the branch to be investigated (9-10 cm. long by $2-2.5 \mathrm{~cm}$. diameter) are placed in gilt buckets of a centrifuge, and the sap yielded after about

those which wilt owing to a lack of water. In the former case the margin of the leaf first becomes darkened and this darkened region gradually invades the leaf between the veins. It then dries and shrivels while the green parts inmediately round the veins remain comparatively fresh. As this change is taking place thesc veins usually become pink and finally brown. This coloration is particularly noticeable when the leaves arc viewed with transmitted light. Shrivelling and withering of the leaf, except at the edges, does not occur until after these changes are complcte.

On the other hand, when leaves fade simply from an insufticient water supply, e.f., on a branch severed from a tree, shrivelling comes on while they are still green. Blackening appear's only after shrivelling and occurs in irlegular patches. The rcins do not change colour and the walls of the trachere do not appear coloured in transverse section. The first colour change is when the ccll-contents of the mesophyll and parenchyma of the vcins colour brown after death. 
five minutes' rotation is collected. The quantities of sap obtained in this way are surprising. Whether in spring, midsummer, autumn, or winter, I have found that four such pieces of the various woods used yielded about $3-5$ c.c. In the same way, sap was collected from pieces of steamed branches. These samples of sap could now be compared physically and chemically. In every case, as was anticipated, profound differences were found to exist between the characters of the saps drawn from the fresh and the steamed branches. Some of the results may be seen in Table 4 : under $\Delta$ the depression of the freezing-point, under $\mathrm{C}$ the electric conductivity is given. Also the reaction of the sap to litmus and the presence of oxydase are noted :-

Table 4.

Chaxges ixtroducen INTo WoOH-sap by Steanixi.

\begin{tabular}{|c|c|c|c|c|c|}
\hline \multirow{2}{*}{ Name. } & \multicolumn{5}{|c|}{ Fresh. } \\
\hline & $د$. & $\mathrm{C} \times 10^{4}$ & Acidity. & Colour. & Oxydase. \\
\hline $\begin{array}{l}\text { Fagus silvatica } \\
\text { Populus alba } \\
\text { llex aquifolium }\end{array}$ & $\begin{array}{l}0 \cdot 083 \\
0.055 \\
0 \cdot 072\end{array}$ & $2 \cdot \frac{3}{6}$ & $\begin{array}{l}\text { very faint } \\
\text { very faint } \\
\text { very faint }\end{array}$ & $\begin{array}{l}\text { colourless } \\
\text { colourless } \\
\text { pale grey }\end{array}$ & $\begin{array}{l}+ \\
+ \\
\ldots\end{array}$ \\
\hline \multirow{2}{*}{ Name. } & \multicolumn{5}{|c|}{ Steamed. } \\
\hline & $\Delta$. & $\mathrm{C} \times 10^{4}$ & Acidity. & Colour. & Oxyilase. \\
\hline $\begin{array}{l}\text { Fragus silcutica } \\
\text { Populus albu . } \\
\text { Dex aquifolinm }\end{array}$ & $\begin{array}{l}0 \cdot 509^{2} \\
0 \cdot 2.31^{2} \\
0 \cdot 321^{\circ}\end{array}$ & $\begin{array}{l}19 \\
11 \\
28\end{array}$ & $\begin{array}{l}\text { marked } \\
\text { mirked } \\
\text { marked }\end{array}$ & $\begin{array}{c}\text { brown } \\
\text { pale brown } \\
\text { pale brown }\end{array}$ & $\begin{array}{l}0 \\
0 \\
0\end{array}$ \\
\hline
\end{tabular}

The change in $\triangle$ brought about by steaming is due to the total increase of the dissolved substances, and indicates that the concentration of the sap has increased four to six times. The changes in conductivity (expressed as the 
reciprocals of the resistances measured in ohms) indicate the relative richness of the saps in electrolytes. ${ }^{1}$ From the table it appears that the concentration of electrolytes has become four to six times greater by steaming. The development of strong acidity during the heating (observed in every case so far examined) shows that the increase of electrolytes is partly due to the introduction of acids into the sap.2 In Fagus and Populus an oxydase was present ${ }^{3}$ in the sap of the unsteamed stem, which coloured guaiacum tincture faintly blue. The blue was intensified by the addition of hydrogen peroxide. The oxydase was, of course, destroyed with heating. The oxydase was not looked for in the case of Ilex.

Qualitative tests on the sugars of the saps from the fresh and steamed branches indicated changes in these bodies also. Where non-reducing sugars are present, they are, of course, hydrolysed by the steaming of the branch, and the acid liberated; and they appear after the heating as reducing sugars. Examples of this were found in Ilex aquifolium, Salix babylonica, and Cotoneaster frigida. In the lastmentioned, however, larger quantities of reducing sugars were found present in the sap of the steamed branch than could, have been formed by the inversion of the nonreducing sugars present in the sap of the fresh branch, so that we must assume that they were introduced into the sap from the neighbouring cells.

These tests are suflicient to substantiate the surmise that the physical and chemical natıre of the sap is profoundly altered by steaming the branch through which it passes.

It is evident that the substances thus introduced into the sap must be swept along in the rising current till they reach the leaves, except for what material is absorbed by

1 I am indebted to Mr. W. R. G. Atkins for the determination of these conductivities.

2 The very faint acidity of the sap from the fresh branches may probably be ascribed to the sap set free from the injured cells at ends of the pieces.

3 It is possible that this oxydase was also derived from the cut cells. 
the walls of the trachere, and by the cells adjoining the water tracts above the heated region. In the leaves, those which are not in a form suitable for assimilation must accumulate; and, if sufficient of the branch has been killed, the accumulation will ultimately-without any other poisonous action--plasmolyse the cells of the leaf. ${ }^{1}$

Reduction in the water-supply may be also brought about by the coagulation of colloids in the sap, and the consequent formation of plugs in the conducting tubes. This condition, as has been noted above, has been observed by several investigators.

Poisonous action of contamination.-It seemed of interest to essay to find out if the sap in steamed branches contained any substance which acted as a protoplasmic poison, and not merely as a plasmolysing agent by simple accumulation. To test this point, saps extracted from branches subjected to various treatments were applied to severed leaves of Elodea canadensis, and the effect on the cells of these leaves microscopically controlled.

In the first place it was found that the cells remained normal, and protoplasmic streaming continued undiminished in the sap from fresh branches for at least five days, and probably much longer. This point was verified in the case of the sap of Ilex aquifolium, Prunus cerasus, Syringa vulgaris, Cotoneaster frigida, and Salix babylonica. In contrast to the sap from the fresh branches, that from the steamed branches of all these, with the exception of Ilex aquifolium produced lethal changes in the leaves of Elodea within two or three days. These changes consisted in a cessation of protoplasmic streaming, in the discoloration of the veins and margins, and in the contraction of the protoplasts of the cells all over the leaf, and their

I It may be noted that l'rspung looked for the production of plasmolysing effiects in the root-hairs of Impatiens sultani hy a decoction of the same plant, but did not find any. Here, of course, concentration would not take place. 
ultimate blackening. The contraction which occurs is not of the nature of plasmolysis ; for more than a day is often required for its production, and it cannot be undone by the transference of the leaf to water.

In each case a sample of sap centrifuged from the fresh branch was tested; other similar tests were made upon that centrifuged from a branch immediately after steaming, or centrifuged from a branch steamed a day or two previously, or with the liquid centrifuged from a branch which had a day or two previously been steamed, and at once depleted of its sap by centrifuging, and refilled with distilled water. These two last tests were made in order to see if the poisonous materials are set free immediately into the sap on steaming, or whether they are produced as subsequent degradation-products of the cells.

\section{TABLE 5.}

Day of Experiment.

1st. 2nd. 3rd. 4th. 5th.

Ilex arnifolium, fresh

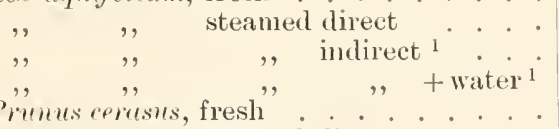

$, \quad, \quad$ steamed direct

", ", indirect + water.

Cotoneaster" frigidu, fresh

,

steamed indirect. . .

", , , water

\begin{tabular}{|c|c|c|c|c}
\hline 0 & 0 & 0 & 0 & 0 \\
0 & 0 & 0 & 0 & 0 \\
0 & 0 & 0 & 0 & 0 \\
0 & 0 & 0 & 0 & 0 \\
0 & 0 & 0 & 0 & 0 \\
0 & + & + & + & + \\
0 & 0 & + & + & + \\
0 & 0 & 0 & 0 & 0 \\
0 & $?$ & + & + & + \\
$?$ & + & + & + & + \\
0 & 0 & 0 & 0 & 0 \\
0 & 0 & $?$ & + & + \\
0 & 0 & 0 & + & + \\
0 & 0 & 0 & 0 & 0 \\
0 & + & + & + & + \\
$?$ & + & + & + & + \\
$?$ & + & + & + & + \\
& & & &
\end{tabular}

In Table 5, the sap obtained by centrifuging immediately after steaming is termed "steamed direct";

1 When the sap had stood in contact with the dead cells for two or more days, discoloration of the veins and blackening of some of the cells without marked contraction occurred on the fifth day. 
that which was centrifuged some days after steaming is called "steamed indirect"; while the liquid obtained from the steamed branches which had been emptied of their sap, and subsequently filled with water, is tabulated as "steamed indirect + water." The ciphers in the table indicate that no effect was observable on that day of the experiment under which the figure is placed, while a plus mark shows that an effect was observed. Query-marks indicate that only some of the leares tested were affected, or that only slight protoplasmic contraction was observable. In each case three or four leaves were immersed in the liquid and examined.

It may be noted that, in the case of Cotoneaster frigida, Syringa vulyaris, and Ilex aquifolium (see footnote, p. 61), the liquid centrifuged from the steamed branch, after it was emptied of sap and filled with water, is more rapidly poisonous than the sap itself. In these cases probably a poison is formed in the cells after death, which is not sufficiently concentrated in the sap centrifuged immediately after steaming. The same explanation probably applies to the observation that the sap extracted from the Syringa branch immediately after steaming is not so quickly lethal as that drawn off a couple of days after death.

The slow generation of poisons indicated in these experiments probably affords an explanation of the fact that, even when steamed branches are washed out immediately after the heating, as described later, some of the leaves above perish from poisoning.

But it is possible to demonstrate the poisonous action of the substances liberated in the killed portions of branches on their own leaves without at the same time curtailing their water supply in any way. This was found feasible in the following manner:-One branch of a bifurcated shoot of Syringa vulgaris was killed by immersion in water at about $90^{\circ} \mathrm{C}$. for ten mimutes. After this the dead branch was stripped of its leaves, and 
cold water supplied through it to the leaves supported on the uninjured branch. These leaves then drew supplies of water from two sources, viz., from the roots, and through the dead branch. To facilitate this latter supply a fresh surface was occasionally cut on its distal extremity. The length of the dead branch in my experiments varied from 30 to $40 \mathrm{~cm}$. Notwithstanding the double supply of water, the leaves on the living branch in each experiment showed signs of wilting. When the supply through the dead branch was cut off, either by the withdrawal of the water from its end, or by its own clogging, the wilted leaves partially recovered. But in several experiments the edges of the leaves were too far injured to recover, and the injury persisted as a brown margin on the leaf.

The experiment may also be carried on with a straight branch from which the upper leaves and side branches are removed. The stripped upper portion is immersed for a short time in water at about $95^{\circ}$, and after death so caused, water is supplied through it to the lower leaves and side branches, which have been left undisturbed. If the supply of water through the upper dead part of the branch is kept up, fading and partial withering of the leaves below will be noticeable in a few days.

Inasmuch as the effect on the leaves depends on the amount of harmful matter carried from the dead cells, it is evident that immediate or complete withering is not to be expected ; for the supply from the dead part is largely diluted with the supply from the roots through the living, and, furthermore, it is difficult to make the supply through the dead part considerable owing to the clogging at the cut surface, and to the internal stoppages caused by the exudations into the water-capillaries from the dead cells.

Another and simpler method of observing the withering effects of the substances liberated from cells, when killed by heat, may be carried out as follows :-A decoction is made by boiling small pieces of a stem in water for a 


\section{$6+$ TRANSPIRATION AND ASCENT OF SAP cн.}

short time. This decoction, after repeated filtering, is supplied to cut branches of the same tree. It will be found that the leaves of the branches supplied with the decoction fade and wither much more rapidly than those of control-branches supplied with water. For example, three branches of Syringa vulgaris, set in a decoction of the stem of the same plant, lost their turgidity within two days, while the leaves of three control-branches were still fresh after five days.

Taken alone, this last observation would not be sufficient to prove that in intact branches the withering of the leaves is due to deleterious substances emerging from the killed cells; for it might be urged that colloid substances in the decoction aggregating on the cut surface obstruct the free transmission of water, and thus cause the fading by partially cutting off the water-supply. The probability of this explanation is lessened by the fact that the decoction causes the fading even after it has been repeatedly filtered. In any case the observation, taken along with the previous experiments, inay be regarded as confirmatory of the view that the fading is largely due to the plasmolysing or poisonous effects of substances extracted from the dead cells.

The contaminated nature of the water supplied through a dead branch may be demonstrated by collecting some of the water transmitted through a branch killed by the application of hot water, as in the previous experiments. If Syringa vulgaris is used, the water is of a dark brown colour, and quite different in appearance from what is transmitted through a living branch in similar circumstances. If this brown fluid is supplied to cut transpiring branches, the latter rapidly fade and wither. When making this experiment, I killed the lower $30 \mathrm{~cm}$. of a straight branch $40 \mathrm{~cm}$. long, by immersion in hot water. The branch was then inverted and water forced through it under a head of $20 \mathrm{~cm}$. The water transmitted was thus filtered through $10 \mathrm{~cm}$. of living wood after its passage 
through the dead portion. Subsequently, it was twice filtered, and supplied to cut branches. These latter faded in two and a half days, while controls did not show signs of fading for several days later.

Removal of Contamination.-It has been found possible to confirm this explanation of the fading of the leaves in another very striking manner. It was to be expected that if poisonous materials generated by the application of heat in the supporting stem caused morbid changes in the leaves above, it should be possible partially or completely to prevent the changes by washing out these materials from the stem as they are formed. We should expect the leaves above such a heated and washed-out stem to last fresh much longer than those above a similar piece of stem which had been heated but was not washed out.

The experiment was performed on a pot plant of Prunus cerasus. The stem of this plant, at a level of about $40 \mathrm{~cm}$. above the soil, bifurcated into two equal branches, $B$ and $C$ (see Fig. 11). B produced two lateral branches, E and D, at 11 and $34 \mathrm{~cm}$. respectively above the bifurcation, while C had two smaller leafy branches about $15 \mathrm{~cm}$. above the bifurcation, and terminated with a tuft of leafy

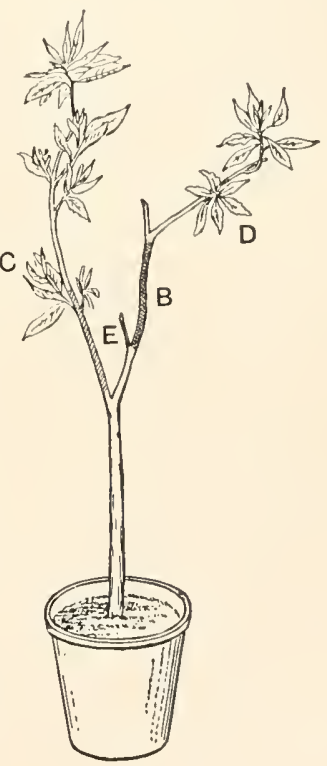

FIt: 11. branches above. The top of $B$ above the base of $\mathrm{D}$ was removed, and, with suitable precautions to minimise clogging, a rubber tube was attached to it. The whole of $\mathrm{E}$, except a few centimetres of its base, was cut away. The cut surface at the top of B was now supplied with distilled water under a head of $33 \mathrm{~cm}$. When the cut surface of E, by becoming moist, 
showed the arrival of this stream below, the intervening space of $23 \mathrm{~cm}$. between the bases of $\mathrm{D}$ and $\mathrm{E}$ was lapped in a cloth and sprayed with boiling water. Meantime the leaves were protected from injury by being covered with damp cloths. 'The hot spraying lasted 10 mins. After it ceased the cloths were removed from all except the leafy branch D. The transpiration of this branch was thus kept at a minimum during 24 hours, while the supply of distilled water was kept up to flush out the materials exuded into the waterways of the heater region. During this time about 35 c.c. were passed in at the top of $B$. After this the plant stood in a cool greenhouse under conditions favourable to transpiration.

Three days later it was observed that the lower leaves of $\mathrm{D}$ and a few of the leaves on the lower branches of $\mathrm{C}$ were slightly discoloured and curled at the edges. Evidently the heating of the part of $B$ had affected not only the leaves above it, but also some of the leaves on a branch springing from below its base.

After seven days from the beginning of the experiment, the leaves on $\mathrm{C}$ and $\mathrm{D}$, which before had shown the slight changes just mentioned, had become quite withered and curled.

Fourteen days later, i.e., twenty-one from the begimning of the experiment, there were still four living leaves on $\mathrm{D}$, but their veins were coloured red, and the edges of two were discoloured brown. The remaining leaves on $\mathrm{D}$ were dry and crisp. On C all the lower leaves had fallen, or, if still attached, were crisp and much discoloured. The remaining upper leaves were apparently still quite healthy.

The lower killed leaves on C were now removed, and the lower $23 \mathrm{~cm}$. of the branch was killed with hot water in the same manner as B had been, while the healthy upper leaves were protected by enveloping them in a damp cloth.

Five days after this treatment, all the leaves on $\mathrm{C}$ were stained and curled, their cells being evidently dead. 
In this experiment we see that all the leaves above a length of stem of $23 \mathrm{~cm}$. which has been killed by heat, show strongly marked morbid changes after five days, while in a similar case, if the heated region is washed out with water, these changes are postponed in some for twenty-one days, and even then are not complete. The experiment also demonstrates that leaves on an uninjured branch may be caused to wither by supplying them with water which has passed through a heated stem.

In another experiment a plant of Cotoneaster frigida was used. Distilled water was supplied at the cut end of the main stem. Below this four lateral branches, A, B, C, and $\mathrm{D}$, took origin, separated from one another by distances on the stem of $18 \mathrm{~cm} ., 5 \mathrm{~cm}$., and $22 \mathrm{~cm}$., respectively, from below upwards (see Fig. 12). From each of these leafy secondary branches sprang. D supported only one secondary branch, and it was cut short by an old injury. C was lopped at the start of the experiment, and left with only one secondary branch. B and A were not interfered with. During twenty-four hours distilled water was supplied at the cuit top of the main stem, and meanwhile the region of the main stem, viz., $22 \mathrm{~cm}$., between $\mathrm{C}$ and $\mathrm{D}$ was killed

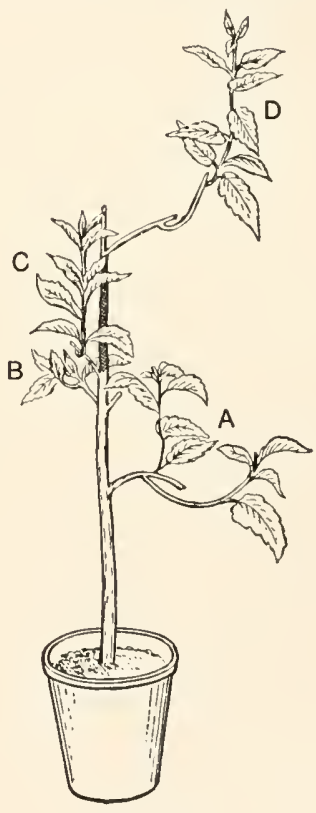

FIG. 12. with hot water as before, while the leaves were suitably protected from injury.

Three days later blotchy discolorations appeared on the lower leaves of $\mathrm{D}$, and less markedly on some of those of $\mathrm{A}, \mathrm{B}$, and $\mathrm{C}$.

On the fourteenth day the four lowermost leaves of $\mathrm{D}$ were completely discoloured, and a small blotch had 
appeared on the fifth leaf from the base, while the seven leaves above were quite healthy. On A there were five leaves dead; on $\mathrm{B}$ two small ones and two large leaves blotched, on $\mathrm{C}$ there was one withered and crisp, and one blotched.

At this stage, $14 \mathrm{~cm}$. at the base of $\mathrm{C}$ was heated, the leaves above being protected.

On the next day all the leaves of $\mathrm{C}$ were stained and beginning to curl. No further changes were noticed in $A$ and $B$.

Six days after the heating of $\mathrm{C}$ all its leaves were dead, while still the uppermost leaf of D was unaffected, although its supply was drawn through $22 \mathrm{~cm}$. of stem which had been killed twenty days previously.

In this experiment, evidently the flushing of the killed branch removed much of the deleterious substances from the supply to D, for its changes were at first less noticeable than those of the branches below, into which evidently the major part of these substances were distributed. The changes observed in $\mathrm{C}$ after its base was heated, indicate the extent and the rapidity of injury we might have expected in D had the killed region not been washed out.

Thus we see there is a large mass of experimental evidence showing that the fading of the leaves on a killed stem is due to the introduction of poisonous or plasmolysing substances into the transpiration sap. In these branches the freedom of motion of the upward water current may be reduced by plugs formed above the heated region and in the veins of the leaves themselves; but, if sufficient length of the stem has been killed, poisoning will apparently always supervene, whether plugging occurs or not. With these facts established, this fading affords no evidence in support of the view that the vital activities of the cells of the stem are essential to the raising of the transpiration stream. 
Attempts to detect the action of vital forces.In another form the vital hypothesis has been lately supported by Ewart. Adopting Janse's method of determining the resistance opposed to the transpiration current, Ewart obtained results which indicate that, in order to move water in stems of plants at the velocity of the transpiration current, pressures equivalent to a head of six to thirty-three times the height of the plant are required. To overcome this resistance, which in the case of the highest trees would amount to 50-100 atm., Ewart feels constrained to fall back on the vital activities of the wood parenchyma. He supposes them to lend a helping hand in some way, and to overcome the resistance of the stem all along its length.

These hypothetical forces, however they are imagined to be exerted by the living cells, Ewart believes to be but feeble, and has not, as he himself admits, in any case obtained nnequivocal evidence for their existence. And yet, according to his own figures, these forces should be easily demonstrable. According to him, the pressure required to raise water at the transpiration-velocity in an elm tree $12 \mathrm{~m}$. high would be equivalent to a head of $75 \cdot 6 \mathrm{~m}$. , i.e., about $7 \cdot 5$ atmospheres. Of this he admits about 2 atmospheres might be supplied by the tension set up by the transpiring leaf-cells, leaving about 5.5 atmospheres to be made good by the lifting forces of the cells in the $12 \mathrm{~m}$. of stem. Therefore, the lifting force of the cells of this stem must amount to 0.45 atmosphere per metre of stem, or to a head of water equal to four and a half times the length of stem.

A lifting force of this magnitude should be easily revealed if the velocity of flow through a branch in the normal direction for a given head were compared with the flow in the reverse direction, or, again, if the amount transmitted downwards in a living stem were compared with that transmitted after death. As is well known, 
experiments have not been able to demonstrate a sensible difference in either case. Furthermore, Ewart, working very carefully by a different method, has failed to detect the existence of these pumping actions in stems. Consequently it is quite impossible to admit that any large amount of work falls on the cells of the stem in the raising of the sap.

While these considerations show that forces of any great

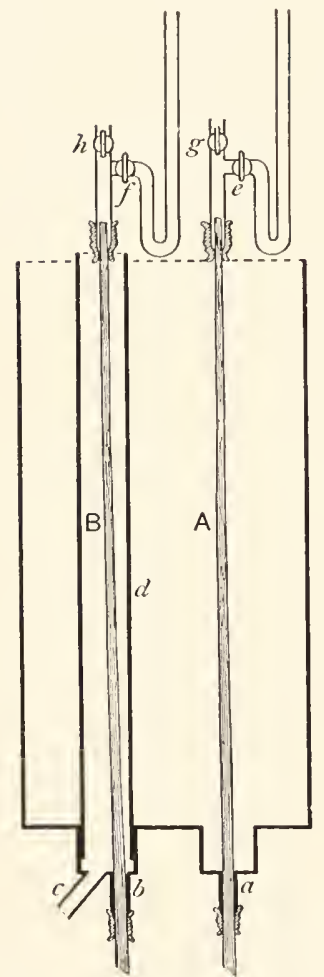

Fit: 13. magnitude are not exerted by the cells in the wood on the transpiration-current, it seemed desirable by some more careful method to test the matter, and see if some much smaller force were not assisting the upward flow of water.

In the ordinary methods of testing this question, uncertainties arise from the fact that conditions are not the same before and after the reversal of the current, or before and after the death of the branches. These differences are principally due to changes in temperature, which, as Ewart has pointed out, entail large differences in viscosity, and to clogging in the experimental stem.

In order to eliminate these sources of error, and so be in a position to detect the effect of even a very small force exerted by the stem-cells in lifting water, I carried out some experiments in the following manner :-

Two straight branches (A and B, Fig. 13), about $80 \mathrm{~cm}$. long, without lateral shoots, and as similar to one another as possible, ${ }^{1}$ were passed through tubulures $(a$ and $b$ ) in

1 I used symingu rulyuris, as similar and straight bameles of this slorub are readily obtained. 
the bottom of a metal cistern, about $65 \mathrm{~cm}$. deep. The upper ends of the branches projected above, and the lower ends below, the cistern. The joints round the lower ends were rendered water-tight by binding on a rubber tube overlapping the tubulures and the projecting ends of the branches. The cistern was then filled with water which, being in motion, secured that both branches were at the same temperature, and so differences in viscosity in the water passing through the branches did not arise.

In order to avoid irregularities in transmission, much care is needed in the preparation of the branches. After selection of the branches, the upper leafy part was cut away, and the cut surface of the lower part still attached to the tree was moistened by a jet of water. This part was then cut off under water, and while still submerged, was removed to the laboratory. Fresh surfaces were next prepared at each end, and smoothed off by a razor, under a stream of distilled water. A wide glass tube about $20 \mathrm{~cm}$. long was attached to the upper end of each branch. This was kept full of distilled water, which acted as the supply and head, driving the water downwards through the branches. If it was desired to apply picric acid or some other poison as a killing agent, the simple glass tube was replaced in each case by one which was provided with a side tubulure, bent in a $\mathbf{J}$ form, and with two stop-cocks placed as shown in Fig. 13 .

The rate of transmission from above downwards was first observed for the two branches by weighing the amount of water transmitted in a given time (say $10 \mathrm{~min}$.). It is evident if vital actions were at work tending to raise the water in the branches, the rate of flow downwards would be reduced by this activity; and inasmuch as both branches are under similar conditions, the reduction of flow would be the same for both. It may here be noted that an alteration in the head of $10 \mathrm{~cm}$. makes a very sensible difference in the amount transmitted, raising it, to take an example, 
from 0.450 gram to 0.500 gram per $10 \mathrm{~min}$. If now one branch be killed, the vital lifting-force, if present, will be removed, and we should expect the amount transmitted by the killed branch to increase correspondingly. This increase, even though small, would be easily seen by comparing the flow through the dead and the living branches, when both have been again brought to the same conditions. For killing the branch I used either a jacket of steam or an injection of poison.

When it was desired to kill the experimental branch with steam, the water in the cistern was run off through a small side-tubulure $(c)$, and, when the cistern was empty, steam was passed by the same tubulure into a wide tube $(d)$, now placed round the experimental branch, and fitting tightly into a socket made for its reception in the bottom of the cistern. The space round the top of this branch, and between it and the tube, was packed with cottonwool. The supply of steam was kept up for 20 min.; the tube $(d)$ was then removed; and the cistern was filled with water through the tubulure $(c)$. After some time, during which the water in the cistern was kept stirred, when it was judged that the experimental and control branches had come to sensibly the same temperature, measurements of the amounts transmitted by each were resumed. In this way it was easy not only to compare dead and living branches under the same conditions, but also rough manipulation and shaking were avoided. These latter are known to cause irregularities in the amounts of water transmitted by cut branches, probably owing to the displacement of, or compacting of, some clogging material on their upper surfaces.

Observations made in this way showed in each case that the amounts transmitted by a branch before and after killing by steam were sensibly the same; or, if they differed in the experimental branch, the same difference was observed in the amounts transmitted by the control 
branch at the same time, the observable differences being due to changes in conditions which affected the flow in the living as well as in the killed branch.

In Tables 6 and 7 is recorded an example of one of these experiments, which is graphically recorded in Fig. 14.

\section{Particulars of Experiment.}

$A$ and B, two similar branches of Syringa vulyaris, each with five year-rings.

A : length, $84.5 \mathrm{~cm}$. long. Upper diam. of wood,

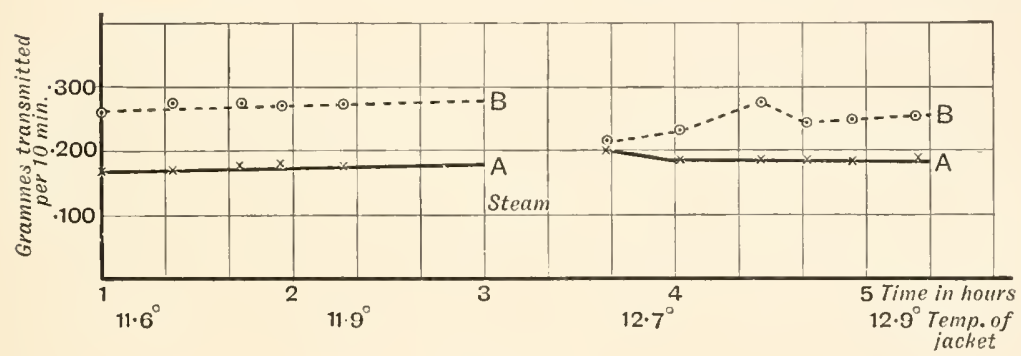

FIt. 14.

$0.8 \mathrm{~cm}$; of pith, $0.15 \mathrm{~cm}$. Lower diam. of wood, $0.9 \mathrm{~cm}$. of pith, $0.23 \mathrm{~cm}$. Head, $9 \cdot 0 \mathrm{~cm}$. of water.

B : length, $83.5 \mathrm{~cm}$. Upper diam. of wood, $0.73 \mathrm{~cm}$; of pith, $0.1 \mathrm{~cm}$. Lower diam. of wood, $0.85 \mathrm{~cm}$. ; of pith, $0 \cdot 1 \mathrm{~cm}$. Head, $9 \cdot 3 \mathrm{~cm}$. of water.

Thibe 6.

Time from start 'Temp. of Cistern. in $\mathrm{min}$.
Amount transmitted Amount transmitted per 10 minutes by $A$. per 10 minutes by $\mathbf{B}$.

\begin{tabular}{r|l|l}
5 & $11 \cdot 6^{\circ} \mathrm{C}$ & $0 \cdot 164 \mathrm{gr}$. \\
28 & $11 \cdot 7^{\circ}$ & $0 \cdot 168$ \\
49 & $11 \cdot 75^{\circ}$ & $0 \cdot 172$ \\
54 & $11 \cdot 85^{\circ}$ & $0 \cdot 172$ \\
80 & $11 \cdot 9^{\circ}$ & $0 \cdot 17: 3$
\end{tabular}

0. $.267 \mathrm{gr}$.

0.273

0.272

$0 \cdot 272$

0.274

The cistern was emptied when the experiment had run for $120 \mathrm{~min}$., and B was surrounded with steam for 


\section{TRANSPIRATION AND ASCENT OF SAP сн.}

20 min. When the cistern was refilled and stirred, the measurements were resumed.

'TABLE 7.

Time

from start Temp, of Cistern. in min.
Amount transmitted Amount transmitted per 10 minutes

by A.

$0.203 \mathrm{gr}$

$0 \cdot 185$

$0 \cdot 184$

$0 \cdot 181$

$0 \cdot 184$

$0 \cdot 186$ per 10 minutes by $B$.
$0 \cdot 215 \mathrm{gr}$.

$0 \cdot 2: 30$

0.268

$0 \cdot 240$

(1).244
$0 \cdot 25.3$
$12 \cdot 9^{3}$

$12 \cdot 9^{2}$

Immediately after the experimental branch is surrounded with steam, the water transmitted through it becomes coloured, at first amber, changing to brown. ${ }^{1}$ This change probably indicates the introduction into the transmitted water of some clogging material; for, instead of an increase in the amount transmitted downwards after the removal of the supposed vital lifting forces, we see from the table that the amount is diminished. According as the downward stream washes out this substance, the original rate of transmission is approximated to, but, during the experiment, is not attained. It is evident that if there was any considerable length of branch below the steamed part, this material would accumulate there.

The small rise in the amount transmitted by the control branch, noted immediately after the observations were renewed, is probably to be attributed to a rise in temperature and consequent reduction of viscosity.

The effect of steaming on the experimental branch, and the uniform behaviour of the control, are clearly brought out in Fig. 14, in which the ordinates are grammes of

1 'The production of the brown eolour inay with probability be assigned to the artion of the oxydases of the stem on a colourless ehromogen before the enzymes, were destroyed by heat. 
water transmitted per 10 min., and the abscissa are the times in hours. The full line connects the successive observations on the control branch; the dotted line joins the observations on the experimental branch. The gap indicates the interval during which the cistern was ernptied, and the steam was applied to the experimental branch.

Change taking place in the experimental branch, demonstrated by the exit of coloured liquid below after the application of the high temperature, renders the experiment somewhat unsatisfactory ; for, although the experiment gives no indication that the removal of vital processes from the stem does away with lifting forces opposing the downward motion of water, yet it is just conceivable that, if these forces previously existed and were removed, the clogging of the branch during the steaming might just compensate for their removal. The possibility of such a coincidence, though very improbable, suggested the use of picric acid as a killing agent in place of steam.

The experiment was at first arranged in exactly the same manner: as before; and the initial rates of transmission of the experimental and control branches were determined. Then some dry picric acid was introduced into the water-tube of the experimental branch, and the observations were continued. No change, which could be assigned to the removal of vital actions by the picric acid, could be detected in the rates of transmission, even when the acid appeared at the lower end of the experimental branch.

The gradual killing of the branch and the slow penetration of the picric acid in this method are open to objection, and would tend to render a change due to death less noticeable. To remove this objection, a modification was introduced by means of which the picric acid is quickly forced through the stem under pressure; and, in order to place the control under similar conditions, distilled water is simultaneously forced through it. This is arranged by having the tubes 
containing the water supplies to each branch provided with a side-tubulure connected with a $J$-shaped glass tube containing a mercurial column. The J-tubes and the tops of the water-supply tubes are provided with stop-cocks (e, $f, g$, and $h$ respectively, Fig. 13, p. 70). At first the side-tubulures ( $e$ and $f$ ) are closed; and the rate of transmission of distilled water under a low pressure is measured for each branch; then picric acid is introduced into the supply-tube of the experimental branch, and the stopcocks at the upper ends of the supply-tubes ( $g$ and $h$ ) of both are closed, and the lateral tubulures ( $e$ and $f$ ) opened ; so that the picric acid is forced through one, and distilled water is forced through the other. When the picric acid appears below, by the suitable manipulation of the stopcocks, the pressure in each is again reduced, and observations are recommenced.

Tables 8 and 9 give the figures of such an experiment, and the results are plotted graphically in Fig. 15.

\section{Particulars of Experiment.}

A and B, two similar branches of Syringa vulgaris: A with seven year-rings; length, $80 \mathrm{~cm}$. Upper diam. of wood, $0.85 \mathrm{~cm}$; of pith, $0.14 \mathrm{~cm}$. Lower diam. of wood, $0.92 \mathrm{~cm}$. ; of pith, $0.20 \mathrm{~cm}$. Head, $24 \mathrm{~cm}$. of water. B with four year-rings; length, $80.5 \mathrm{~cm}$. Upper diam. of wood, $0.85 \mathrm{~cm}$; of pith, $0.16 \mathrm{~cm}$. Lower diam. of wood, $0.95 \mathrm{~cm}$. ; of pith, $0.20 \mathrm{~cm}$. Head, $24 \mathrm{~cm}$. of water.

\section{TABLe 8.}

Time

from start 'Temp. of Cistern. in min.
Amount transmitted Amount transmitted per 10 minutes by $A$. per 10 minutes by $\mathrm{B}$.

$\begin{array}{llll}10 & 11.7^{\circ} \mathrm{C} & 0.455 \mathrm{gr} & 0.471 \mathrm{gr} \\ 2.3 & 11.8 & 0.445 & 0.468 \\ 44 & 11.8 & 0.450 & 0.471\end{array}$


About 30 min. after the last observation, picric acid was supplied to B, and forced through under a head of $41.5 \mathrm{~cm}$. of mercury. At the same time, water was forced through A under a head of $44 \mathrm{~cm}$. of mercury. After twentyfive minutes when the picric acid had appeared in quantity at the lower end of $\mathrm{B}$, the head of $24 \mathrm{~cm}$. of water was restored to both.

TABLE 9.

Time

from start Temp. of Cistem. in min.

107

123

136

160

174

189)

204

$22: 3$

244

263
$11 \cdot 8^{\circ} \mathrm{C}$

$11 \cdot 9^{\circ}$

$12 \cdot 0$

$12 \cdot 0^{2}$

$12 \cdot()^{\circ}$

$12 \cdot 1^{\circ}$

$12 \cdot 1^{\circ}$

$12 \cdot 2^{\circ}$

$12 \cdot 3$

$12 \cdot 4^{\circ}$
Amount transmitted Amount transmitted per 10 minutes by $A$. per 10 minutes by $\mathrm{B}$.

$0.500 \mathrm{gr}$.

$0 \cdot 501$

$0 \cdot 503$

$0 \cdot 506$

$0 \cdot 507$

$0 \cdot 520$

$0 \cdot 508$

$0 \cdot 512$

$0 \cdot 515$

$0 \cdot 511$

It will be seen that the mean rate of transmission before the high pressure was applied was $0 \cdot 450^{\circ} \mathrm{g}$. and $0.469 \mathrm{~g}$. per

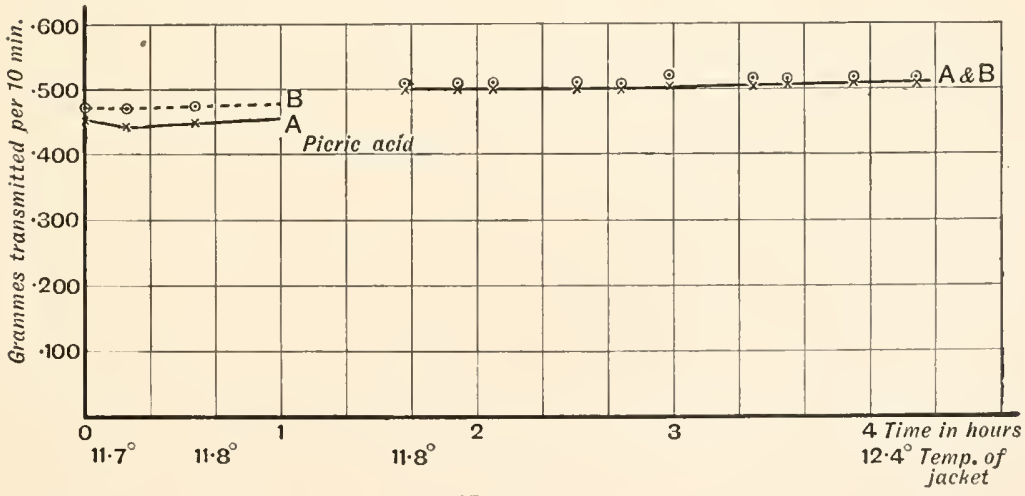

FIG. 15.

$10 \mathrm{~min}$. for the control and experimental branches respectively. During this time the average temperature was $118^{\circ}$. 
After the pressure was applied, forcing distilled water through the control, and picric acid through the experimental branch, the rates rose to $0.502 \mathrm{~g}$. and $0.508 \mathrm{~g}$. respectively for an average temperature of $12 \cdot 0^{\circ}$. That is, the rate of transmission of the killed branch has increased by $8 \cdot 3$ per cent., while that of the living control has increased by 11.5 per cent. Probably the rise in both cases is due chiefly to the flushing-out of the branch and the washing away of mechanical obstructions by the stream under high pressure, and partly to the small rise in temperature form $11 \cdot 8^{\circ}$ to $12 \cdot 0^{\circ}$, which would perceptibly diminish the viscosity of the water. Inasmuch as the observed rise is as great in the case of the living branch as in that which is killed during the observations, it follows that there were no vital actions in either retarding the transmission.

As was pointed out above, Ewart had recourse to the vital theory, believing that the physical forces available are insufficient to overcome the resistance to the transpiration current offered by the conducting tracts. It will be shown later that this view was based on an erroneously high estimate of both the resistance experienced and the velocity attained by upward moving water.

Summary. - The structure of the conducting tissues to which the Vitalists appeal as supporting their views not only does not render this support, but the relation of the living cells to the tubes renders it even impossible for them to exert an elevating force upon the water contained in the tubes.

Experiments which had been quoted in support of the vital hypothesis as demonstrating that when the vital actions of the cells are removed the transpiration stream is so slowed down, that the leaves above fade from lack of water, have been shown rather to indicate that the death of these cells is followed by a stoppage of the trachex and the more or less complete poisoning of the leaves. 
Crucial experiments have failed to show directly the presence of vital sap-lifting forces.

Experiments have abundantly shown that even when the vital activities of the cells of the wood have been eliminated, water under the action of purely physical forces rises in the stems of high trees.

\section{LiteratiRe.}

Biot, J. B., "Remaruques scientifiques à l'occasion de la lettre de M. Boucherie insérée au dernier numéro du Compte rendu," Compt. rend., 1841, 'T. 12, p. 357.

Boucherie, "Rapport sur une mémoire de M. le docteur Boucherie relatif á la conservation des bois," Compt. rend., 1840, 'T. 11, p. 894.

Dixon, H. H., "Physics of the Transpiration Current," Notes from the Botunical School of Trinity College, Dullin, vol. i, p. 57.

Id., "Transpiration and the Ascent of Sap," Progressus Rei Botunicue, 1909 , Bu. iii, s. 1.

Id., "Note on the Supply of Water to Leaves on a Dead Branch," Proc. Ro!y. Dublin Soc., 1905. vol, xi. (N. S.) p. 7.

Id., "Yitality and the Transmission of Witer through the Stems of Plants," Proc. Roy. Dublin Soc., 1909, vol. xii (N. S.), p. 21, and Notes from the Botenical School of Trinity College, Dublin, vol. ii, p. 5.

Id., "Note on the Spread of Morbid Changes through Plants from Branches killed by Heat," Pioc. Roy. Dublin Soc., 1914, vol. xiv (N. S.), p. 205.

Id., "Changes produced in the Sap by the Heating of Branches," Proc. Roy. Dublin Soc., 1914, vol. xir (N. S.) p. 224.

Ewart, A. J., "The Ascent of Water in 'Trees," Phil. Trans. Roy. Soc. London, 1905, vol. $108 \mathrm{~B}$, and 1908, vol. 199 B, p. 362.

Id., "Protoplasmic Streaming." Oxford, 1903.

Godlewski, E., "Zur Theorie der Wasserbewegung in den Pflanzen," Jahrl.f. Wiss. Rot., 1884, Bd. 15, s. 569.

Hartig, R., "Ueber die Vertheilung der organischen Substanz, des Wassers und des Luftraumes in den Bäumen und über die Ursache der Wasserbewegung in transpirirenden Ptlanzen," Untersuchungen aus $d$. Forst. Bot. Inst. an München, ii and iii, 1882-1883.

Janse, J. M., "Die Mitwirkung der Markstrahlen bei Wasserbewegung im Hulz," Juhil. f. Wiss. Bot., 1887, Bd. 18, s. 1.

Id., "Der Aufsteigende Strom in der Ptlanze, I.," Juhrl. f. Wiss. Rot., 1908, Bd. 45, s. 305.

Id., "Der Aufsteigende Strom in der Ptlanze, II.," Juhrb. f. Wiss. But., 1913, Bd. 52, s. 509.

Id., "Die Wirkung des Protoplasten in den Zellen welche bei der Wasserbewegung beteiligt sind," Juhrl. f. Wiss. Bot., 1913, Bd. 52, s. 603. 
Overton, J. P., "Transpiration and Sap-flow," Bot. Ga:ette, 1911, Pl. 28 and 102.

Schultz, J. A., "Neues, wohlfeiles mul bewïhrtes Verfahren, das Holz zu conserviren, dasselbe auch gegen Faulniss, Schwamm und Wurmstich zu schiiltzen, u.s.w. Weimar, $18+4$.

Schwendener, S., "Zur Kritik der neuesten Untersuchungen iiber das Saftsteigen," Sitzunysb. d. Preuss. Alad. d. Wiss., 1892, 44, s. 911.

Strasburger, E., "U'eber den Ban und Verrichtungen der Leitungsbahnen in den PHanzen," Jena, 1891.

Td., "Ueber das Saftsteigen," Jena, 1893.

Ursprung, A., "Untersuchumgen über die Beteiligung lebender Zellen am Saftsteigen," Beihefte \%., Rot. Cen'rulblutt, 1904, Bd. 17, s. 147.

Id., "Die Beteiligung lebender Zellen am Saftsteigen," Jahrl. f. I' iss. Bot., 1906, Bit. 42, s. 50:3.

Id., "Studien Ceber die Wasserversorgen der Pflanzen" Biol. Centrulblutt, 1907 , Bd. 27, s. 33.

Id., "Leber die L'rsache des Welkens," Beilieftes. Bot. Centrululutt, 1907, Bd. 27 , s. 1 .

Id., "Alitötungs- und Ringelungs-Tersuche an einige Holzp,flanzen," Julub. f. Wiss. Bot., 1907, Bd. 44, s. 287.

Id., "'/ur Frage nach der Beteiligung lelender Zellen am Saftsteigen," Beihefte $\approx$ Bot. Centrulb., 1912, Bd. 28, s. 311.

Vesque, J., "Sur le prétendu rôle des tissus vivants du hois dans l'ascension de la sève," Comp'. reml., 1885, 101, 1. 757.

Veber, C. A., "Ueber den Kinfluss höherer Temperaturen auf die Fähigkeit des Holzes den Transpirationsstrom zu leiten," Ber. d. Deutsch. Bot. Gesell., 1885, Bd. 3, s. 345 .

Westermaier, M., "Zur Kenntniss der osmotischen Leistungen des lebenden Parenchyns," Ber. d. Deutsch. Bot. Gessell., 1883, Bd. i., s. 371.

Id., "Die Bederstung todter Röhren und lebender /ellen für Wisserbewegung," Sit:b. d. I'ienss. Alird. d. W'iss., 1884, Bd. 48, s. 1105. 


\section{CIIAP'TER IV}

COHESION THEORY OF THE ASCENT OF SAP IN STEMS

Origin of the theory.-IN 1894 Dr. J. Joly and the author published the first account of their cohesion theory of the ascent of sap. Our attention had been directed to the problem in the year 1892, when the late Professor Strasburger had been good enough to show us some of his experiments on high trees. After more than a year's experimental work and discussion, we were able to give an outline of our theory to the Dublin University Experimental Science Association in March, 1894, and all the essentials were communicated to the Royal Society in October of the same year.

Other hypotheses examined.-In the work leading up to our theory we of course submitted the theories of previous investigators, so far as we were acquainted with them, to full consideration and experimental examination. In addition to these we subjected to investigation various other hypotheses formed by ourselves. As these investigations naturally lead us up to the cohesion theory it may be permissible to outline them here briefly.

Gravitational theory.-In the first place it seemed possible that gravitation itself might furnish the force for lifting the upward moving water. This at first seems paradoxical. Suppose the dilute sap in the leaves to be concentrated by evaporation and 
by the addition of carbo-hydrates. The denser fluid thus produced and passed into the tracheids would settle downwards. As it passed down it would displace upwards the less concentrated solutions entering at the root. An accumulation of the denser material in the lower part of the tree may be supposed to be prevented by the abstraction of materials from the concentrated sap all the way down. In this way it is secured that the ascending " raw" sap is just overbalanced by the denser descending column, and the very dilute solutions brought into the root might in this way be raised to any height. A model illustrating the hypothesis is easily set up. A tube say $1 \mathrm{~mm}$. bore and closed at the lower end is filled with a solution of a dye, e.g., fuchsin, and set upright. A small funnel containing a denser salt-solution is attached to its upper end. The heavy solution immediately begins to gravitate downwards, and in doing so displaces an equal volume of the lighter fluid upwards. The rise may be noted by the passage of the coloured fluid upward into the funnel.

There is no doubt that this mechanism could work in uninjured plants the roots of which continued to pass comparatively pure water into the conducting tracts, provided there were an arrangement to prevent the mixing of the descending and ascending fluids. In the plant, we may suppose, the column is not supported below as in the model, but is held up by the capillary forces of the imbibed cellwalls. This would explain the presence of reduced air pressure in the cavities of some of the wood trachere, which would be impossible if the water surrounding them were in compression. But however promising for a time, the theory had to be given up. The mingling of the dilute ascending solutions with the concentrated descending liquids which inevitably takes place in narrow tubes, would certainly destroy this gravitational action in the trachex of plants, and there is no evidence whatever of isolated upward and downward currents. 
Electrical theory.-An electrical theory also presented itself. It is well known that when a colloid dispersed through water is exposed to an electric field the colloid tends to move to one pole or the other, depending upon its electric sign. If the colloid is held stationary, the water will be translated in the opposite direction. Consequently, if there is a difference of electric potential at the upper and lower extremities of a stem, we would expect a tendency to motion upwards or downwards according to the sign of the colloidal walls of the conducting tracts. It seemed possible that atmospheric electricity, which maintains a potential gradient usually amounting to 50-150 volts per metre elevation from the ground, might produce the necessary field.

It was disappointing to find that no experimental evidence could be obtained in support of this hypothesis. Thus, when leads coming from the terminals of a Wimshurst electrical machine were introduced into small reservoirs fixed to the opposite ends of a piece of stem about $2 \mathrm{~m}$. long, actuation of the machine brought about no observable motion of water from one reservoir to the other, whether the branch and reservoirs were filled with water or with a dilute solution.

Tensile film theory.-Quincke's theory (which suggested itself independently to us), viz., that the water is drawn up in a tensile state over the surfaces of the walls of the conducting trachex in the form of a thin film, had also to be laid aside. Our reason for discarding it was not that which led Sachs to oppose it; for he objected to it on the grounds that there are not continuous tubes in plants. In reality this objection is quite invalid, since the water films may be regarded as continuous through the imbibed material of the transverse and oblique walls. Nevertheless, the theory had to be abandoned, since, as we shall see later, such a film of water unsupported on one side if exposed to tension, infallibly 
draws out thimner and thinner until it leaves no water on the surface.

Theory of a tensile sap imbibed in the cell walls.-A modification of this theory, combining it with the Unger-Sachs imbibition theory, then occurred to us. In order to escape the inevitable thinning out of the unsupported water films, we assumed with Sachs that the moving water is located in the substance of the walls, and that the surface-tension forces developed at the surface of the fine-textured substance of the wall prevent the water column from becoming indefinitely attenuated. Thus the tension generated at the leaves is transmitted downwards through the imbibed water in the walls. This theory has undoubted advantages over the imbibition hypothesis. It replaces the diffusion flow by a movement under great tensions, and so the rate of transmission may be increased proportionately to the increased tension. But it is open to many of the objections which overthrew the imbibition hypothesis, viz., the lumina are known to transmit the major part of the current, and it seems improbable, even where we can invoke forces only limited by the tensile strength of water, that they could suffice to drag an adequate water supply through the fine-grained cell-walls.

When we found ourselves compelled to give up these hypotheses, the one as assuming conditions inimical to the transmission of tension in the water, and the other because it did not agree with the ascertained fact that the water moved in the lumina, it was an easy transition to arrive at the conclusion that the water passed up in the lumina in a state of tension. How, in the lumina of the conducting wood, the necessary conditions for the production of tension are fulfilled, we shall now proceed to inquire.

Cohesion of water.-Perhaps the easiest method of realising the cohesion of water and the conditions 
necessary to bring this property of liquids into play is by performing the following experiment.

The vessel in which the liquid is to be enclosed is a Jshaped glass tube about $1 \mathrm{~cm}$. in diameter (see Fig. 16). The long limb of the $J$ is about $90 \mathrm{~cm}$., while the shorter one is about $20 \mathrm{~cm}$. long. On the shorter limb there is a bulb with a capacity of about 60 c.c. The shorter limb is continued beyond the bulb as a narrow tube drawn out to a point. The whole tube is carefully washed out in the manner to be described in the following chapter, and about 100 c.c. of repeatedly boiled water is introduced into it. In order to be certain that the glass is thoroughly wetted, and also to make sure that the water is in perfect contact with any dust particles contained in it, the liquid is again repeatedly boiled after introduction into the tube. Before sealing off the fine tube the whole of the space unoccupied by the liquid is filled with steam by bringing the water to ebullition, and, when the steam has expelled the air, and is issuing through the narrow tube the latter is sealed off. When the whole has cooled, it will be found that the

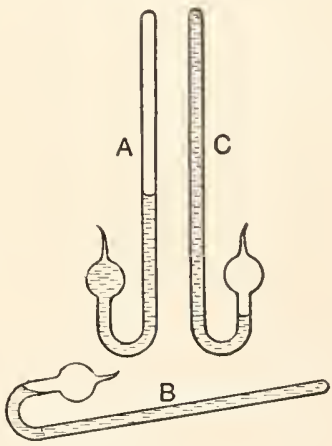

$F_{I t:} 16$. J-tube acts as a water-hammer, i.e., if, by inclining the tube the water is made to travel from end to end, its concussion makes a metallic ring. This is owing to the fact that very little air has been included when the tube was sealed, and water-vapour at normal temperatures is unable to act as an elastic pad in the same way as air at normal atmospheric pressure would. The clicking metallic ring, then, may be taken as an indication that the gaspressure within the tube is very slight. Care, indeed, must be taken not to let the concussion become too violent, as in that way the tube may be easily shattered. 
If now, by gradually inclining the tube, the long limb is completely filled with water (Fig. 16 B) and all the bubbles are chased out of that limb by holding the bent end uppermost, so that no breaks, even the most minute, remain, we shall find, on inverting the tube, that the water remains in the long limb and does not, under the force of gravity, take up the lowest possible level in both limbs (Fig. $16 \mathrm{C}$ ). From the level in the two limbs it is evident that the hydrostatic pressure of the shorter column cannot possibly balance the pressure of the column in the longer limb; the one is about $85 \mathrm{~cm}$. higher than the other. The water in this case hangs in the tube. The liquid in the long limb is in contact with the glass all over, and, since it wets it perfectly, it adheres to it. To the film of water adhering to the glass the rest of the water coheres, and this cohesion is well able to sustain the weight of the column of water which is counterbalanced by no other upholding force. In this way the lower part of the water in the longer limb of the tube transmits a stress through the upper part to the glass equivalent to its gravitational pull.

The reality of this pull becomes all the more evident when, by destroying the cohesion at one spot, a rupture is started. This rupture, which may at first be invisibly small, rapidly spreads across the whole column. The rupture may usually be started by a sharp knock administered to the side of the longer limb; but, when the cohesion is very perfect, to produce a rupture may require a shock so violent as to be liable to shatter the tube. When the rupture is started, the lower part tears suddenly away from the upper part of the column and falls into the bend of the tube. The upper part follows it more slowly, trickling down the inside of the tube, and all the water comes to occupy a position in the lower part of the tube (Fig. $16 \mathrm{~A}$ ).

It is instructive to note how the cohesion of the water 
in these experiments is overcome. The rupture starts as an extremely small discontinuity in the water. Surface tension forces develop immediately at the surface of this bubble. At its inception, being extremely small, these forces are very great, but if the bubble enlarges, the surface tension forces tending to close it rapidly diminish. In our experiments the forces tending to open it are (1) the momentum of the water conferred on it by the shock, and (2) the gravitational pull giving rise to the tension in the liquid. We may neglect the vapour pressure of the bubble, since it is balanced by the vapour in the other limb. If the break opened by the shock is so small that its surface tension can withstand the tension in the liquid, it will close again. But if once the bubble formed is so large that its surface tension is overcome by the inertia and weight of the liquid, an unstable condition is entered on, and the bubble is continually enlarged till the tension in the liquid is nil. It is, however, evident that if at any moment we could confine the bubble and prevent it from enlarging, the liquid would again pass into a state of tension due to the weight of the lower parts.

Cohesion theory.-The theory of the ascent of sap, which Dr. Joly and the author advocate, assumes that the water in the conducting tracts of high trees hangs there by virtue of its cohesion, just in the same way as the water hangs in the experiment with the J-tube described above. 'The adhesion of water to the walls of the trachere we have shown to be very great. For, as will be seen, if a fresh piece of rood from the conducting tracts is enclosed in a vessel filled with water in a state of tension, in every case rupture will tend to occur at the surface of the glass rather than at the walls of the tracher, showing that the adhesion of water to the walls of the conducting tubes is thus always greater than the adhesion of water to glass. This is quite to be expected, when we take into 
account the manner in which water permeates the substance of the walls of the tracher when brought into contact with them.

The teaching of these experiments obviously is that water under suitable conditions can transmit a tension just like a rigid solid. In the liquid, however, the stress is hydrostatic, and, like hydrostatic pressure, is transmitted equally in all directions. It is not sustained consequently by a single point but affects the whole internal wetted surface of the containing vessel. In another particular the stressed liquid differs greatly from the stressed solid; it is much more unstable. A small flaw (i.e., a bubble) in the tensile liquid rapidly spreads and almost instantaneously severs the whole column; it matters not how large the cross section of the unbroken part may be, a comparatively feeble tension will tear it across. In the solid - a metal wire, for example-on the other hand, if the cross section of the unbroken part is sufficient, a small discontinuity in its substance is immaterial, and the stress may be successfully resisted by the intact part. This difference in the behaviour of the two forms of matter: when submitted to a stretching force is to be referred to the fact that the particles of a liquid are perfectly mobile and are free to move round each other without being opposed by any sensible internal forces, whereas in solids there is a great opposition to the relative motion of the parts. 'To this property solids owe their rigidity. In fact, in tension experiments the liquid becomes capable of sustaining and transmitting tensile stresses only when it is adhering completely to a rigid envelope which confers on the liquid a pseudo-rigidity. The state of tension then persists because the stretching forces act solely against the cohesive properties of the liquid (i.e., in an endeavour to separate the water molecules from one another-a separation which a liquid is able to withstand as well as a solid). If, however, the liquid is free to change its 
shape, not adhering to any rigid envelope, the smallest forces, whether of compression or of tension, spend themselves in leading to a readjustment of form, to which the liquid owing to its mobility readily submits, and no stress is produced. On the other hand, if a pull is exerted on a liquid which thoroughly wets and adheres to the internal surface of a rigid vessel, and, if there are no bubbles or discontinuities in the liquid, a state of tension inevitably supervenes.

We have seen that the evaporation taking place from the outer surfaces of the mesophyll cells is continually abstracting water from the tracheæ of the leaf. It is a matter of common observation that these trachere are constantly filled with water, and they enclose no bubbles. Experiments on pieces of the conducting tracts of plants to be described later, show that the adhesion between their walls and water is at least as great as, and probably much greater than, the adhesion between glass and water. Hence, if water is given off from the cells more rapidly than lifting forces raise it in the trachex, the water in the latter must inevitably fall into a state of tension.

Apart from root-pressure, investigation has shown that the only force from below which could be effective in raising water in plants is the pressure exerted by the atmosphere. The amounts of water forced up by root-pressure are insignificant compared with the losses due to transpiration. Atmospheric pressure can supply the evaporating cells at most only up to a level of about 10.3 metres. When allowance is made for the resistance opposed by the conducting tracts to the motion of water in them, wemust conclude, that the supply of water raised by these two forces to a height of 10 metres above the roots, must be exceedingly small. It follows that the water in the trachex above this level is at all times in tension, and, in times of vigorous transpiration, whenever the loss cannot be made good by the lifting pressure of the atmosphere, the water in the tracher 
of leaves, at lower levels also, is in a tensile state. This tensile state is no less inevitable at the top of a column of water unsupported at the base, such as is found in a high tree, than is the state of compression at the bottom of a deep vessel filled with water. The former is caused by the weight acting against the cohesive forces of the water, while the latter is necessitated by the weight acting against the resistance of the water to crushing.

Owing to the permeable nature of the walls, the water in one trachea is continuous with that in its neighbours, and, consequently, the tension in one is transmitted to the water in adjacent tracher. Thus the tension applied at the mesophyll cell-surfaces is transmitted downwards, through the water in the trachex of the leaf and of the petiole, to the water in those of the stem.

Effect of bubbles. - While air bubbles are found extremely rarely in the tracher of the vascular bundles of the leaf, investigators seem agreed that they are of common occurrence in the conducting tissues of the stem. It is evident that in the tensile sap of plants these bubbles will behave in exactly the same way as we have seen bubbles behave in the experiments on tensile liquids. If they are sufficiently minute they will have a very small radius of curvature, and the surface tension forces preventing them from enlarging will be correspondingly great. When these forces balance, or are greater than, the tension in the water, the tension will be transmitted past the bubbles, and, if the bubbles adhere to the walls of the trachea, the tensile stream will be drawn past them. Kammerling has shown that a bubble having a radius of $0.01 \mathrm{~mm}$. is in equilibrium with a pull equal to the hydrostatic head of $1.65 \mathrm{~m}$., while one having a radius of $0.001 \mathrm{~mm} .,=1 \mu$, could resist the tension exerted by a column of $16.5 \mathrm{~m}$. of water. Bubbles having a radius of $1 \mu$ would just be visible with the highest dry objectives commonly in use, their diameter 
being about one-fifth of the diameter of the limen of the finest tracheids of the pine. Bubbles of this minute size are scarcely ever observed in the tracheæ of plants. In fact, the methods of preparation, involving as they do the relief of the existing tension, or even the exposure to atmospheric pressure, would cause bubbles of this magnitude to disappear. A tension anything greater than that exerted by a column of water $1.65 \mathrm{~m}$. will overcome the surface tension of bubbles having a diameter of $0.02 \mathrm{~mm}$. and they will tend to expand indefinitely under its action. Tensions as great as this must frequently occur in plants.

On first thoughts it might appear then, that one bubble having a diameter of $0.02 \mathrm{~mm}$. or more would destroy the possibility of tension in the water of the conducting tracts. A moment's consideration, however, will show that the structure of these tracts sets a limit to the enlargement of the bubble. In the conducting tracts, after the formation of a bubble, the sequence of events will be as follows: The water round the bubble is drawn away by the tension, and the surface of the bubble comes to rest against the wall of the trachea in which it has developed. The retreating surface is held by the wall, and, as more water is drawn away, the bubble can enlarge only longitudinally. At this moment the surface tension of the spherical bubble is replaced by the capillary forces of the tubular trachea, and, the capillary forces developed in these tubes being insufficient to withstand the tension, the bubble gradually pulls out till it completely fills the trachea. When this stage is reached the bubble can enlarge no more; its surface is restrained on all sides by the walls of the trachea which, as is well known, though very permeable to water, are so fine-grained that their capillary or imbibitional forces are enormous and hold the surface of the water, limiting the bubble close to their inner surface. Surrounded thus by the imbibed and rigid wall of the trachea the bubble becomes just like a wetted solid or rigid body 
in the tensile current. No doubt it diminishes the effective cross section of the flow, but, owing to the fact that the conducting tracts are subdivided into such numbers of minute compartments, the development of even a large $n$ minber of bubbles is unable to wreck the stability of the tensile column of water in the wood.

The state of affairs in the conducting tissues is illus-

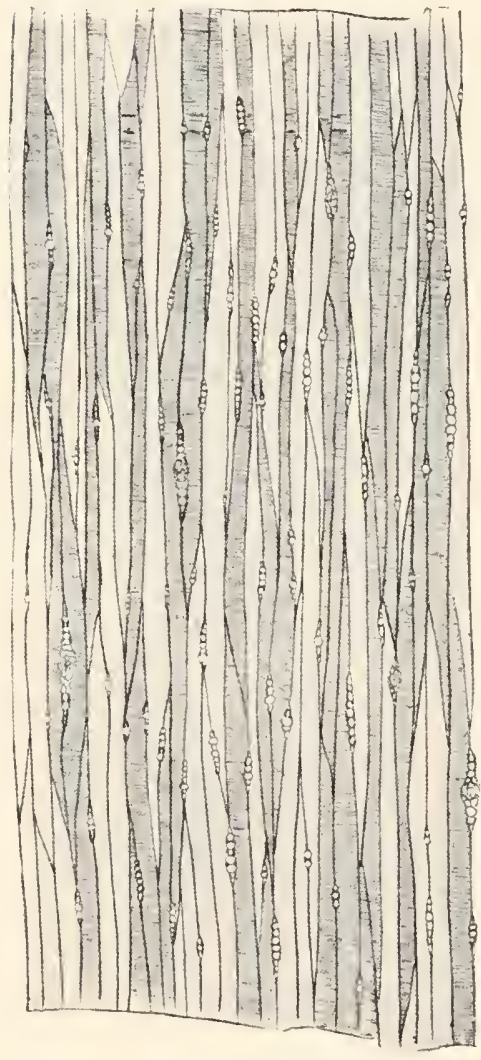

FI: 17. trated in Fig. 17. For the sake of simplicity a longitudinal section of a conifer's wood is represented. The shaded tracheids are supposed to be filled with water, whilst the light spaces indicate those containing airbubbles, which have been expanded by the tension of the transpiration stream till they completely fill the tracheids in which the bubbles occur. It is evident that even when a large number of tracheids are blocked with air, the water column in the wood need not be broken, but may be drawn up round the bubbles enclosed in, and rendered harmless by, the walls of the tracheids. In the figure, for example, 50 per cent. of the tracheids contain bubbles, and yet a considerable volume of water might be drawn up in the remaining tubes. The imbibitional properties of the walls of contiguous water-filled tracheids render the water throughout the stem continuous. Consequently, the 
tension developed above is transmitted round the air bubbles and draws the stream past them, to use Schwendener's figure, like islands in a river. Hence it is evident that it would be impossible to sever the continuity of the water in the conducting tracts, i.e., to prevent evaporation above from transmitting a pull to the water in the roots, unless trachea containing bubbles were to form in some place an unbroken diaphragm across the conducting tissues of the stem.

Number of air-containing tracheæ. - From these considerations it appears that, unless an exceedingly large number of the conducting tubes contain air and are arranged in a special mamner, there is no likelihood of the tensile column being broken. On the other hand, the amount of water transmitted in the stream will be affected by the number of trachere which contain bubbles and are consequently put out of action in the transmission of water drawn upwards under tension. Hence it is of interest to inquire into our state of knowledge as to the air-contents of the conducting tracts.

Results like Hartig's, where the amount of air present is estimated as a percentage of the volume, cannot be utilised here. These results do not tell us how the air is distributed, and it is evident that 10 per cent. of air occurring in each trachea might effectively destroy the cohesion of the transpiration current, while 50 per cent. placed in half the tracheæ would only diminish the maximum transmissibility for a given tension to one half.

Attempts to estimate the number of the vessels and tracheids which contain air have been made on various occasions; but, unfortunately, all the methods hitherto devised are probably open to error. Of these, Strasburger's results seem to be the most reliable.

His general conclusion is that, while a limited amount of air does not make the conducting tracts impassable to water, yet in the peripheral parts, which are principally used in 
the transport of water, the number of air-bubbles is a minimum.

On the whole, Ewart's estimate of the number of tracher completely filled with water is lower than that of Strasburger. On the other hand, Strasburger's results are much more numerous, and possibly Ewart's were made when the water content of the branches was extremely low. The methods employed by both investigators seem open to criticism.

When a branch is cut, even under water, it is possible that bubbles are formed in the trachere by the act of cutting. Bubbles may be formed anywhere close to the knife, but naturally mostly in the tracheæ in contact with the knife on either side, as the knife introduces a discontinuity, and the water adheres feebly to it. Probably some of the bubbles observed were thus formed at the moment of making the preparation for examination, and were non-existent when the plant was transpiring.

In Fwart's experiments the internal and external pressures were not given time to come into equilibrium ; consequently, supposing 20 per cent. or 30 per cent. of the vessels contained continuous water, while the remaining 70-80 per cent. contained gas at reduced pressure, as soon as the branch was cut across, atmospheric pressure would drive the water from the full vessels opening on to the cut surface into those which contained gas at a low pressure, and vessels which had been full and transmitting a tensile stress during transpiration, would appear almost empty after cutting. Ewart himself considers that 10 per cent. of the vessels of last year's wood would transmit enough to cover the losses of the most vigorous transpiration. Even if a much larger percentage than this were completely filled with water at the time of cutting, they would elude observation in this method of investigation.

Both Strasburger and Ewart have shown that coloured 
liquids rise most rapidly in the trachere containing unbroken columms.

It will be seen that although our knowledge as to the actual proportion of trachex containing bubbles during transpiration is very unsatisfactory, yet observation supports the view that always during transpiration there are continuous tracts of trachea free from air of considerable cross section. It is also to be remembered that the periodic flooding of the trachea with water forced upwards by root-pressure will bring the bubbles into solution and will re-establish the conditions for tension throughout the water-tracts.

Evidence from structure.-Here it will be interesting to consider the structure of the conducting tracts, and to see how far their details bear out the theory of the tensile sap.

The salient feature of this structure is the subdivision of the water-ways by an immense number of longitudinal and transverse partitions into minute compartments - the vessels and tracheids. For a system the function of which is to conduct fluids, this is evidently a most unexpected configuration. It is true that the partitions are permeable to water; but when a considerable distance is to be traversed, the sum of the resistances opposed by the walls to the flow becomes important. This becomes clear' from the experiments of Böhm, Elfving, and Strasburger, comparing the conductivity of wood in tangential and longitudinal directions. From their experiments it is seen that the pressure required to force water in a tangential direction is immensely greater than that needed to urge it longitudinally in the wood, although in both cases the water is free to move through the pits. In the tangential direction, however, in the same distance the number of walls traversed may be hundreds of times greater than in the longitudinal path. It is evident that the persistence of the walls in the development of the water-conduits of plants-introducing, 
as they are shown to do, an immense resistance to flowis inexplicable on any view which regards the water as being forced through the stem. Viewed, however, in the light of the tension hypothesis, this structure becomes a most beautiful adaptation to confer stability on the tensilely stressed transpiration stream, and one which transforms the water, despite its mobility, into a substance which is stable while sustaining very great stresses, just as if it were a rigid body. True, the tensile stream experiences the resistance opposed by the numerous walls, but the presence of the partitions, conferring, in the manner just pointed out, a new property on the water, renders available such an enormous source of energy at the evaporating surfaces in the leaves for the lifting of the sap, that the amount of energy which is spent in overcoming the resistance opposed by the walls is relatively insignificant.

The elongated form of the conducting elements secures that the resistance shall be small consistently with the stability of the water; for, of course, if the tension is great, a bubble in a long tube renders a larger portion of the conducting tissues useless than does one confined in a short vessel; but on the other hand, when the long tube is completely filled, it transmits more readily than if it were subdivided into a number of tracheids. Hence we may regard the tissue formed of long vessels as the path of the most rapid part of the transpiration current when the plant has an abundant supply of water, while the tracheids transmit the slowly moving water and continue in function even when supplies are very limited. It is also evident that the small cross section of the tubes, though introducing resistance, is most essential. In this way each bubble which is formed occupies only an infinitesimal part of the cross-section of the whole water current.

The structure of the walls themselves is also in complete harmony with the tension hypothesis, and finds its 
most natural explanation viewed in the light of that hypothesis.

It has long been recognised that the thickenings found on the walls of the trachex, viz., the internal supports in the form of ammuli, spirals, and networks, are of such a nature that they are pre-eminently suited to resist crushing forces. Such strengthenings are quite meaningless from the point of view of the imbibition and the various vital hypotheses; and even according to those views which regarded the sap pressed upwards by gas or atmospheric pressure they are needlessly strong. For it has been shown that it is impossible to crush the tubes of a leaf by an external pressure amounting to 30 atmospheres, when, according to the theories just alluded to, they would be exposed at most to one atmosphere. 'The presence of these thickenings in the tracher of the leaves forbids us accepting Elfving's view that they protect the tubes from the pressure of the growing tissues. If needlessly bulky they are disadvantageous because they produce friction and introduce turbulent motion into the upward stream. Ewart finds that, owing to the presence of these thickenings and to the transverse walls, the flow of water through the capillary tubes of plants (viz., tracheæ) is only about half what we would expect to find, calculating the flow by Poiseuille's formula. Consequently, for ordinary methods of transference assumed in earlier theories, the trachex of the plant cannot be regarded as efficient. For the transmission and stability of a tensile stream, however, these thickenings are essential. And their strength, so far from being superfluous, is probably often tested severely in times when the transpiration removes large quantities of water, and so develops high tensions in the sap. The whole wall is not thickened uniformly, because the permeability of the thinner parts is essential. The thickenings confer on the thin walls the rigidity necessary to support the tensile stresses in the sap. 
It is interesting to find that we often have indications that the unsupported wall would not in itself have sufficient rigidity to bear the crushing forces it is exposed to. These indications are particularly frequent in the protoxylem. Here, commonly, when elongation has widely separated the rings and spirals, the thin part of the walls of the vessels is drawn in as a constriction between the spiral or annular supports, and often the whole vessel is collapsed if the supports have become too oblique. That this is not dne to the pressure exerted by the growth of the surrounding tissues follows from the fact that these instances are most frequently found in leaves.

The most perfect adaptation, to secure the advantages of ease of flow without seriously reducing the rigidity of the tracher, is to be found in the most general of all the wall-structures, viz., the bordered pit. The membrane and torus of each bordered pit in the conducting trachere is able to take up three positions-a median position, symmetrically dividing each domed chamber of the pit from the other, and two aspirated or lateral positions. The median position is naturally assumed by the more or less tightly stretched membrane when it is not acted upon by lateral forces. In the aspirated positions the membrane is deflected against one dome or the other, and the torus lies over and fills the opening into the dome. The membranes of pits in the common wall separating two adjacent trachere filled with water, naturally take up the median position. Pappenheim found that an immense rush of water through the pit was needed to deflect the membrane to one side. A moderate flow does not disturb it from its median position. 'T'he reason for this is to be found in the fact that the membrane round the torus is very permeable to water and, consequently, water moving at a moderate speed passes through it easily without displacing it.

The normal transpiration current never possesses the 
velocities which Pappenheim found were necessary to deflect the membrane, and, of course, hydrostatic tension in the liquid on each side of the membrane will not tend to displace it. Hence it is that the tensile transpiration current, passing from one trachea to another through the bordered pits, experiences only the very small resistance of the porous and thin membrane. But the very delicacy and porosity of the membrane render it unsuitable for sustaining any severe stress. Hence we find, when a bubble develops in a trachea and is gradually distended by the tension in the liquid, or by a difference of gas pressure, till it fills the trachea, the membranes of the pits in the walls of the trachea become aspirated away from the bubble, and the membrane is supported by the dome, while the torus lies over the perforation in the latter like a valve on its seat (see Fig. 18). In this position of the membrane the tension of the water and the gas pressure are withstood, not by the thin and delicate membrane, but by the surface of the water supported by the denser and more rigid material of the wall and of the torus, while the delicate membrane is shielded from all stress.

Thus, from the point of view of the tension hypothesis, we regard the bordered pits as mechanisms to render the walls as permeable as possible to con-

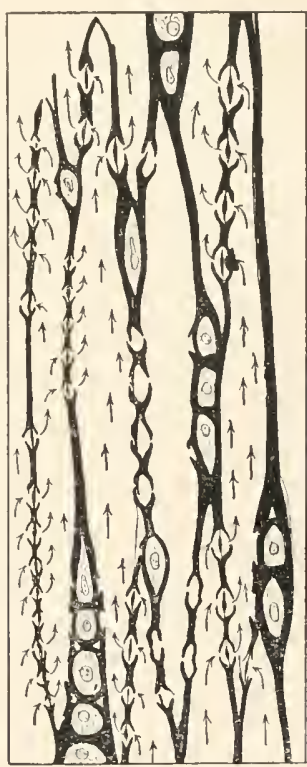

Fit. 18. tinuous water streams, while, when conditions require, they provide, by an automatic change, a rigid support to the tensile sap and oppose an impermeable barrier to undissolved gas. 


\section{LiteratiR.}

Böhm, J., "De la cause du nouvement de l'eau et de la faible pression de l'air diuns les plintes," Amn des Srieners Nul. But., 1881, 12, p. 233.

Id. "Ueber die Ursache der Wasserbewegung und der geringeren Luftension in transpirirenden Pflanzen," Bot. Zt!1., 1881, 49, s. 801 and 817.

Dixon H. H., "(In the Physics of the 'Trunspiration Current," Notes fiom the Bot. School Tirin. Coll., Dullin. vol. i, p. 57.

Dixon H. H., and Joly J., "On the Ascent of Sap" (alstract), Proc. Rion. Soc. London, 1894, vol. 57 B, p. 3.

Id. "On the Ascent of Sap," Phil. Trans. Roy!. Soc. London, 1895. vol. $186 ; \mathrm{B}, \mathrm{p} .56 ; 3$.

Fwart, A. J., "Ascent of Water in Trees," Phil. Trans. Roy. Soc. London, 1905 , vol. 198, p. 41.

Id. "Ascent of Water in Trees," Phil. Truns. Roy. Soc. London, 1908, vol. $19 ! 3 \mathrm{~B}, \mathrm{p} .36 \%$.

Hartig, R., "Ueher die Tertheilung der organischen Substanz, des Wassers und des Luftraumes in den Bäumen, und ïber die Trsache der Wasserbewegung in Transpirirenden Pllanzen," Berlin 1882.

Joly, J., "Report of a Discussion on the Ascent of Water in Trees," Brit. Assoce. Report, 1898.

Kammerling, \%., "()l,erflächenspannung und Cohäsion," Bot. Centralb., 1898,73, s. 369,439 , and 465 .

Pappenheim K., "Zur Frage der V'erschlussfähigkeit der Hoftüpfel in Splintholze der Comiferen," Ber. d. Deutsch. But. Gesell., 1889, T, s. 2.

von Sachs, J., "Lectures on the Physiology of Plants," translated by H. Marshall Ward (Oxford 1887.)

Strashurger, E., " Teher den Bau und Verrichtungen der Leitungsbahnen in den Ptlanzen" (Jena 1891). 


\section{CHAPTER V}

TENSILE STRENGTH OF THE SAl' OF TREES

Even in text-books of Physics the cohesion of liquids is seldom discussed, and the conditions necessary to produce a state in which liquids may transmit a tensile stress are not adequately treated.

Cohesion of liquids.-Donny in 1846 showed that it was possible for a column of sulphuric acid $1.255 \mathrm{~m}$. high to hang in a vertical tube closed at its upper end, when atmospheric pressure was not allowed to press the liquid upwards from below. He coinpares the phenomenon to the well-known experience that the mercury of a barometer may be retained above the actual barometric height, if the tube, filled by inclining it, is raised gradually to a vertical position. He further states that this phenomenon has been explained by Laplace as being due to the cohesion of the mercury and to its adhesion to the glass. Donny also looked for the cohesion or tensile strength of water. He appears, however, to have failed to demonstrate it in the same way in which he had successfully showed it in the case of sulphuric acid. He observed, however, the tensile strength of water in the following less direct manner: If a vertical glass tube one metre long, partially filled with water and sealed at both ends, is struck vigorously on the lower end with the palm of the hand, bubbles open in the liquid and instantly close again with a metallic 
click. A blow on a tube, which has been similarly set up, but from which the air has been removed by careful exhaustion, produces no bubbles; nor is a click heard. Donny explained that in the first case the blow causes minute bubbles to be opened against the forces of surface tension and of atmospheric pressure, therefore, in the second case where bubbles are not formed the cohesion must be greater than these two forces together. Donny believed that even a little air in solution suffices to reduce the cohesion of a liquid to an insensible figure. This error, soon to be corrected, has been frequently copied by writers on this subject. Donny also pointed out that the boiling of liquids is retarded when air is removed, owing to their increased cohesion, and it is the sudden rupture of the liquid which causes explosive boiling.

As will presently be made clear, the absence of dissolved air from the water is a condition by no means necessary for its cohesion, and in these experiments it appeared necessary only because by the removal of the dissolved air perfect contact with the glass and complete wetting of the dust particles suspended in the liquid was secured.

In his memoir Donny ${ }^{1}$ points out that when one withdraws a plane dise from contact with a surface of water the tensile strength of the latter does not come into play. As the disc is raised, water adheres to its lower surface, but the column of water connecting the disc with the liquid below grows gradually thinner, until at a moment when the disc is removed a certain distance above the general level of the lower liquid, the column spontaneously draws in from the edges, and, when its diameter becomes extremely small, breaks in two. He shows also that, in a tensile liquid column, a bubble, sufficiently small to have

1 'The plesence of undissoliven air, or unwetted surfaces, or both, probilly prevented . Janse foom olutaining ennsilerable tensions in the experiment

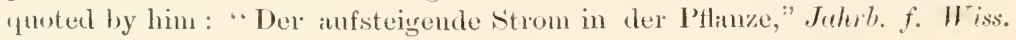
bot., 1908, 45, 3, 1. 314. 
surface-tension forces capable of supporting the hydrostatic head of the liquid below, will not destroy the tensile state.

Berthelot's estimate.-Berthelot a few years afterwards succeeded in showing directly that water has a very considerable cohesive strength and, under proper conditions, can sustain a very great tensile stress. His procedure was as follows: He filled a strong capillary tube, which was sealed at one end and drawn to a fine point at the other, with water at a temperature of $28^{\circ}$ or $30^{\circ}$. He allowed it to cool to $18^{\circ}$, and, as it cooled, to draw in air. Then the fine-drawn end was sealed. The tube was now heated to $28^{\circ}$, or over, and the air forced into solution in the water which now occupied the whole of the internal space of the tube. On cooling to $18^{\circ}$ or lower, it was found that the liquid continued to occupy the entire space enclosed by the tube. From this he argued that the water preserved the same density from $28^{\circ}$ to $18^{\circ}$. The dilatation needed to effect this is very large, viz., 1-420th of its volume at $18^{\circ}$. To produce a similar effect in the opposite sense would require a pressure of about $50 \mathrm{~atm}$. ; and it was concluded that the experiment showed that neither the adhesion to the glass nor the cohesion of the water is less than $50 \mathrm{~atm}$.

Berthelot's experiment has been variously misquoted, (1) with regard to the dilatation observed, and (2) as to the effect of dissolved air on the tensile strength of water. The dilatation has been quoted as amounting to 1-120th of the volume instead of 1-420th. This, of course, gives a much too high result for the tension obtained in the experiment. Hence Ewart's quotation of Berthelot in support of the statement that air-free water can sustain a tension of $200 \mathrm{~atm}$. was illegitimate. The minor limit obtained in Berthelot's experiment was 50 and not $200 \mathrm{~atm}$.

Again, it is quite usual, when treating of the cohesion of liquids, to state that Berthelot's experiments were 
carried out with air-free liquids. As a matter of fact, his method of experiment shows that the water contained air, and he expressly states that the water was, in his first experiments, supersaturated, and that it was only at Regnault's suggestion that he carried out experiments on air-free water. His final conclusion is "Le phénomène [dilatation of water under tension] se produit done dans le vide aussi bien que dans l'air, et est indépendant de la sursaturation."

Cohesion of water containing dissolved air.Misled by the misquotations just alluded to, although a priori there seemed no reason to suspect that the presence of dissolved air would weaken the tensile strength of water, Dr. Joly and the author considered it necessary to investigate the point specially.

We used a cylindrical glass vessel with rounded ends and provided at one end with a narrow tubulure. This vessel was very carefully cleansed by washing it internally successively with caustic potash solution, dilute acid, and distilled water. Half filled with water it was boiled for some time to make sure that the walls were thoroughly wetted; then it was almost completely filled with water which had been previously boiled to get rid of undissolved air and to wet thoroughly all dust particles which might have been contained in the liquid. By subsequent exposure, this water was allowed to become saturated with dissolved air. During this care was taken to shield the water from dust, which might not have been completely wetted, or which might have introduced small bubbles. To fill the vessel a small quantity of water in it was raised to ebullition, and, while steam was issuing from the attenuated tubulure, the latter was submerged in the dust-free water. As the steam within condensed, and the vessel cooled, the latter became completely filled with water. $\Lambda$ small bubble was then introduced, and the vessel was closed by sealing off the tubulure. 
If the vessel was then cautiously heated, the water expanded more than its glass envelope, and the air bubble was compressed. The bubble became smaller and smaller as the temperature rose and the contained gas was forced into solution. When the bubble had reached very small dimensions and was about to disappear, great care had to be exercised in the further application of heat; for, if the water expanded too much and strained the glass beyond its elastic limit, the whole experiment was rendered abortive by the breaking of the glass. But, if the heating process had been carried out successfully, all the air had been dissolved so that the water had been made to fill the vessel completely without breaking it.

At this moment the water in the vessel was either in compression, being constrained by a tension in the glasswalls, or it was quite unconstrained, just exactly filling the envelope, and neither suffering compression nor causing tension in the walls. As soon as cooling began, the water and the glass commenced to contract. The coefficient of thermal expansion of water being greater than that of glass, the water tended to contract more. This contraction, however, was resisted by its adhesion to the glass and its own cohesion, and consequently a tension, which kept it sufficiently dilated to fill the glass, was set up. As cooling proceeded the tension grew greater and greater, till at last either the adhesion or cohesion was overcome and a break appeared between the water and the glass or in the substance of the water itself. This rupture was signalised by a sharp click, and a bubble sprang into existence, which rapidly augmented in size as the water, now relieved from the stretching forces, assumed a volume corresponding to its temperature at the moment. Bubbles appeared round the original bubble and passed into it.

By estimating the amount of deformation of the glass envelope when strained by the contracting water, and by 
determining experimentally the pressure needed to produce the same deformation, the amount of the tensile stress, which was sustained by the water before rupture, was determined. In an experiment, carried out in the manner just described, water was subjected to a tension equivalent to $7 \cdot 5$ atmospheres before its cohesion was overcome.

Cohesion of a soap film.- It may here be pointed out that every stretched water film not only gives us a demonstration of the tensile strength of water, but also enables us to set to it a minor limit, which does not fall far short of that determined by Berthelot.

A film of soapy water stretched upon a rigid frame is stable even when it is only $12 \mu \mu$, or $12 \times 10^{-7} \mathrm{~cm}$. thick. ${ }^{1}$ The thickness of the film is measured by the interference phenomena of light from the opposite surfaces of the film. When thus stretched, the film supports the stress of twice the surface tension ( $\mathrm{T}$ ) of the soap solution. This force has been determined as about 25 dynes per centimetre. Hence it follows that the film which has a cross section of $12 \times 10^{-7} \mathrm{sq}$. cm. supports a tension of 50 dynes or $\frac{50 \times 10}{12}$ dynes per sq. cm. An atmosphere pressure is equivalent to $1.0132 \times 10^{6}$ dynes. So we find, according to this method, that the cohesive strength or tenacity of water must at least be equal to $41 \cdot 3$ atmospheres. ${ }^{2}$

New determinations on water.-Berthelot's experiment with water enclosed in thick capillary tubes, just quoted, is quite easy of repetition. As some of my experiments with this method have given a much higher minor limit for the tensile strength of water than his, I have thought it of interest to record them here.

The lengths of the tubes used in my experiments varied between $14.5 \mathrm{~cm}$. and $22.0 \mathrm{~cm}$.

1 In the second black lihn, Johomot states the thickness maty be anly $6 \mu \mu$.

2 I an indebted to Mr. J. R. Cotter for this ealcukation. 
In each case the tubes were first cleaned with a solution of caustic potash, which was afterwards removed by repeated rinsing with boiled, distilled water. A piece of the wood of the yew (Taxus baccata) was then introduced, and, after being filled with boiling water, the tube was kept submerged in boiling water for an hour or so. Before sealing the drawn-out end, the water was allowed to cool; and a millimetre or more of the bore was cleared of water by warming the point in a flame. When all was cool, the fine end was sealed.

In the table given on p. 108 is a record of my experiments; for each experiment the temperature $t_{2}$ at which the tube is completely filled, and the temperature $t_{1}$ at which rupture took place, are given in the fifth and sixth columns respectively.

From these observations the tension may be roughly determined according to the formula

$$
\beta=\frac{1}{V_{1}} \cdot \frac{V_{1}-V_{2}}{P_{2}-P_{1}},
$$

where $\beta=$ the coefficient of compressibility of water, $V_{1}=$ volume under the lower pressure $P_{1}, V_{2}=$ volume under the increased pressure $P_{2}$. A tension $=P_{2}$ will bring about the same change of volume in the opposite sense. Evidently the apparent change of volume of the water due to this tension must be corrected for the contraction of the glass cooling through the range of the experiment. The correction is allowed for by the formula

where

$$
T=\frac{(a-y)\left(t_{2}-t_{1}\right)}{\beta\left[1-a\left(t_{2}-t_{1}\right)\right]},
$$

\footnotetext{
$T=$ tension

$a=$ coeflicient of expansion of water over the range ;

$y=$ coefticient of cubic expansion of glass $=2.4 \times 10^{-5}$;

$t_{1}=$ temperature of rupture;

$t_{2}=$ temperature when tube is full.
} 
Introducing the correction for the elastic yield of the glass, this becomes

$$
T=\frac{(a-y)\left(t_{2}-t_{1}\right)}{\beta\left[1-a\left(t_{2}-t_{1}\right)\right]+\frac{1}{k^{2}-r^{2}}\left(\frac{r^{2}}{k}+\frac{k^{2}}{n}\right)}, 1
$$

where

$$
\begin{aligned}
& l=\text { external radius of tube, } \\
& r=\text { internal radius of tube, } \\
& k=\text { compression modulus of glass (rolume elasticity) }=4 \times 10^{5} \mathrm{~atm} . \\
& n=\text { torsion modulus of glass (torsional rigidity) }=3 \times 10^{5} \mathrm{~atm} .
\end{aligned}
$$

The value of $a$ was obtained from the table of the volume of water at different temperatures in Landolt-Börnstein, Physikalisch-Chemische Tabellen, by R. Börnstein and

\begin{tabular}{|c|c|c|c|c|c|c|c|c|}
\hline 1 & 2 & 3 & 4 & 5 & 6 & 7 & 8 & 9 \\
\hline $\begin{array}{l}\text { No. of } \\
\text { Experi- } \\
\text { ment. }\end{array}$ & $\begin{array}{l}\text { No. of } \\
\text { Tube. }\end{array}$ & $R$ & $r$ & $t_{2}$ & $t_{1}$ & $\beta \times 10^{2}$ & $a \times 10^{3}$ & $\begin{array}{c}T \\
\text { in atmo- } \\
\text { spheres. }\end{array}$ \\
\hline 1 & I. & 2.5 & 0.5 & $40 \cdot 0$ & $28 \cdot 4$ & $437 \cdot 0$ & 36 & $125 \cdot 8$ \\
\hline 2 & I. & $2 \cdot 5$ & 0.5 & $46 ; 0$ & $27 \cdot 5$ & $438 \cdot 0$ & 36 & $132 \cdot 0$ \\
\hline 3 & I. & $2 \cdot 5$ & $0 \cdot 5$ & $47 \cdot y^{2}$ & $25 \cdot 8$ & $43: 10$ & 36 & 157.5 \\
\hline 4 & II. & $2 \cdot 5$ & 0.5 & $85 \cdot 0$ & $75 \cdot 8$ & $444 \cdot 8$ & 65 & 120.5 \\
\hline 5 & II. & $2 \cdot 5$ & 0.5 & $84.9^{\circ}$ & $72 \cdot 9^{3}$ & 4419 & 65 & 158.4 \\
\hline ij & II. & $2 \cdot 5$ & 0.5 & $84 \cdot 4^{3}$ & $72 \cdot 9$ & 44199 & 65 & $151 \cdot 7$ \\
\hline 7 & II. & $2 \cdot 5$ & 0.5 & $8: 3 \cdot i^{\circ}$ & 745 & 4435 & $6 \overline{5}$ & $119 \cdot 5$ \\
\hline 8 & III. & 35 & $0 \%$ & $46 \cdot 6)$ & $30 \cdot 6$ & $453 \cdot 0$ & $3 !$ & 70.8 \\
\hline 9 & III. & 3 & 0.5 & $45 \cdot 9$ & $36.2^{\circ}$ & 453.0 & 39 & $73 \cdot 1$ \\
\hline 10) & III. & $3 \cdot 5$ & 0. & $41 ; \cdot 0$ & $36 \cdot 6$ & $453 \cdot 0$ & $3 !)$ & $70 \cdot 8$ \\
\hline 11 & IV. & $3 \cdot 5$ & 0.5 & $34 \cdot 5$ & $25 \cdot 6^{3}$ & $46+\cdot 0$ & 30 & $49 \cdot 4$ \\
\hline 12 & IV. & 35 & 0.5 & 34.5 & $27 \cdot 7^{2}$ & $464 \cdot 0$ & 30 & 37.7 \\
\hline 13 & V. & 35 & 0.5 & $50 \cdot 0^{3}$ & $45 \cdot 0$ & $44 !) \cdot 0$ & 44 & $4: 3 \cdot 1$ \\
\hline 14 & VI. & $3 \cdot 5$ & 0.5 & $50 \cdot 0$ & $45 \cdot 0$ & $427 \cdot 0$ & $46 ;$ & $104 \cdot 4$ \\
\hline 15 & VII. & $3 \cdot 5$ & 0.5 & $\left(69 \cdot 3^{3}\right.$ & (ill 8 & $456 \cdot 0$ & 57 & $83 \cdot 8$ \\
\hline $16 i$ & VII. & 35 & $0 . \overline{3}$ & 711.2 & $(i 2) 8$ & $457 \cdot 0$ & 57 & $82 \cdot 5$ \\
\hline 17 & VIII. & $3 \cdot 5$ & 0.5 & $70 \cdot 0$ & (i4.7 & $458 \cdot 0$ & 58 & $(6) \cdot 1)$ \\
\hline 18 & VIII. & $3 \cdot 5$ & $0 . \overline{1}$ & $70 \cdot 2$ & $59 \div 3$ & $4: 7 \cdot 0$ & E) & 127.4 \\
\hline
\end{tabular}
W. Meyerhofer, Berlin, 1905, pp. 38 and 39. The compressibility coefficients $\beta$ for different pressures and temperatures are given on p. 60 of the same tables.

TABLE 10.

1 I an indehted to Mr. J. R. Cotter for athpting these formulie and rendering them suitable for application to these experiments. 
In Table 10 are detailed the experiments on eight different tubes, and in it are recorded the radii $R$ and $r$, the observed temperature when the tubes were full $t_{2}$, and the temperature at which the rupture took place $t_{1}$, together with $a$, the coefficient of expansion for water over the range $\left(t_{2}-t_{1}\right)$, and finally the tension calculated according to the above formula.

In making the observations on the temperatures, the tubes were set in a large beaker of water. The temperature at which the tube became filled was then roughly determined by warming the beaker up very slowly till the bubble in the tube disappeared. The tube was then allowed to cool, and the bubble to reappear. The beaker was again raised to a temperature one degree below that at which it was expected the bubble would disappear. The beaker was kept at this temperature for five or ten minutes, and the water within it was kept in motion to secure a fairly uniform temperature. Fifteen minutes were occupied in raising the water of the beaker through the next degree, so that the water in the capillary tube must have very closely approximated to the temperature indicated by the thermometer in the beaker. By proceeding in this way every effort was made to avoid exaggerating the temperature at which the tube filled. The large amount of water in the beaker secured that the cooling should be extremely slow before the reappearance of the bubble, so that it is improbable that the thermometer gave readings sensibly different from the temperature of the tube.

In spite of these precautions, differences are observed in the successive experiments with the same tube. These can scarcely be due to errors of observation. It generally happened that when a tube was heated on successive days, lower readings were obtained for the "full" temperatures in the later observations. See Experiments 4, 5, and 6 on tube II. Occasionally, however, the "full " tempera- 
ture rises after à time, viz., Fxperiments 1, 2, and 3 on tube $\mathrm{I}$.

As a general rule, the temperature of rupture lowers with time, suggesting that adhesion is improving. It may be noted that some very high values of adhesion of water to copper were accidentally obtained in tube II., in which by chance some minute shavings of copper were included.

These experiments amply confirm Berthelot's observations of the tensile strength of water containing air, and they raise the minor limit obtained by him of its cohesion and its adhesion to glass from 50 atm. to more than 150 atm. They further show that the adhesion to the walls of the conducting tracts is also over this figure.

Tensile strength of sap.-In many instances sap adhering to the vegetable tissues introduced into the tension tubes showed that its cohesion was no less than the rest of the water, and, indeed, there was no reason to suspect that it would have less tensile strength. However, recently the doubt has been raised that sap, especially if containing dissolved air, has not the same cohesive properties as water. Consequently it seemed proper to test the matter by direct experiment.

With this end in view, the sap centrifuged from pieces of branches of Fagus silvatica, cut from about 70 feet above the level of the ground, was enclosed in a tension-tube. This sap, after collection, was boiled on three successive days for about one hour in order to secure the complete vetting of dust-particles fortuitously contained in it. After its last boiling it was exposed for twenty-four hours as a thin layer about $4 \mathrm{~mm}$. deep to the air, but shielded from dust. In this way it must have become practically saturated with dissolved air. The capillary tube, into which it was now drawn by alternate heating and cooling, had been very carefully cleaned by successive washings out with chromic acid, caustic potash, and boiled water. After this cleaning the tube was boiled for about an hour on three successive 
days in water, heating and cooling being effected in the same water. The tube was emptied before each boiling, and allowed to fill with the freshly boiled water. The object of this was to wet the tube thoroughly, and any dust-particles it contained, by bringing all undissolved air on their surfaces into solution. The tube, after filling with the sap to within a few millimetres of its end, was sealed off. The heating of the tube was effected, as in my previous work, in a large volume of water, and was very slow.

In the first tube submitted to experiment the airbubble disappeared at $63.5^{\circ}$, which may be described as the "closing" temperature, and reappeared with the characteristic click at $59 \cdot 1^{\circ}$. Three other observations were made with this tube. All four agree in indicating that the sap withstood a tension of more than 45 atmospheres before rupture (cp. Experiments 1, 2, 3, and 4 in Table 11, p. 113).

A second tube was charged with some of the same sample of sap; it was found to become completely filled at $66.2^{\circ}$, and ruptured at $59 \cdot 5^{\circ}$. Calculating the tension developed in this case the result is more than 70 atmospheres (see Experiment 5 in the Table). In another experiment with this tube a tension of about 50 atmospheres was produced (see No.6).

It was thought that possibly, by keeping one of these tubes after closing at a temperature close to that at which the bubble disappeared, greater tensions might be attained. This surmise was not realised. The tube used in the first experiments described above was kept for two days at a temperature of about $61^{\circ}$. However, when ultimately allowed to cool slowly, the rupture occurred at $59 \cdot 2^{\circ}$, a temperature not quite so low as had sometimes before been successfully passed. This experiment is recorded as No. 3 in Table 11.

It may be noted that there is no reason to believe that the tensions produced in these experiments are indications 
of the maximum cohesion of boiled sap. The results quoted happen to be the first obtained. Other experiments were not made, as these are sufficient to demonstrate that the boiled sap possesses cohesive properties of the same order as those of water.

Having found that sap, free from unwetted nuclei, but saturated with air, is able to sustain considerable tensions, it seemed worth while trying if unboiled sap could be put into the tensile condition. The consideration that heating the enclosed sap in the glass envelope until the last visible bubble disappeared would probably remove completely all invisible bubbles encouraged me in this attempt. Accordingly a quantity of sap was collected from a branch of Ilex aquifolium by means of centrifuging; and this after exposure to air and without any special treatment was introduced into several capillary tubes, which had been prepared in a manner similar to those used in the other experiments.

The first tube closed at a temperature of $78 \cdot 2^{\circ}$, and ruptured on cooling to a temperature of $72 \cdot 0^{\circ}$ (see Experiment No. 7 in Table 11). This rupture occurred simultaneously with a slight shock accidentally dealt it by the stirrer of the vessel of water in which it was immersed. Had it not been for this, probably a lower temperature would have been attained without rupture. Taking these figures and the dimensions of the tube into account, the tension developed must have been about 75 atmospheres.

Another tube containing some of the same sample of sap completely filled at a temperature of $91 \cdot 10^{\circ} \mathrm{C}$. On one occasion rupture took place only when a temperature of $76 \cdot 2^{\circ}$ was reached, on another a rupture developed at some temperature below $81.5^{\circ}$. In the latter case, when the tube had fallen to $81.5^{\circ}$, it was withdrawn from the water for examination, and rupture occurred some seconds after it was lifted from the water. In the first instance the tension must have approxi- 
mated to 207 atmospheres; while in the second a tension of about 132 atmospheres was attained before rupture occurred.

The former of these is, I believe, the highest tension yet experimentally produced in any liquid. Possibly this very good cohesion possessed by unboiled sap is due to the presence of colloids in it. It seems probable that when the tension is just adequate to start a rupture, if the latter remains sufficiently small, its surface tension will be able to withstand the stretching action due to the contraction and cohesion of the liquid. Thus, if the rupture, at its first inception, can be delayed in spreading, it may be obliterated and cohesion re-established. The presence of the colloid may bring about the necessary delay. The appearance

Table 11.

\begin{tabular}{|c|c|c|c|c|c|c|c|c|}
\hline $\begin{array}{l}\text { No. of } \\
\text { Experi- } \\
\text { ment. }\end{array}$ & $\begin{array}{l}\text { No of } \\
\text { Tube. }\end{array}$ & $\begin{array}{c}\text { Extemal } \\
\text { Radiuss } \\
\text { li. }\end{array}$ & $\begin{array}{c}\text { Internal } \\
\text { Radius } \\
\quad r\end{array}$ & $\begin{array}{l}\text { Closing } \\
\text { Tempera- } \\
\text { ture } t_{2} \text {. }\end{array}$ & $\begin{array}{c}\text { Tempera- } \\
\text { ture of } \\
\text { Rupture } \\
t_{1} \text {. }\end{array}$ & $\begin{array}{c}\text { Coefficicut } \\
\text { of Com- } \\
\text { pressibility } \\
\beta \times 10\end{array}$ & $\begin{array}{c}\text { Coefficient } \\
\text { of Expan- } \\
\text { sion } \\
a \times 10^{5} \text {. }\end{array}$ & $\begin{array}{l}\text { Tension } \\
\text { in Atmo } \\
\text { spheres. }\end{array}$ \\
\hline 1 & $S_{1}$ & $3 \cdot 57$ & 0.50 & 63.5 & $59 \cdot 1^{\circ}$ & $455 \cdot 9$ & $54 \cdot 1$ & 47 \\
\hline 2 & $s_{1}$ & $3 \cdot 57$ & 0.50 & $(33) 5$ & $59 \cdot 2$ & $455 \cdot 9$ & $54 \cdot 1$ & 45 \\
\hline$: 3$ & $s_{1}$ & 3.57 & 0.50 & $6.3 \cdot 5$ & $59 \cdot 2$ & $455 \cdot 9$ & $54 \cdot 1$ & $4 \pi$ \\
\hline 4 & $s_{1}$ & $3 \cdot 57$ & $0 \cdot 50$ & $63 \cdot 4$ & $5 !) \cdot 11$ & $455 \cdot 9$ & $54 \cdot 1$ & $46 j$ \\
\hline 5 & $S_{.}^{1}$ & $3 \cdot 57$ & 0.50 & $66 \cdot 2$ & $59 \cdot 5$ & $457 \cdot 0$ & $55 \cdot 1$ & 73 \\
\hline 6 & $\mathrm{~S}_{2}$ & 8.57 & $0 \cdot 50$ & $66 \cdot 2$ & $61)^{\prime}$ & $457 \cdot 6$ & $5.7 \cdot 7$ & 54 \\
\hline 7 & $\mathrm{~S}_{3}^{2}$ & $3 \cdot 50$ & 100 & 78.2 & $72 \cdot 0$ & $464 \cdot 4$ & $63 \cdot 1$ & 75 \\
\hline 8 & $\mathrm{~S}_{t}^{5}$ & $3 \cdot 50$ & $1 \cdot 00$ & $91.1^{\circ}$ & $77 \cdot 2$ & $453 \cdot 0$ & 68.6 & 192 \\
\hline 9 & $\mathrm{~S}_{4}^{+}$ & 350 & $1 \cdot 00$ & $91 \cdot 1^{\circ}$ & 815 & 454.5 & $70 \cdot 11$ & 132 \\
\hline 10 & $S_{4}^{*}$ & $3 \cdot 50$ & $1 \cdot(x)$ & $91.1^{\circ}$ & $76 \cdot 2$ & 440.5 & $68: \because$ & 207 \\
\hline
\end{tabular}

exhibited occasionally in these sap-containing tubes may be interpreted as favouring this view. The click of rupture is not, in these cases, attended by the development of a single bubble becoming surrounded by a group of small visible bubbles, but, at the moment of rupture, a milky, semi-opaque region develops in the tube. This slowly rises, and clears away, as it turns into a mass of excessively minute bubbles. Here, apparently at the de- 


\section{4 TRANSPIRATION AND ASCENT OF SAP ch.}

struction of cohesion, comntless numbers of minute ruptures have been simultaneously produced.

Experiment No. 8 gives the details of a third observation with this tube.

The tubes $\mathrm{S}_{1}$ and $\mathrm{S}_{2}$ were filled with boiled sap of Fagus silvatica, which was, however, subsequent to boiling, exposed in a thin layer to the air ; while the tubes $\mathrm{S}_{3}$ and $\mathrm{S}_{4}$, on which Experiments 7, 8, 9, and 10 were performed, contained unboiled sap of Ilex aquifolium.

In Experiment 3, after the bubble had been "closed" at a temperature of $63^{\circ}$, the tube was maintained at about $61^{\circ}$ for two days. During this time no rupture appeared.

The foregoing shows that the sap of trees has considerable tensile strength, and in this respect does not differ from water. In the few experiments made, the ease with which tension was generated and its magnitude before rupture occurred, possibly indicate that sap is somewhat more stable under tension than pure water.

\section{Literature.}

Berthelot, M., "Śrur quel ques phénomènes de dilatation forcée des liquides," Alun. de Phys. of de Chim. 1850, 31), p. 23:2.

Dixon, H. H., "Note on the Tensile Strength of Water," Proc. Roy. Dublin Sur. 1909, vol. xii (N. S.), p. 60, and Notes from The Potunical Schol, Trinit! College, Mublin, vol. ii, p. 38.

Id. "Vitality and the Transmission of Water through the stems of Plants," Pror. Rouy. Dublin Sor. 190!), vol. xii (N. S.), 1) 21, and Notes from the Potunial school, Trinity College, B)ublim, vol. ii, p. 38.

Id. "On the Tensile Strength of Sap," Proc. Rony. Dublin Soc. 1914, rol. xiv (N. s.), 1. :209.

Dixon, H. H., and Joly, J., "On the Ascent of Sap," Phil. T'rrns. Riny. Sre. Lomlon, 1895, vol. 186; P, p. 568.

Id. "The Path of the Transpiration Current," Ann. of Bot. 1895, 9, 1. 404 .

Donny, J., "Sux la colrésion des liquides et sur leur adhésion aux corjs solides," Anu. de Phys. of Chim. 184ti, 16 Sér. iii, P. 167.

Ewart, A. J., "liesistance to Flow in Wood Vesisels," Ann. of Rotrmy, 1905, vol. 19, 1) 442.

Johommot, E. S., "Thickness of the Black Spot in Liquid Fihns," Phil. M(1). 189!, No. 289!, p. 501. 


\section{v TENSILE STRENGTH OF SAP OF TREES I I 5}

Laplace, "T'raité de Mécanirur. Céleste," Supplément au X libre, p. :.

Poynting, J. H., and Thomson, J. .J., "T'ext liosk of Physies, Properties of Matter," 'nd ed., 1. 123

T'rsprung, A., "Zur Demonstration der Flussiglieits-Kohäsion," Ber. d. Deutsch But. Gesell. 1913, Bd. 31, s. 888.

I. "Ueber die Bedentung der Kohäsion für das Saftsteigen," Bri. d. Dentsh Bot. Gesell. 191:3, 13i. :31, s. 401.

Worthington, A. M., "On the Mechanical Stretching of Lirunids," Phil. Truns. Ron!. Sire. London, 18!2, vol. $183 \mathrm{~A}$, p. 355. 


\section{CHAPTER VI}

ESTIMATE OF THE TENSION REQUIRED TO RAISE THE SAP

In the previous chapter it has been convenient to quote the various estimates hitherto obtained as to the tensile strength of water. We have seen that, contrary to what our everyday experience seems to teach us, water has a very considerable tenacity, amounting at least to $150 \mathrm{atmo-}$ spheres, about 15 kilos. per sq. cm. Sap extracted from the conducting tracts is, in this respect, not inferior to pure water. Moreover, the presence of dissolved air in it does not diminish its cohesion, which, in this condition, has been demonstrated up to 200 atm., or 20 kilos. per sq. cm.

It now remains to determine how far this tenacity will be taxed, and what forces are required for moving the tensile sap through the water tracts of the plant.

Ewart's high estimate of the resistance.In a paper published in 1905, Ewart investigates the question as to what force is required to move water through the waterways of plants at the same velocity as the transpiration current. His general conclusion is that the resistance is so great that neither are sufficient forces generated in the leaves to raise the water at the required velocity, nor is the tensile strength of water adequate to transmit these forces downwards, if such existed. In a subsequent paper he seems to have modified this latter 
view, and misquotes Berthelot as stating that air-free water may support a tension of more than 200 atmospheres.

It is needless to criticise Ewart's calculations of the resistance based on Poiseuille's formula, which he himself admits is quite inapplicable to the case, owing to the presence of transverse partitions and irregularities in the cross-sections of the tracheal tubes. It may be noticed, however, that when care was taken that discontinuities were not present in the water columns of the wood experimented upon, the flow observed was of the same order as that calculated by the formula. In an experiment on a piece of yew wood the approximation was very remarkable. The actual amount transmitted through a length of $15 \mathrm{~cm}$. was $4 \cdot 2$ c.c. per hour, while the calculated amount was 9.8 c.c. The average distance from one another of the cross-partitions in the fine tubes composing the wood is $0.25 \mathrm{~cm}$. Therefore, about 60 partitions must be traversed in passing through a length of $15 \mathrm{~cm}$. This indicates that the resistance offered by the walls, or rather by the pits in the walls, to the passage of water is very slight.

First method. - Ewart also endeavours to find experimentally the resistance offered to the transpiration current. His first method, that of Janse and Strasburger, was as follows: "Leafy branches 4 to 8 feet in length were cut under water and kept in darkness for half an hour. Clean ends were then cut under water, placed in freshly filtered eosin solution, and at once exposed in the open on bright, cloudless, breezy June days between 10 a.m. and 1 p.m., with a shade temperature averaging $18^{\circ}$ to $22^{\circ}$ C. The conditions for transpiration were, therefore, optimal.

"After a timed period the stem was removed, and rapidly sectionised from apex downwards until the eosin solution was visible in the wood, the length of the remaining portion of the stem giving the rate of flow during the 
period of observation. Portions of the same stems, and also similar ones from the same plants were then subjected to varying water pressures until closely corresponding rates of flow were reached."

By this method, and by assuming that the velocities shown in these branches are maintained throughout the stem, Ewart obtains results which indicate that, in order to move water in the stems of plants at the velocity of the transpiration current, pressures equivalent to a head of water from 6 to 33 times the height of the plant are required.

Objections.--There are several reasons why this unexpected result of Ewart's must be regarded as incorrect. (1) The velocity of flow given in Ewart's experiment is probably far in excess of even the maximum velocity of the transpiration current in the intact plant. (2) The velocity cannot be assumed to be uniform throughout high trees; but may fall off from below upwards. (3) Ewart's results for the resistance to flow in stems are not in agreement with a large body of experiment to be quoted presently, but appear to be excessive.

First, with regard to the velocities in Ewart's experiment and in intact trees. In the latter the lifting forces generated in the leaves must do work against the resistance to flow all along the path of the current, and, if the supply is inadequate from the roots, against other opposing forces in addition, and against the whole hydrostatic head. In Ewart's experiment, not only are the resistance of the lower part of the conducting system, the other opposing forces, and the hydrostatic head removed, but they are replaced by the atmospheric pressure acting as a vis a tergo, urging the water upwards. Naturally, then, a much greater velocity is attained in the latter case than when the branch is still attached to the tree. ${ }^{\mathrm{I}}$

1 It maty be mentioned that Janse's method of observing the amomt of transpiration by successive weighings of a severed branch is not falsified by 
The subsequent wilting of the leaves of cut branches shows that clogging afterwards greatly reduces the flow; but, of course, in the experiment quoted it is only the initial stage which is recorded.

The assumption that the velocity in the terminal branches is as great or greater, than in the trunk, is also not justified. The lower leafy branches have to do work against a smaller hydrostatic head, and against a smaller resistance than the outer and upper branches, and consequently the flow will be faster through the lower parts than above. Furthermore, in many cases the effective cross-section supplying unit transpiring area is greater above than below. A good instance of this was brought under my notice by Dr. J. Joly, in a young specimen of Abies excelsa, which had just been felled. The tree was $550 \mathrm{~cm}$. high. The section at its base showed 17 year rings. The lateral branches were almost uniformly clothed with leaves, so that the length of the branches was approximately proportional to the leaf-area they supported. At $52 \mathrm{~cm}$. from the apex the area of the cross-section of the wood was 0.63 sq. cm., and the sum of the lengths of the leafy branches above this was $170 \mathrm{~cm}$. At $134 \mathrm{~cm}$. from the apex the cross-section was $4 \cdot 29 \mathrm{sq}$. cm., and the sum of the lengths of the leaf-bearing branches above was $1500 \mathrm{~cm}$. At the higher level the cross-section of the supply conduits was $0.37 \mathrm{sq}$. cm. per $100 \mathrm{~cm}$. of leafy branch, at the lower point the cross-section of the supply was $0.286 \mathrm{sq}$. cm. per $100 \mathrm{~cm}$. of branch. Therefore, in the case of this tree, if all the leaves were transpiring uniformly, the velocity at the lower level must be greater than above. Hence, in Ewart's experiments it is quite possible that the velocity below was considerably in excess of that in the upper parts of his severed branch, and

this error, but probably gives too small an amount after transpiration has proceeded for some time. Strasburger consider's that this is corrected more or less accurately by his over-estimate of the resistance. 
certainly without special measurements it is not legitimate to assume that the velocity throughout the length of the branch was uniform. This is equally true with regard to intact large trees.

With regard to the resistance, it will be seen later on that Ewart's results are considerably too high.

Second method.-The second method of determining the maximum velocity of the transpiration current employed by Ewart is also open to objection. It is described by him as follows: A small branch bearing a small number of leaves, while still attached to the tree, is led through a split rubber cork into an air-tight glass chamber containing a weighed quantity of calcium chloride. The gain in weight of the latter gives the amount of water transpired by the leaves in a given time. Assuming, then, that all the leaves of the tree may act like those in the closed glass chamber, the number of leaves on the whole tree will give the weight of water transpired by the tree, and consequently the amount of water which passes up the tree in a given time. Then, by measuring the effective cross-section of the trunk, the velocity of the transpiration current may be estimated.

Criticism. - The objections to this method are obvious.

1. When the branch is first introduced into the desiccated chamber it will lose water more rapidly than when it was transpiring into the less dry external air. It will continue this abnormally rapid rate of transpiration until the concentration of the vacuoles of the evaporating cells reaches a steady state, depending on the freedom of supply from the water conduits and the vapour pressure in the chamber, but, until this steady state is attained, the amount of water entering the calcium chloride may be largely in excess of that passing up the stem.

2. But a more serious source of error is the assumption that all the leaves of the tree can transpire at the same 
rate as those on the single desiccated branch, whereas the supply, which, under the conditions of the experiment, is available for the very actively transpiring branch, would be largely encroached upon if all the branches were under equally favourable conditions for transpiration. In fact, the single branch in the desiccater chamber and still attached to the rest of the tree, which is under normal conditions of moisture, is under conditions of supply approximating to those of a cut branch set in water and, for the same reasons, cannot be assumed to give a correct estimate of the velocity of the transpiration current throughout the whole tree.

The validity of this objection may be demonstrated experimentally by weighing the amount of water given off by a given number of leaves in a desiccated chamber, and comparing this amount with the quantity of water transpired by the same number of leaves on the same tree exposed to normal conditions of maximum transpiration.

It will be of interest to quote one of these experiments : A small yew-tree was removed from the flower-pot in which it had been grown, and the roots, and their surrounding soil, enclosed in a rubber bag; to prevent loss of water, except from the leaves, the opening of the bag was tied tightly round the stem. Periodic weighings gave the amount of water transpired. At the same time, a branch still attached to the tree was introduced into a hermetically closed flask containing calcium chloride. The flask could be removed and weighed periodically. A rubber bag, similar to that enclosing the roots, filled with moist earth and closed, was exposed to the same conditions and weighed simultaneously, thus giving a small correction for loss through the bag. In one of these experiments the unenclosed branches supported approximately 9500 leaves, the enclosed branch 520, i.e., the proportion of leaves on the single branch to those on the whole tree was $1: 18$. When the tree was exposed in a hot sun and 
brisk breeze, air temperature being about $24^{\circ}$ in the month of July, the amount transpired was 5.171 grammes per hour, or 0.544 gramme per 1000 leaves. The amount transpired by the desiccated branch, on the other hand, was 0.781 gramme per hour, or 1.502 grammes per 1000 leaves per hour. Hence, the leaves in the desiccated chamber transpired nearly three times as much as the others under normal conditions of maximum transpiration. In this experiment the loss of water from the enclosed branch does not represent any temporary desiccation of the surface tissues, for before the weighings were made the branch had been enclosed in the flask for a day. If this initial desiccation had been included, as it was in Ewart's experiments, the difference between the amounts given off by the enclosed and unenclosed leaves would have appeared greater.

In diffuse light the difference is not so marked. 'The unenclosed leaves of the tree used in the last experiment in diffuse light with a temperature of $21^{\circ}$ transpired 1.250 grammes per hour, or $0 \cdot 130$ gramme per 1000 leaves ; the enclosed leaves simultaneously transpired $0 \cdot 099$ gramme, or $0 \cdot 192$ per 1000 leaves per hour. The desiccated leaves are nearly one and a half times as active in transpiration as those under the normal conditions.

Transpiration controlled by supply.--These experiments show that it is not justifiable to assume that the rate at which water is given off by an isolated branch under conditions of abnormal desiccation is attained by all the branches when all alike are exposed to conditions most favourable to transpiration. The excess evaporation from the desiccated leaves will be greater when the bulk of the isolated branch is but a small fraction of the bulk of the whole tree; for the greater the preponderance of the latter the larger will be the supply available for the brancl, and, consequently, the less the resistance to transpiration. In Ewart's experiment, 
then, where the branch had only 500 leaves, while the whole tree had $9,000,000(1: \mathbf{1 8 , 0 0 0 )}$, it is probable that the effectiveness of the former was much greater than that of the remaining leaves of the tree. Such an overestimate in the amount transpired involves, according to the method, an exaggeration in the velocity of the current in the trunk.

The control of transpiration exercised by the freedom of supply may be easily observed by means of the weighing method. The amount transpired will be found to fall off as the plant exhausts the water in the soil round its roots, and to rise when the soil is again rendered moist. The following numbers (Table 12) illustrate this fact in the case of a small yew-tree which was exposed to conditions favourable to transpiration on seven successive days. The conditions were fairly uniform, as throughout the experiment the sky was lightly overcast and a light east wind blew.

\section{TABLE 12.}

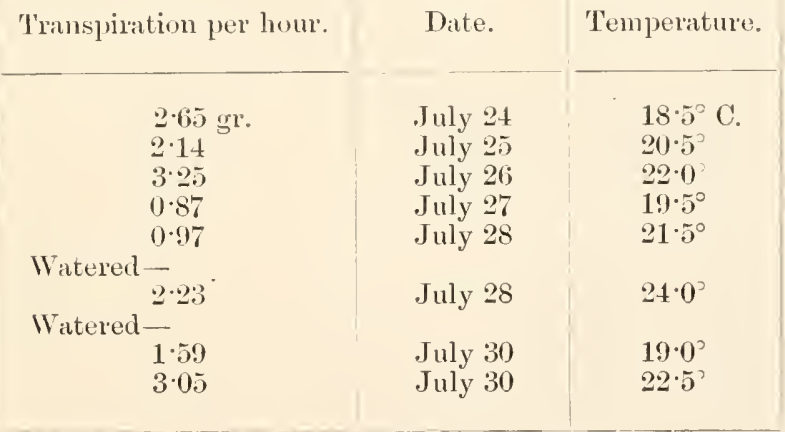

The dependence of transpiration on the supply is prettily illustrated by Darwin's experiment with the horn hygroscope. Darwin records that when the hygroscope is applied to the leaves of a branch severed from a plant, it indicates a gradually diminishing rate of transpiration as the store of water in the branch is gradually exhausted. 
A diminished rate of transpiration is also indicated by the hygroscope when the supply to a branch is reduced by the application of a clamp constricting the water conduits leading to its leaves.

The diminution in the rate of transpiration in these experiments is, no doubt, due to a rise in the tension of the water columns supplying the evaporating cells. The tension rises in the first case as the limited water store is drawn upon, and the water surface is dragged into the cut surface of the branch. The surface-tension forces developed there then oppose the transpiration current. In the second experiment the tension is increased by the rise of the resistance brought about by the reduction of the calibre of the conduits. Further reduction of transpiration is occasioned by the closing of the stomata and by other phenomena, which are themselves direct or indirect consequences of the rise of tension in the water.

According to this view an interesting observation of Darwin's receives a ready explanation. There is a momentary increase of transpiration in these experiments immediately after the separation of the branch, and immediately after the application of the clamp. In the first case, we may assume that the tension in the water supply is reduced by fracture, in the second case, by the compression applied when screwing up the clamp. Transpiration obviously soon re-establishes tension, which becomes greater in both cases than it was originally.

In many ways, then, we see it is established that supply largely controls transpiration, and in neglecting this factor Ewart considerably exaggerated the maximum velocities of the transpiration through the stems of trees.

Determination of the resistance.--We come now to consider the amount of resistance experienced by the transpiration current in its passage through the water conduits. 
Advantage of using small pressures.-To obtain the resistance, Ewart forced water through lengths of branches under various pressures. The pressure which gave the same velocity in the branch as that estimated by his methods for the transpiration current he took to be equivalent to the resistance experienced by the transpiration current. Ewart does not mention how he prepared the pieces, or how he cleansed the water for the experiment. The introduction of air-bubbles or of any clogging substance at the cut surface would materially exaggerate the pressure needed to obtain the observed velocity. Indeed, if the branch were transpiring actively when the experimental pieces were removed, it would not be sufficient to cut it under: water; for the liquid in the branch being in tension, bubbles would be formed at the surface of the cutting knife. These bubbles would require some time to dissolve and disappear. The slimy materials exuding from the injured cells also clog the branch and raise the apparent resistance of its conduits. The comparatively high pressures with which Ewart worked would render the clogging from this source and from any impurity in the water more marked. The curves reproduced in Fig. 19 illustrate this point. The ordinates of the curves there shown indicate weights of filtered tap-ivater transmitted through $3 \mathrm{~cm}$. of wood of Abies pectinata per second. The abscissæ indicate time in minutes. The curves show the diminution in the rate of transmission for each pressure, the fall-off in the amount being much more rapid for the higher pressures. From these it is seen that it is desirable (especially when using colour solutions, which, from the nature of the case, cannot be distilled) to employ low pressures in order to determine the resistance of the conduits apart from the surface resistance. For this reason, then, when the resistance of the tracheidal tubes was being determined it seemed preferable to experiment with very low pressures, 
assuming that the flow for higher pressures would be proportional to the head. This point was examined later.

The wood used in these experiments was that of Taxus baccata. The uniformity and comparative homogeneity of structure (resulting from the fact that it is composed solely of tracheids, and is not penetrated by resin ducts) recommend it as by far the most suitable wood for experiment, when the qualities of the water-conducting tissues

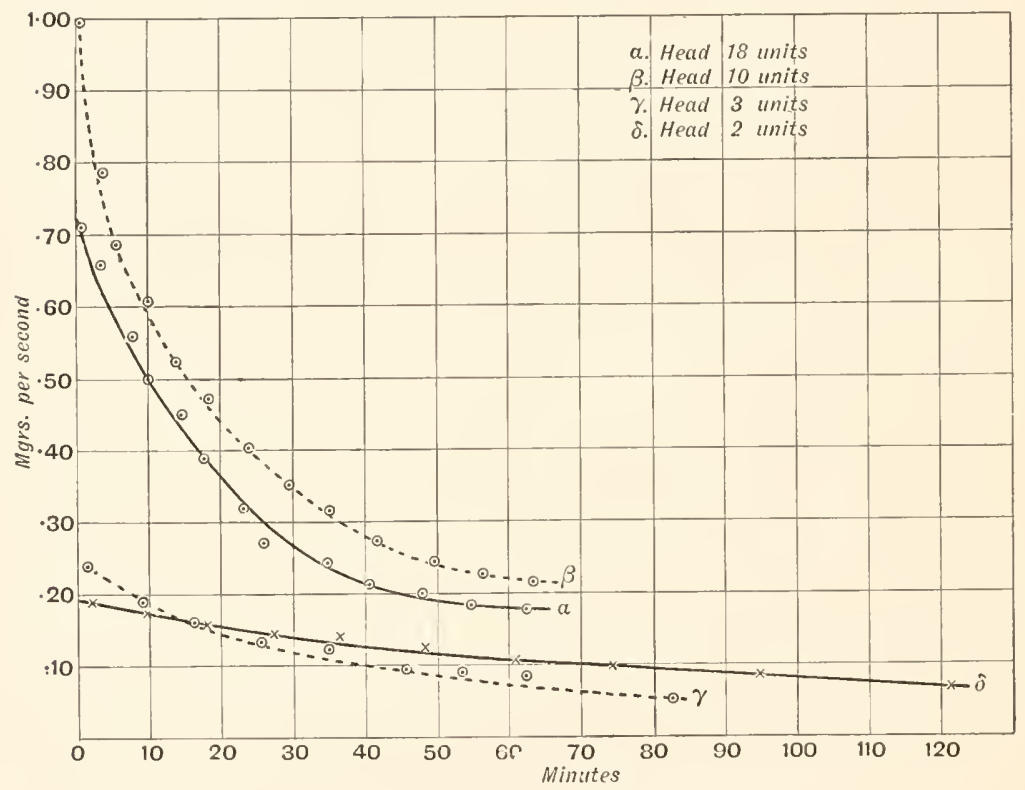

FIf. 19.

are being examined. The tracheids composing the wood of Taxus baccata are elongate spindle-shaped chambers 1 to $5 \mathrm{~mm}$. long, and approximately square in crosssection. The cavity of these chambers is comparatively small. In cross-section the lumen forms about a quarter the entire area of the tracheid. The only other constituents of the wood are the cells of the medullary rays, which are radial tiers of cells 0.4 to $0.02 \mathrm{~mm}$. in height. They do not differ materially in percentage from one level 
in the stem to another, and consequently do not introduce differences of serious mannitude. 'The fact, however, that they exude small amounts of slimy materials sometimes causes difficulties. But inasmuch as there are approximately the same amount of medullary-ray-cells per unit area in every cross-section, the clogging introduced in this manner is uniform and, it is to be noticed, tends to increase the apparent resistance. The presence in other woods of large medullary rays, of wood parenchyma, of vessels of variable size, or even of resin ducts, renders them unsuitable for experiment.

Preparation of material.-Certain precautions are necessary in preparing the wood for these transmission experiments. It is best to cut away the transpiring leaves from the selected branch, and then to cut off a short length of it (say 15 to $25 \mathrm{~cm}$.) under water. Five to ten centimetres are now cut from each end, and the remainder, after lying in water for at least 30 minutes, may be used directly or reduced to smaller lengths for experiments These precautions are necessary, so that bubbles shall not be generated in the conduits. It seems possible that Ewart's high estimate of the resistance was, in part, due to bubbles being generated in the conduits while preparing the wood for his resistance experiments. He certainly does not mention having taken these or similar precautions in this connection, and his results are three to four times as high as those given when these precautions are taken.

Measure of the resistance.-When determining the velocity of flow with colour solutions, I usually worked with a head of water equal to, or less than, the length of the piece of wood experimented with. When using unit head (i.e., the head equal to the length of wood used), a fresh surface was cut with a razor on one end of a piece of a branch prepared as just described. The piece was supported vertically with the 
fresh surface uppermost, and a little vaseline smeared round the bark of that end. A drop of filtered concentrated eosin solution was placed on the upper surface, and as the drops formed at the lower end they were drawn away by lightly touching them with bibulous paper. As the eosin sank through the wood it was kept constantly replenished drop by drop above. After a definite time the experiment was stopped, and longitudinal cleavage of the piece of wood showed the distance travelled by the eosin solution during the duration of the observation at unit head. The following are the results of some of these observations :

TABLE 13.

\begin{tabular}{|c|c|c|c|}
\hline $\begin{array}{l}\text { Length of } \\
\text { Piece. }\end{array}$ & $\begin{array}{l}\text { Duration of } \\
\text { Observation. }\end{array}$ & $\begin{array}{l}\text { Distance } \\
\text { Travelled. }\end{array}$ & $\begin{array}{l}\text { Velocity } \\
\text { per Hour. }\end{array}$ \\
\hline $\begin{array}{c}\text { Centimetres. } \\
\begin{array}{c}7 \cdot 2 \\
6 \cdot 0 \\
4 \cdot 0 \\
3 \cdot 5 \\
10 \cdot 0 \\
3 \cdot 0\end{array}\end{array}$ & $\begin{array}{l}\text { Minutes. } \\
15 \cdot 0 \\
10 \cdot 0 \\
15 \cdot 0 \\
15 \cdot 0 \\
20 \cdot 0 \\
25 \cdot 5\end{array}$ & $\begin{array}{l}\text { Centimetres. } \\
\begin{array}{c}1.7 \\
1.2 \\
1.7 \\
1.8 \\
2 \cdot 2 \\
3 \cdot 0\end{array}\end{array}$ & $\begin{array}{c}\text { Centimetres. } \\
\begin{array}{c}6 \cdot 8 \\
7 \cdot 2 \\
6 \cdot 8 \\
7 \cdot 2 \\
6 \cdot 6 \\
6 \cdot 9\end{array}\end{array}$ \\
\hline
\end{tabular}

In the last experiment the fluid transmitted was a solution of ferrocyanide of potassium. Its presence below was detected by ferric chloride. The mean of these experiments gives a velocity of $6.9 \mathrm{~cm}$. per hour under a pressure equivalent to a head of water equal in length to the experimental piece of wood.

Experiments were also made at lower pressures. For these the water-pressure was applied at the lower end of a vertical piece of wood, through a rubber tube bent into a $U$-shape. This tube was filled with eosin solution, and the surface of the solution was raised to the desired height above the upper surface of the wood.

The mean of these observations is $8.5 \mathrm{~cm}$. per hour, calculated to unit head. If we exclude the two extreme 
observations we get $7 \cdot \mathbf{6} \mathrm{cm}$. per hour as the velocity under a head equal in length to the stem. The last observation of the series was made on a piece of a narrow branch about $0.5 \mathrm{~cm}$. in diameter, the others on pieces about $1 \mathrm{~cm}$. in diameter. The thin distal portions of the wood in almost every case offer a greater resistance to flow than the thicker parts. The high estimates of resistance are

Table 14.

\begin{tabular}{|c|c|c|c|c|}
\hline $\begin{array}{l}\text { Length of } \\
\text { Piece. }\end{array}$ & Head. & $\begin{array}{l}\text { Distance } \\
\text { Traversed. }\end{array}$ & $\begin{array}{l}\text { Duration of } \\
\text { Experiment. }\end{array}$ & $\begin{array}{l}\text { Velocity per Hom } \\
\text { per Init Heal. }\end{array}$ \\
\hline $\begin{array}{c}\text { Centimetres. } \\
8 \\
6 \\
6 \\
6 \\
6\end{array}$ & $\begin{array}{c}\text { Centimetres. } \\
2 \\
2 \\
3 \\
3 \\
3\end{array}$ & $\begin{array}{l}\text { Centimetre. } \\
\begin{array}{c}0.7 \\
0.8 \\
1.8 \\
0.9 \\
0.7\end{array}\end{array}$ & $\begin{array}{c}\text { Minutes. } \\
20 \\
20 \\
15 \\
15 \\
15\end{array}$ & $\begin{array}{c}\text { Centimetres. } \\
8 \cdot 4 \\
7 \cdot 2 \\
14 \cdot 4 \\
7.2 \\
5.6\end{array}$ \\
\hline
\end{tabular}

almost always obtained with the former. This difference appeared almost constantly in my experiments. This fact is probably of importance in determining the total resistance in the intact plant. I have included the third observation in the table, although it diverges so markedly from the mean, because I could see no error in the experiment, and it is quite possible that a maximum result like this is the nearest to the actual velocity in the uninjured tree.

The higher mean in the second series of experiments for the velocity of transmission is probably due to the fact that clogging substances are less likely to accumulate owing to the actually slower flow and to the position of the surface of application.

With care, good results may be obtained with higher pressures, if the supply is from below. In the following experiments (Table 15) the cylinder of wood was fixed in the short arm of a vertical $\mathbf{J}$-tube filled with a repeatedly filtered solution of ferrocyanide of potassium. The moment of penetration through the wood, which was $3 \mathrm{~cm}$. long in 
each case, was determined by its reaction with ferric chloride applied in a piece of bibulous paper to the upper surface of the cylinder.

The mean of the entire series gives $6.9 \mathrm{~cm}$. per hour as the velocity at unit head. As all the known errors, such as the introduction of bubbles, clogging and injury of the tracheidal tubes, tend to reduce the result, it is probable that the velocity in the intact tree would be at least 7 to $8 \mathrm{~cm}$. per hour under the same pressure. The occasional high results obtained indicate a still higher figure as the probable velocity.

Thale 15.

\begin{tabular}{|c|c|c|}
\hline Head. & $\begin{array}{c}\text { Time } \\
\text { Traversing } 3 \mathrm{~cm} .\end{array}$ & $\begin{array}{l}\text { Velocity per Hour } \\
\text { at Cnit Head. }\end{array}$ \\
\hline $\begin{array}{c}\text { Centimetres. } \\
30 \\
30 \\
27 \\
27 \\
24 \\
24 \\
24 \\
21 \\
18 \\
18 \\
18 \\
15 \\
15 \\
12 \\
12 \\
12 \\
\vdots \\
\vdots \\
0 \\
10 \\
0 \\
: 3\end{array}$ & $\begin{array}{c}\text { Minutes. } \\
2 \cdot 0 \\
3 \cdot 0 \\
2 \cdot 0 \\
2 \cdot 5 \\
3 \cdot 75 \\
3 \cdot 5 \\
3 \cdot 5 \\
4 \cdot 5 \\
5 \cdot 25 \\
4 \cdot 5 \\
4 \cdot 75 \\
4 \cdot 5 \\
4 \cdot 5 \\
5 \cdot 5 \\
7 \cdot 0 \\
5 \cdot 5 \\
10 \cdot 25 \\
7 \cdot 75 \\
9 \cdot 5 \\
12 \cdot 75 \\
13 \cdot 0 \\
25 \cdot 5\end{array}$ & $\begin{array}{c}\text { Centimetres. } \\
9 \cdot 0 \\
(i \cdot 0 \\
10 \cdot 0 \\
8 \cdot 0 \\
6 \cdot 0 \\
6 \cdot 4 \\
6 \cdot 4 \\
5 \cdot 7 \\
5 \cdot 7 \\
6 \cdot 6 \\
6 \cdot 3 \\
8 \cdot 0 \\
8 \cdot 0 \\
8 \cdot 2 \\
6 \cdot 3 \\
8 \cdot 2 \\
5 \cdot 8 \\
7 \cdot 7 \\
6 \cdot 3 \\
7 \cdot 0 \\
6 \cdot 9 \\
7 \cdot 0\end{array}$ \\
\hline
\end{tabular}

In Fig. 20 I have plotted these results. The ordinates represent the lengths traversed in one hour, while the abscisse indicate the pressures, considering a head equal to the length of the branch as unity. 
vI TENSION REQUIRED TO RAISE THE SAP I3I

It may be noticed that the most divergent observations are those made at the higher pressures.

Comparison of results. - When we compare these results with Ewart's, a very wide discrepancy is apparent. The results of three of his experiments allow themselves readily to be compared with my figures.

(1) He found that water travelled in a piece of yew stem, $35 \mathrm{~cm}$. long, at the rate of $11.7 \mathrm{~cm}$. per hour under a head of 3 metres. The head here is nearly $8 \cdot 6$ times the length of the transmitting wood. Assmming the velocity

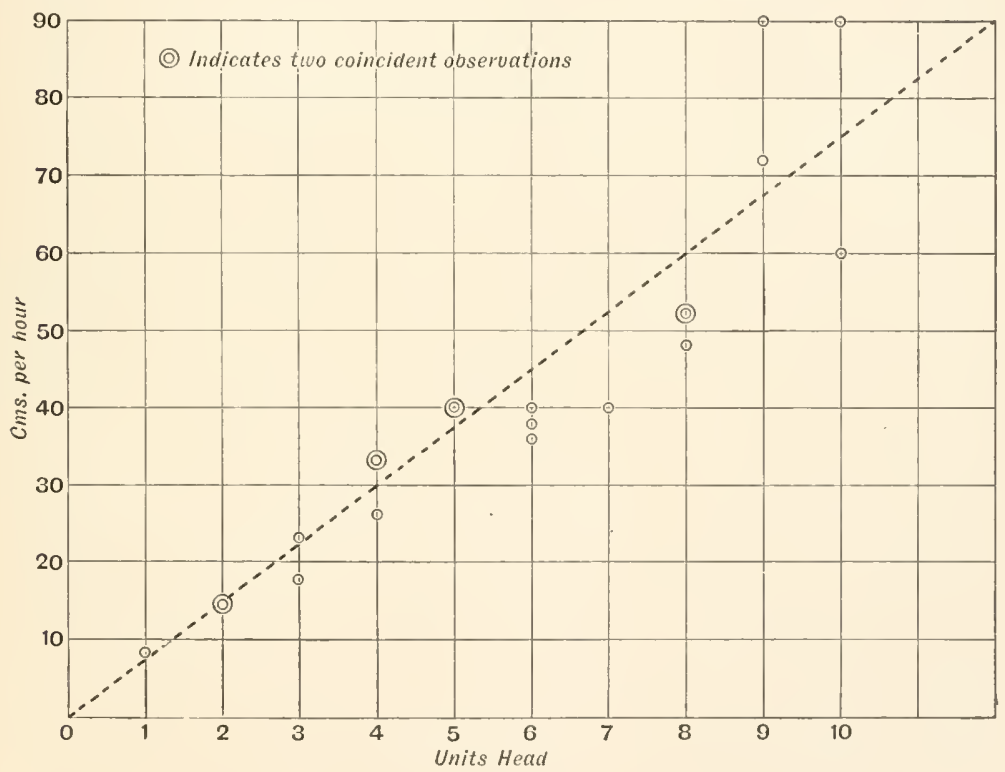

Fir: 20.

proportional to the pressure, at unit head the water would travel at $1.36 \mathrm{~cm}$. per hour. This rate is stated to be above the average.

(2) On pp. 51 and 52 of Ewart's paper iu is stated that the rate of flow in a piece of yew wood, $25 \mathrm{~cm}$. long, under a head of 3 metres is $26 \mathrm{~cm}$. per hour. In this experiment the head is equal to a column 12 times the length of the 
transmitting branch; when reduced to velocity under unit head the result is $2 \cdot 17 \mathrm{~cm}$. per hour.

(3) Again, on p. 55 an experiment is recorded which is suitable for comparison. A velocity of $19 \mathrm{~cm}$. per hour was observed in a branch $25 \mathrm{~cm}$. long under a head of 4 metres. This becomes $1 \cdot 19 \mathrm{~cm}$. per hour under unit head.

The mean of these three observations gives $1.57 \mathrm{~cm}$. per hour as the maximum velocity of flow in the yew wood under unit head.

The results of my own numerous observations, on the other hand, made under very various conditions of pressure and by different methods, point to a velocity exceeding $7 \mathrm{~cm}$. per hour with the same head.

The only explanation of this discrepancy which appears possible is that in Ewart's experiments sufficient care was not taken to prevent bubbles forming in the opened conduits, and to obviate clogging at the surface. This last effect would be exaggerated in his experiments, as he worked apparently in every case at such high pressures. Reference to Fig. 20 illustrates this point. 'There it appears that the erratic observations are those made at high pressures, although at both high and low pressures similar precautions were taken. It is in only the first of Ewart's experiments quoted above that it is mentioned that the expermental branch was cut under water. Other precautions are not mentioned.

Whatever is the cause of the discrepancy, it is certain that if Ewart had obtained my results, the difficulty of resistance, which he finds to be fatal to the cohesiontheory of the ascent of sap, would not have presented itself to him, for the velocity of $7 \mathrm{~cm}$. per hour, which he demands in the stem of the yew, would not require a pressure equivalent to a head of 65 metres of water, as he supposes, but only to 11 metres. The recognition of the fact that unit head produces a velocity of about $7 \mathrm{~cm}$. per hour invalidates his whole calculation, intended to 
show that to raise the sap in trees 150 metres high would require a pressure approaching 100 atmospheres. The facts of the case would be more correctly stated by saying that if the amounts transpired by isolated branches, under exceptionally favourable conditions for transpiration, were transpired by the remaining branches of the yew, and if we further assume that the velocity in the trunk is maintained out into the finest branches of high trees, then the resistance to flow in the conducting tracts would be about equal to a head of water the same height as the tree.

My results for the resistance, which were obtained as described already by directly measuring the velocity of flow under a given head, were fully confirmed by other experiments in which the amount transmitted under a given head was observed. An estimate of the crosssection effective in transmitting the current then gives the velocity.

A piece of a branch of Taxus baccata, $4 \mathrm{~cm}$. long and having a woody cylinder $1.35 \mathrm{~cm}$. in diameter, was placed with its long axis vertical. Water was supplied at its upper surface just as quickly as it percolated through the wood, so that the upper surface of the wood was continually wet, but the water was never appreciably piled upon it. The amount of water transmitted in this manner under unit head was 1.356 grammes per hour. In order to find the effective cross-section, after this observation was made, a solution of eosin was supplied under similar conditions. By this means the transmitting portions were coloured, and the area of their cross-section easily estimated. A mean of three such estimations gave the effective crosssection as $0.7 \mathrm{sq} . \mathrm{cm}$. From this it appears that under unit head 1.93 grammes is transmitted per square centimetre per hour. Assuming with Ewart that the lumina occupy about 0.25 of the cross-section, the velocity to secure this rate must have been $7.5 \mathrm{~cm}$. per hour. This 


\section{I34 TRANSPIRATION AND ASCENT OF SAP ch.}

agrees well with the results obtained with the other method.

Method of eliminating surface clogging.-In order to determine the amount of flow without danger from the error of clogging at the surface of supply, it was measured in a lateral branch springing from a stont stem. Water under pressure was supplied at the two cut ends of the stem. With this arrangement, owing to the relatively large surfaces of supply, the clogging taking place at these does not encroach upon the amount necessary for the supply of the small lateral branch for several hours, and consequently the rate of transmission in the lateral branch remains constant for this period. To quote one of these experiments: A piece of yew stem $7 \cdot 3 \mathrm{~cm}$. long, having a straight lateral branch about its middle, was selected. The diameter of the stem was $0.85 \mathrm{~cm}$. and $1.05 \mathrm{~cm}$. at each end respectively. Its wood was also laid bare by an oval scar where another lateral branch was removed. This scar was $1 \cdot 3 \mathrm{~cm}$. by $1 \cdot 1 \mathrm{~cm}$. The small lateral branch was cut to a length of $10.5 \mathrm{~cm}$., and its wood had a diameter of $0.47 \mathrm{~cm}$. Not more than a quarter of its cross-section was in a state suitable for transmitting water-the greater part being occupied by blackened duramen. This lateral branch was fixed watertight in a rubber bung in an orifice in the bottom of a tank in such a manner that the cut end of the lateral branch projected from the tank, while the supporting stem was immersed in the water in the tank. With the head of $30 \mathrm{~cm} .0 \cdot 300$ gramme was transmitted per hour. The transmitting cross-section was about $0.043 \mathrm{sq} . \mathrm{cm}$. One-quarter of this area would be lumen: therefore the velocity of flow must have been $27 \cdot 2 \mathrm{~cm}$. per hour. If we reduce this to unit head the velocity becomes about equal to $9.4 \mathrm{~cm}$. per hour, which again falls within the limits of the results obtained by the previous method. 
Velocity proportional to the pressure.--Throughout this discussion it has been assumed that the velocity is proportional to the pressure. This is usually done. Fig. 21 shows that this is certainly approximately true for pressures up to 16 units head. In this diagram are plotted the results of many experiments, the object of which was to determine if the amount transmitted in a given time is proportional to the pressure, as the former assumption would involve. The utmost care was taken to obtain clean water to supply to the wood and to free the latter from clogging material as much as possible. The water used was distilled, the vessels and tubes of supply were repeatedly washed with distilled water before using, and the surface of the wood freshly cut and rinsed with distilled water im-

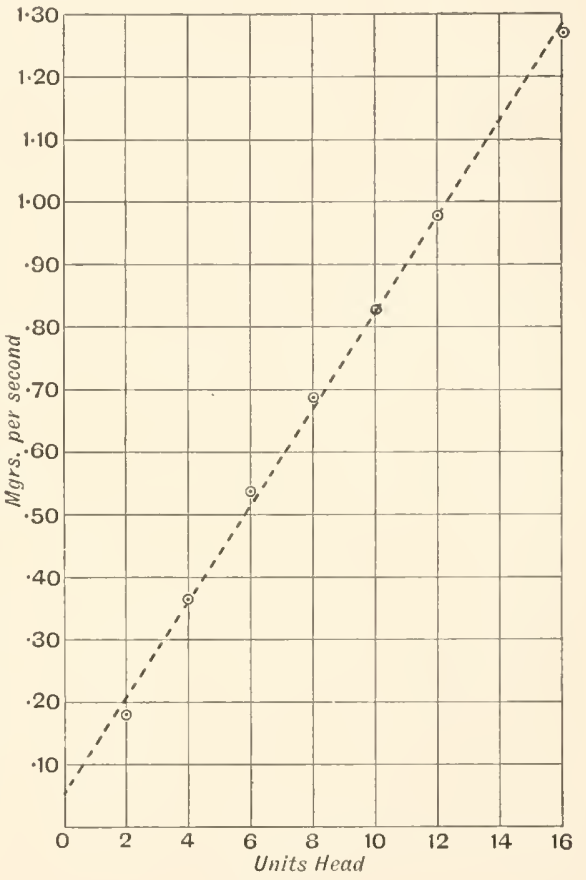

FIt: 21. mediately before the experiment began. The woody cylinder was $3 \mathrm{~cm}$. long. It was supported horizontally, and a tongue of bibulous paper was applied to the outer surface of the wood and hung down vertically into a little phial which received the drops of transmitted water. The time required for five drops to fall from the tongue was noted by means of a stopwatch, and the weight of these five drops determined by weighing the phial. The mean of three such observations is given in Table 16 for each pressure. 


\section{36 TRANSPIRATION AND ASCENT OF SAP ch.}

These results confirm the received view that the amount transmitted varies directly with the pressure. The slight bending over of the line joining the observations at the high pressures is amply explained by the gradual clogging which takes place despite all precautions; for the experiments giving these results were made with the same piece of wood after those at lower pressures had been carried out.

\section{Table 16.}

\begin{tabular}{|c|c|c|c|}
\hline Нені. & $\begin{array}{l}\text { Milligrammes } \\
\text { T'ransmitterl. }\end{array}$ & $\begin{array}{l}\text { Duration of Ex- } \\
\text { periment. }\end{array}$ & $\begin{array}{l}\text { Milligrammes per } \\
\text { Second. }\end{array}$ \\
\hline $\begin{array}{c}\text { Centimetres. } \\
6 \\
12 \\
18 \\
24 \\
30 \\
36 \\
48\end{array}$ & $\begin{array}{l}44 \cdot 0 \\
50 \cdot 0 \\
53 \cdot 0 \\
50 \cdot 0 \\
52 \cdot 0 \\
58 \cdot 0 \\
59 \cdot 5\end{array}$ & $\begin{array}{l}\text { Seconts. } \\
246 \\
1: 7 \\
9 ! \\
7: 3 \\
6 ; 3 \\
60 \\
47\end{array}$ & $\begin{array}{l}0 \cdot 182 \\
0 \cdot 365 \\
0 \cdot 585 \\
0 \cdot 685 \\
0 \cdot 825 \\
0 \cdot 6465 \\
1 \cdot 266\end{array}$ \\
\hline
\end{tabular}

The proportionality of head to flow may be indirectly investigated in another manner. A straight branch fixed in a horizontal position is connected to a large vessel of distilled water. Precautions are taken to clean the connections and the freshly cut inner end of the branch. A tongue of bibulous paper is applied to the outer end to draw off the transmitted water. The head once adjusted is kept constant; but after each determination the branch is shortened. Fig. 22 records such a series of experiments. The head throughout these was $100 \mathrm{~cm}$. The initial length was $25 \mathrm{~cm}$. At that length the flow was $1.18 \mathrm{mg}$. per second. Five centimetres were then cut off the outer end and the flow rose to $1.66 \mathrm{mg}$. per second. A shortening to $15 \mathrm{~cm}$. increased the flow to $2.33 \mathrm{mg}$. When the branch was $10 \mathrm{~cm}$. and $5 \mathrm{~cm}$. long, the flow was $3.79 \mathrm{mg}$. and $6.70 \mathrm{mg}$. respectively. The curve plotted in Fig. 22 is a rectangular hyperbola in which $\mathrm{II}=\mathrm{K} / l$; M being the number of milli- 
grammes transmitted per second, $l=$ length of wood, and $\mathrm{K}=$ average value of the product $\mathrm{M} l$ observed. The observations, it may be seen, approximate fairly closely to

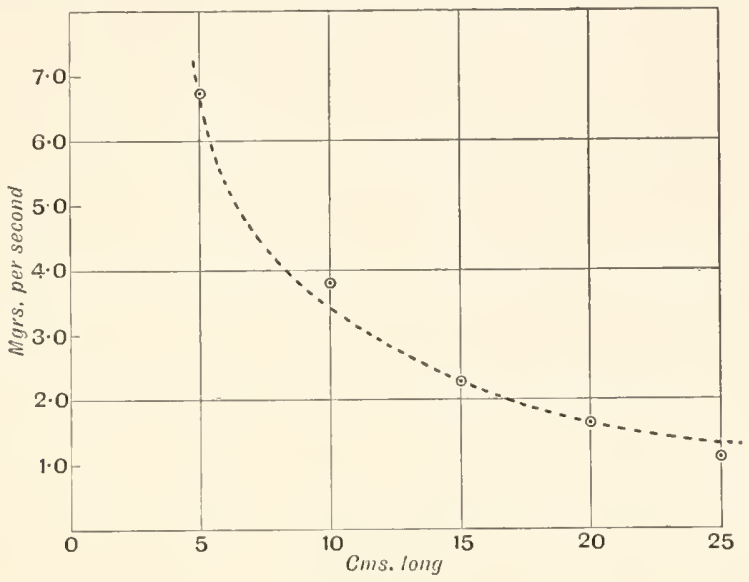

FIt: 22.

this curve. When the weights of transmitted water are plotted against units head the curve shown in Fig. 23 is obtained. Here the proportionality of flow to head, or,

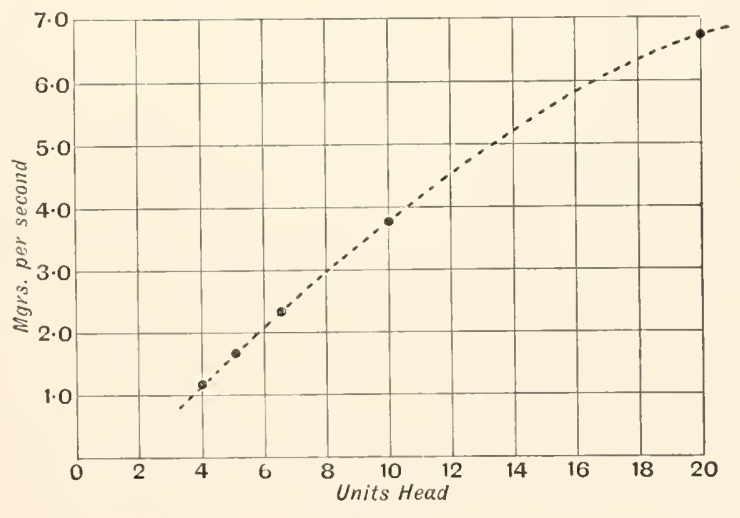

F'Iti. 2:3.

rather, the inverse proportionality of flow to length, is immediately apparent. Up to 10 units the curve is almost a straight line. 'The bending over which occurs 
after that point is to be attributed to the clogging, which is practically unavoidable when the flow is rapid.

Summary.-It appears that water may be moved through a stem in a horizontal position with the velocity of the transpiration current if urged by a head equal to the length of the stem. To raise water in a vertical stem at the same velocity, evidently twice the head will be required. Consequently when the force is applied as tension at the upper end, the greatest stress the water need be subjected to is double the weight of the moving column. Even in the highest trees this is vanishingly small compared to the tensile strength of water.

\section{Literateie.}

Darwin, F., "Olsservations on Stomata," Phil. Thans. Romy. Śm. Lomlon, 1898, vol. $190 \mathrm{li}, \mathrm{p}$. 5899.

Dixon, H. H., "On the Transpiration Current in Plants," Pore. Rony. Sere. Lon.lom, 1907, vol. 79) B, 1) 41.

Ewart, A. J., "Ascent of Water in Trees," Phil. Truns. Rom. S'se. London, 1905, vol. $198 \mathrm{~B}, \mathrm{l}$. 41.

Id. "Resistance to Flow in Wood Vessels," Ann. of Botany, 1905, vol. 19, p. 442.

Strasburger, E., "Ueber den Ban und Verrichtumgen der Leitungsbahmen in den Pflanzen" (Jena, 1891.) 


\section{CHAPTER VII}

OSMOTIC PRESSURES OF LEAF-CELLS

We have seen that the force required to move the sap at the rate of the transpiration current must at least be equal to the pressure produced at the base of a column of water which is twice the height of the transpiring tree. Is it possible to obtain any measure of the force actually available to produce such a stress? It will be of interest, if this measurement can be made, to know whether the force is taxed to its limits to produce the upward motion of the sap or whether there is plenty of reserve.

A gauge for measuring this available force is provided in the leaf cells of the transpiring tree.

Forces available for raising the sap.-During transpiration the cells of the leaves are normally in a turgid condition. This distension is caused by the osmotic pressure of the dissolved substances acting upon the protoplasmic membranes of the cells and pressing them against the cell walls. We have seen that secretion or evaporation abstracts water from these cells, and so tends to concentrate the solutions within them. This loss of water can only be made good by drawing in water from the adjacent trachex, and this pull acting on the upper ends of the cohering columns of sap is propagated downwards through the tree. We may then regard secretion or evaporation as the force which actually exerts the 
tension on the sap, and this tension is transmitted through the leaf cells to the sap in the conducting tracts.

Pressure and tension in leaf-cells.-The simultaneous presence of pressure and tension within these cells, at first sight, appears paradoxical; but a moment's consideration will show that it is quite possible for the solvent, water, to be in a state of tension, i.e., at a negative pressure, while the dissolved substances may be at a positive pressure and be active as a distending force in the cell.

Although, by thus distinguishing the pressure conditions of the solvent and of the dissolved substances, it is easy to conceive how the water in a turgid cell may be in a state of tension, it appeared of interest to show experimentally in the following way that this peculiar state of affairs is possible.

It is well known that when a small piece is cut from the young stem of an herbaceous plant, and immersed in water, its curvature will show if its cells are distended by osinotic pressure or not; for the outer surface, being less extensible, will become concave, if the cells of its tissues are distended by osmotic pressure, and it will remain straight, or become convex, in the absence of these pressures. If, then, such a piece of tissue assumes and retains this concavity when immersed in a tensile water column, we may be assured that an osmotic pressure is exercised by the solute, while at the same time the solvent is in a state of tension.

The experiment may be carried out as follows: A long piece of glass-tubing bent into a $\mathbf{J}$-form is carefully cleaned by washing with caustic potash solution, followed by methylated spirit. Its upper end is then sealed, and it is nearly filled with water which has been boiled for some time. A piece of tissue cut from the stem of some suitable plant (I used the peduncle of Doronicum austriacum), after soaking for several hours in wellboiled water, is introduced into the J-tube, and passed 
up to the upper end, where there is a small bend made to receive it. The $J$-tube is now set in a vertical position, and its short limb is connected with an air-pump. By the action of the pump the atmospheric pressure is removed from the lower end of the column of water in the tube, and the weight of the lower parts of this column, hanging from the upper parts, puts them in tension. As the piece of tissue occupies the top of the tube, the water in it and around it is in a tensile state. It will be noticed that, although exposed to this tension for a considerable time, the tissue will retain its curvature, indicating, as we have seen, an osmotic pressure in its cells. I have exposed a piece of the peduncle of Doronicum austriacum to a tension of $50 \mathrm{~cm}$. of water for two hours, withont being able to detect any diminution of curvature.

In order to expose the water surrounding the piece of tissue to a greater tension, the lower part of the water columm may be replaced by mercury. Working in this way I have submitted the osmotic cells of the peduncle of Doronicum to a tension of $75 \mathrm{~cm}$. of mercury for one hour. During this time the turgor of the cells remained unaltered.

These experiments show the possibility of realising experimentally the conditions we have assumed of pressure and tension in the transpiring cells of the leaves.

Osmotic pressure in leaf-cells a gauge of tension in tracheæ.-From the foregoing considerations it is evident that so long as the force applied to the upper ends of the sap in the tracheæ of the leaves is less than the osmotic pressure of the vacuoles of the leafcells, these cells will remain distended and the leaf will appear fresh and stiff; whilst if the force drawing off water from the cells is greater than that which they can exert on the water in the tracher, they will collapse and the leaf will fade. Under normal conditions of transpiration this collapse does not take place. Hence the 
force applied to the sap in the trachere during normal transpiration does not exceed the osmotic pressure in the leaf-cells; and consequently, if we can determine the osmotic pressure in the leaf-cells we shall have a measure of the maximum stress which is applied to the sap during normal transpiration.

Until recently the most usual way of determining the osmotic pressure in cells was the well-known plasmolytic, method.

There are several reasons why the application of this method is not suitable to leaf-cells. In the first place, it is necessary to cut sections of the leaf in order to apply the solutions and to allow of microscopic observation. The injury involved in sectioning acts as a violent stimulus to the tissues, which may in itself evoke a change in the concentration of the vacuoles or a contraction of the protoplasm. Secondly, accurate determination of the plasmolysing concentration is very difficult, as the contraction of the protoplasmic membrane must be considerable before it can be observed microscopically.

It was owing to these objections that the plasmolytic method was abandoned and other means for estimating the osmotic pressures in the cells of leaves were sought. The first method devised was the following:-

Osmotic pressure balanced against gas-pressure.-A branch bearing a number of leaves is enclosed in a strong glass cylinder, capable of resisting high gas-pressure (e.g., 50 to 100 atmospheres), and the pressure is raised in this vessel by means of an air compression-pump, or by attaching it directly to a cylinder containing liquid carbon dioxide. The lower portion of the branch projects from the cylinder and dips into a glass vessel containing a weighed quantity of water. These arrangements are shown in Fig. 24.

It is evident that when the gas-pressure in the glass ressel surrounding the branch is raised and maintained 
above the osmotic pressure of the cells of the leaf, water will be forced from these cells back into the conduits of the branch and into the vessel beneath. This will become apparent in two ways: first, by the flagging of the leaf, inasmuch as the rigidity of the leaf is due to the internal pressure of these cells, so that when this pressure is overcome by the external gas-pressure the leaf will flag; secondly, by the inrrease of weight in the vessel beneath containing the water into which the branch dips. For every branch, then, we may expect to find a pressure above which water will be forced back from the leaves into the stem by reason of the squeezing out of the osmotic cells, and below which water will rise through the conduits to the leaves, on account of the osmotic attraction of the cell-sap and evaporation from the outside of the cells.

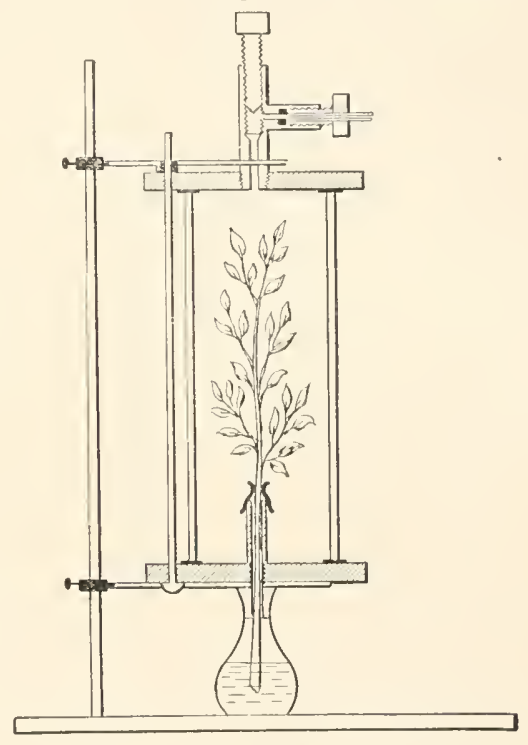

Fit. 24.

To carry out these observations, the form of apparatus I used consisted of a strong glass cylinder of specially well-amnealed glass, $50 \mathrm{~cm}$. long, $10 \mathrm{~cm}$. in diameter, and with walls $1 \mathrm{~cm}$. thick. Such a glass cylinder should, according to calculation, be capable of resisting an internal pressure of at least 100 atmospheres. The ends of this glass cylinder were closed by means of two heavy gunmetal castings, which projected over the side of the cylinder so as to take three long bolts with nuts, which drew the castings together on the cylinder. Leather washers, soaked in bees' wax and turpentine, were inserted 
between the ends, which were ground flat, and the cylinder, to make the joints air-tight. The lower end was perforated centrally, and in the perforation was sealed hermetically a narrow brass tube, about $0.5 \mathrm{~cm}$. in diameter, projecting into the cylinder. This tube included the stem of the plant to be experimented with, the lower end of the stem projecting out of the cylinder while the leaves were enclosed. To make an air-tight connection between the tube and the stem, a stout rubber tube was first bound on to the upper end of the brass tube. The branch was then inserted into the rubber tube, and, before it had been completely pushed down, a portion of it just above the rubber was coated with thick glue, so that when it was shoved down into its final position with reference to the tube, it carried this glue down into the rubber tube. When it was in position, a copper wire was bound tightly round the rubber, and drew it into close contact with the glue. To complete the joint, a little glue was smeared over it.

The upper end of the cylinder was also perforated centrally to admit the gas coming from the pump or bottle. This was a simple screw-joint, made tight by a leather-washer. To the upper end, and on the inside, were also attached three hooks, from which were suspended a wire basket, carrying drying materials, and a manometer. The latter consisted of a simple, straight glass-tube, closed at one end ; the other end dipped into a small vessel containing mercury. This tube was marked off with $\frac{1}{2}, \frac{1}{3}, \frac{1}{4}, \frac{1}{1}$, etc., of its length from its closed end, and the position of the mercury index gave the pressures directly in atmospheres. When the upper end of the glass cylinder was in position, the drying materials and manometer hung in the cylinder. The connection between the glass cylinder and pump or bottle of carbon dioxide was made by means of a flexible lead tube with screw couplings.

Observations with compressed carbon dioxide.When making these observations I was unable to procure, by 
the pump at my disposal, air-pressures above 8 to 10 atmospheres. Higher pressures were obtained by means of liquid carbon dioxide. At the time there seemed a priori no reason to believe that the presence of carbon dioxide would falsify the results of experiments, which were not continued for a long duration. However, subsequent experimental work showed that the presence of this gas profoundly modified the behaviour of the leaves when exposed to high pressures, and consequently rendered the experiments made with carbon dioxide of little value in estimating the actual osmotic pressures obtaining in the leaves under normal conditions.

In the first experiment, a short branch of Acer macrophyllum was sealed into the apparatus, and the pressure raised by means of an air-pump, and maintained for fifteen minutes between 8 and 10 atmospheres. During this time gas was continually bubbling out from the lower end of the branch, showing that the pressure had been transmitted to the inner tissues. No loss of turgescence, however, of the leaves could be observed.

In a second experiment, a similar branch was exposed to a pressure of 8 , or nearly 8 , atmospheres, for fifteen minutes, and during this time showed no loss of turgescence.

From these two preliminary experiments, it appears that the pressure within the cells of the leaves of Acer macrophyllum, which confers rigidity on the leaves, was greater than 8 atmospheres. The osmotic attraction which would give rise to this pressure would be capable of drawing up a column of water 240 feet high.

In a similar experiment, a branch of Cratogus oxyacantha was exposed to a pressure of about 8 atmospheres for fifteen minutes without showing signs of loss of turgidity.

As the pump I had at my disposal was unable to compress air above a pressure of about 10 atmospheres, I discarded it in favour of a bottle containing liquid carbon dioxide. 


\section{TRANSPIRATION AND ASCENT OF SAP CH.}

This was connected with the high-pressure apparatus by suitable couplings; and, by gradually opening the valve at the mouth of the bottle, the pressure could be adjusted at will to any pressure up to 60 atmospheres. This has the additional advantage that careful observations are possible while raising the pressure, which cannot be done while using the pump unless an assistant is employed.

By means of this arrangement, the pressure was raised round the same branch as was used in the last experiment, to $\mathbf{1 6}$ atmospheres, and was maintained at this for fifteen minutes. But even at this pressure the leaves showed no loss of turgescence. When the pressure reached 10 atmospheres, the bubbling of gas through the stem became very marked.

As it appeared possible that a certain amount of collapse of the osmotic cells of the leaves might take place without making itself noticeable by the flagging of the leaves, a number of experiments were made in which the branch dipped into a vessel beneath, the latter being weighed before and after the experiment. Any increase in weight of this vessel would be due to the forcing backwards by the external pressure of the cell-sap contained in the cells of the leaves, which would in turn displace a certain amount of water from the conduits of the branch into the vessel. A decrease, on the other hand, of the weight of the vessel would show that the external pressure had not crushed the osmotic cells, and that they had, in spite of its action, drawn up water from the vessel.

The first experiment of this kind was made on a branch of Acer macrophyllum, which bore 14 well-grown leaves. This branch was sealed into the high-pressure apparatus, and lept at a pressure of 8 atmospheres; during one hour of intermittent sunlight this branch drew up $0^{\circ} 1 \mathrm{gr}$. of water from the vessel below.

A similar branch, similarly arranged, and exposed to a pressure between 8 and 9 atmospheres, drew up, in one 
and a half hour's sunshine, $0 \cdot 3+2 \mathrm{gr}$. of water from the weighed vessel.

From these experiments it follows that the osmotic cells of the leaves of Acer macrophyllum were able to remain turgescent and draw up water against a pressure of 8 atmospheres. Consequently, the osmotic solution in the cells must be capable of generating a tension equivalent to 8 atmospheres pressure, by attracting water from the conduits.

All the trees with which I have experimented do not, however, show that their leaves possess such high osmotic pressures when surrounded with carbon dioxide. Thus the specimens of Cytisus laburmum, investigated by means of the high-pressure apparatus, showed that their cells began to collapse under an external pressure of 6 atmospheres. Above this pressure the leaves faded, and water was forced back from them into the stem. It is, however, very probable that all the leaves were not put out of activity in transpiration simultaneously. Thus, I have observed, with Cytisus laburnum, that the old leaves begin to show collapse by losing their glossy surface, and rolling back from the edges at a pressure of 6 to 7 atmospheres, while the young, small leaves, which are composed of growing tissues, remain stiff and turgescent, even at 16 atmospheres. ${ }^{1}$

A preliminary experiment on Cytisus laburmum showed that the leaves of this plant flagged markedly after an exposure of five to ten minutes to a pressure of 16 atmospheres. The flagging in this case is indicated by the folding down of a leaf from the base of its petiole, and the folding back of its leaflets, so that the whole leaf has the appearance of the leaf of a sensitive plant (Mimosa pudica)

1 This phenomenon is probably correlated with the relative sizes of the vacuoles in the old and the young cells; for it will appear later that the osmotic pressure of the sap of the young is less than that of the older leaves. 
which has been stimulated. Besides these motions, the surface of the leaf loses its gloss and becomes dried-looking, the edges of the leaf roll up, and the expanded portion becomes crumpled. The general appearance of the leaves after twenty minutes' exposure to 16 atmospheres is that of a leaf which has been exposed to a high temperature and afterwards dried. Microscopic examination of the cells of these leaves shows the protoplasm contracted from the cell-wall just as it is in plasmolysed cells. This appearance is probably brought about by the cell-wall being pressed in on the protoplasm, and causing the latter to force out its watery contents. When the pressure is relieved, the cell-wall, by virtue of its elasticity, recovers its form, while the protoplasm remains contracted within. The space included by the cell-walls does not, however, attain the dimensions it possessed when the cell was turgescent, as in that case it was distended by internal pressure and consequently the leaf formed of such collapsed cells is flaccid.

After obtaining this result, I set about to determine the critical pressure for this plant, i.e., the pressure at which the cells of the leaf would be forced to collapse, and water would be driven back from them into the stem.

(1) In the first experiment, a small branch of this tree carrying 9 leaves was fixed in the apparatus. The pressure was maintained at 16 atmospheres. During one hour of diffuse light, while the conditions within the apparatus were kept favourable to transpiration, i.e., the space was dried by calcium chloride, $0.950 \mathrm{gr}$. was forced from the leaves through the stem into the flask below. During the first ten minutes of this experiment the leaves began to flag, and soon showed all the appearances described above.

(2) A branch of the same tree, carrying 12 leaves, some old and some young, was submitted to a pressure of 8 atmospheres. After one hour of bright sumshine the 
vessel into which the branch dipped was found to have gained $0.400 \mathrm{gr}$. During this time the old leaves liad become flaccid, while the young leaves remained turgid. Even the old leaves did not become markedly flaccid during the first forty minutes of the experiment.

(3) A branch with 8 leaves was exposed to a pressure of 6 atmospheres during one hour mostly of bright sunshine. During this time the leaves showed no signs of becoming flaccid, but the surface lost some of its gloss. On weighing, it was found that the vessel below had lost $0.007 \mathrm{gr}$. of water. This amount, however, comes within the limits of error of the experiment, and, consequently, we may assume that neither upward nor downward motion of water occurs in these branches when the leaves are exposed to a pressure of $\mathbf{6}$ atmospheres. In this experiment, when the pressure was removed, the leaves recovered their gloss.

(4) Against 4 atmospheres, the same branch, in intermittent sunshine, transpired $0.622 \mathrm{gr}$. in one hour and twenty minutes, while all the leaves remained quite turgid.

At the conclusion of the series on this branch the amount it transpired at normal pressures still surrounded with carbon dioxide gas was measured, and was found to be $1 \cdot 244 \mathrm{gr}$. in one hour and ten minutes. In air at 11ormal pressure the same branch transpired in one hour $0.966 \mathrm{gr}$. During these last two experiments, the leaves were slightly faded.

The decrease in the rate of transpiration with the increase of pressure which is indicated by these results is, doubtless, more marked than here appears, as it is well known that the rate of transpiration of a branch falls off rapidly from the time of cutting it. In Experiment 3, at 6 atmospheres, which was the second to be made with this branch, this decrease would have been small, but in the succeeding experiments would have become more exaggerated. 
As it appeared quite possible that different examples of the same species might have different osmotic pressures in their leaves, these branches were all taken from the same individual, and from a height of about six feet from the ground.

In this series of experiments there are two sources of error tending to make the critical pressure appear lower than it is in reality :-First, there is the mechanical crushing of the conduits themselves owing to the external pressure. When the osmotic cells experience the pressure, they may, without themselves suffering any collapse, move in on the conducting tissues, which, although they are specially adapted to resist external pressure as well as internal tension, are elastic to some extent, and consequently will become somewhat contracted. This will expel a certain quantity of water from them into the vessel beneath : and, as the vessel was taken away immediately after the pressure in the glass cylinder was lowered, the conducting tissues may not have had time to reassume their former volume. By this means a quantity of water would be forced back into the vessel and remain there, and would tend to counteract the loss due to transpiration. As the greatest amount of water I have observed forced back in this way from a branch, which was larger than the branch used in these experiments, was about $0 \cdot 1$ gr., as will be seen later, we may place the critical pressure of the branch of Cytisus laburnum at 6 to 8 atmospheres.

Effect of carbon dioxide on the osmotic pressure.-The second source of error is more difficult to allow for. The presence of the carbon dioxide surrounding the leaves undoubtedly acts injuriously on the cells of the leaf, so that a leaf which has been surrounded with carbon dioxide for several hours sometimes shows a darkened appearance, and collapses at a lower pressure than one which has been put in fresh into the apparatus. With this plant (Cytisus laburnum), however, the injurious 
effects of carbon dioxide are not so marked nor so rapid in their manifestation as in others.

Tables 17 and 18 embodying the experiments on Tilia americana, which was found very sensitive to this gas, illustrate how carbon dioxide affects the transpiration and turgescence of the leaves.

\section{'TABLE 17.}

Titia americana in Carbon Dioxide.

\begin{tabular}{|c|c|c|c|c|c|}
\hline $\begin{array}{l}\text { Experi- } \\
\text { ment. }\end{array}$ & $\begin{array}{l}\text { Pres- } \\
\text { sures in } \\
\text { Atmo- } \\
\text { spheres. }\end{array}$ & $\begin{array}{l}\text { Conclitions } \\
\text { of Light. }\end{array}$ & $\begin{array}{l}\text { Duration } \\
\text { of Fxperi- } \\
\text { ment. }\end{array}$ & $\begin{array}{l}\text { Amsunt of } \\
\text { Water } \\
\text { forced from } \\
\text { Branch. }\end{array}$ & Remarks. \\
\hline$\Lambda$ & $15-16$ & Dull. & (ii) minutes. & $2 \cdot 284 \mathrm{gr}$ & $\begin{array}{l}\text { After } 15 \text { minutes col- } \\
\text { lapse of leaves ap- } \\
\text { parent. Finally all } \\
\text { leaves were shriv- } \\
\text { elled. }\end{array}$ \\
\hline P & 10 & Dull. & 40 minutes. & 1).988 gr. & $\begin{array}{l}\text { Slight eollapse at end } \\
\text { of experiment. }\end{array}$ \\
\hline C & $7-10$ & Dull. & 60 minutes. & $0 \cdot 171 \mathrm{gl}$. & $\begin{array}{l}\text { The leaves became } \\
\text { flaceid immedi- } \\
\text { ately. }\end{array}$ \\
\hline D & $7-8$ & Dull. & 60 minutes. & $1.452 \mathrm{gr}$. & $\begin{array}{l}\text { Collapse slight. } \\
\text { Leaves rolled at } \\
\text { edges. }\end{array}$ \\
\hline $\mathbf{E}$ & 6 & Sumshine. & 60 minutes. & $0.659 \mathrm{gr}$. & $\begin{array}{l}\text { No loss of tur- } \\
\text { gescence. }\end{array}$ \\
\hline $\mathrm{F}$ & 4 & $\begin{array}{l}\text { Bright dif- } \\
\text { fuse light. }\end{array}$ & 45 minutes. & $0.257 \mathrm{gr}$. & $\begin{array}{l}\text { After } 30 \text { minutes } \\
\text { some leaves } \\
\text { slightly crumpled. }\end{array}$ \\
\hline G & 4 & $\begin{array}{l}\text { Sunshine } \\
\text { and bright } \\
\text { light. }\end{array}$ & 60 minutes. & $0.182 \mathrm{gr}$. & $\begin{array}{l}\text { Remained quite tur- } \\
\text { gescent. }\end{array}$ \\
\hline II & 3 & $\begin{array}{l}\text { Sunshine } \\
\text { and bright } \\
\text { light. }\end{array}$ & 60 minutes. & $-0.506 \mathrm{gr}^{2}$. & $\begin{array}{l}\text { Remained quite tur- } \\
\text { \&escent. }\end{array}$ \\
\hline
\end{tabular}

In experiments $\mathrm{A}, \mathrm{B}, \mathrm{D}, \mathrm{E}, \mathrm{G}$, and $\mathrm{H}$ fresh branches with 8-11 leaves were used; in $\mathrm{C}$ and $\mathrm{F}$ the branches 
152 TRANSPIRATION AND ASCENT OF SAP ch.

already used in A and E were observed. Consequently they had already been exposed for some time to carbon dioxide.

At the end of experiment D, when the pressure had been reduced to normal for about $10 \mathrm{~min}$, the margins of the leaves unrolled and their usual appearance was reassumed.

Thabe: 18.

Tilin rmericena in Air.

\begin{tabular}{|c|c|c|c|c|c|}
\hline $\begin{array}{l}\text { Experi- } \\
\text { ment. }\end{array}$ & $\begin{array}{l}\text { Pressure } \\
\text { in Atmo- } \\
\text { spheres. }\end{array}$ & $\begin{array}{l}\text { Conditions } \\
\text { of Light. }\end{array}$ & $\begin{array}{l}\text { Duration } \\
\text { of Experi- } \\
\text { ment. }\end{array}$ & $\begin{array}{l}\text { Amount } \\
\text { of Water } \\
\text { 'Trans- } \\
\text { pired. }\end{array}$ & Remaks. \\
\hline A & 6 & Dull light. & 15 minutes. & $+0.029 \mathrm{gr}$. & $\begin{array}{l}\text { Fresh branch with } \\
4 \text { large leaves. }\end{array}$ \\
\hline B & 5 & $\begin{array}{l}\text { Diffuse } \\
\text { light. }\end{array}$ & 60 minutes. & $+0.07 t i g r$. & $\begin{array}{l}\text { Fresh branch with } \\
9 \text { leaves. No loss } \\
\text { of turgescence ap- } \\
\text { parent. }\end{array}$ \\
\hline $\mathrm{C}$ & 4 & $\begin{array}{l}\text { Diffuse } \\
\text { light. }\end{array}$ & 60 minutes. & $+0 \cdot 111 \mathrm{gl}$. & $\begin{array}{l}\text { No loss of turges- } \\
\text { cence. }\end{array}$ \\
\hline
\end{tabular}

Experiment $\mathrm{C}$ in 'Table 18 is subject to a correction for the elasticity of the branches' conduits. In determining the amount of the water transpired, the vessel beneath was placed in position before the pressure was raised in the glass cylinder and removed for its second weighing, while the pressure was still maintained. Consequently, some water was squeezed back from the conduits, owing to their elastic yield, and remained in the vessel, diminishing the amount of transpiration observed. In order to estimate how much ought to be allowed for this, an experiment was made in which the same branch was raised to a pressure of 6 atmospheres for ten minutes. While this was maintained, a 
weighed vessel containing water was supplied to its protruding end, and then the pressure was lowered to that of the atmosphere. After ten minutes, the vessel was re-weighed and was found to have lost $0.108 \mathrm{gr}$. due to the elastic recovery of the conduits. When this allowance is made in experiment $\mathrm{C}$, Table 18 , the amount transpired becomes $0 \cdot 219 \mathrm{gr}$. instead of $0.111 \mathrm{gr}$.

In order to determine whether this elastic contraction of the conduits occurred chiefly in the conduits of the stem or leaf, experiments were made in which a branch was first exposed to a pressure of 6 atmospheres for ten minutes, and while this was still maintained, a weighed quantity of water was supplied to its lower end which protruded from the high-pressure apparatus. The pressure was then immediately lowered, and the branch was left to draw up water from below for ten minutes by means of its elasticity, the amount drawn up being measured by a second weighing. When this amount is compared with the amount drawn up in a similar experiment with the same branch when all the blades of the leaves are removed, it is found that the former is very much greater than the latter quantity. Thus, with a branch of Tilia americana bearing 11 leaves, the first amount was $0.108 \mathrm{gr}$., while the latter was only $0.02 \mathrm{gr}$., a quantity which approaches the limits of error of the experiment. From this we may conclude that the elastic contraction takes place chiefly in the conduits of the leaves.

Determinations with compressed air.-At a subsequent date, when it was possible for me to generate higher air pressures, it was found that the leaves were able to withstand considerably higher pressures when not exposed to the harmful effects of carbon dioxide. Thus the leaves of Helianthus multiflorus in air do not collapse until a pressure of 20 atmospheres is applied to them, while those of Cytisus laburmum and Tilia americana did 


\section{54 TRANSPIRATION AND ASCENT OF SAP $\mathrm{cH}$. VII}

not lose their lustrous appearance or roll at the edges till pressures between 26 and 38 atmospheres were applied. Hence, under normal conditions we may believe that the leaves of these plants will not show signs of fading till tensions equivalent to 20-30 atmospheres are generated.

By means of this method useful results were obtained, but danger attended the determmations. Despite the strength of the glass cylinders used, two explosions occurred, fortunately attended by delay in the work only, so that after a comparatively small number of observations, a more suitable method was looked for.

\section{Literatitre.}

Dixon, H. H., "On the (Ismotic Pressures in the Cells of Leares," Pro. Lion. Irish Acad. vol. iv (Se1. 3), p. 61, and Notes from the Botuniral Sichool Trinity Gollege, Dublin, vol. i, p. 44.

Id. "On the Physics of the Transpiration Current," Notes from the Botanical School, Trinity College, Dublin, vol, i, 1. 57.

Id. "A Transpiration Model," Proc. Ruy Dublin Soc. 1903, vol. x (N. S.), 1. 114, and Notes from the Botanical School, Trinity College, Imblin, vol. i, p. 217 .

Dixon, H. H., and Joly, J., "On the Ascent of Sap," Phil. Truns. Rimy. Soc. London, 1895, vol. $186 \mathrm{~B}$, 1. 563. 


\section{CHAPTER VIII}

THE THERMO-ELECTRIC METHOD OF CRIOSCOPY

Relation between osmotic pressure and freezing-point.--The method finally adopted for determining the osmotic pressures in leaves is an indirect one. As is well known, a relationship exists between the freezing-point of a solution and the osmotic pressure it can exert against a semi-permeable membrane. Hence, if we can determine the freezing-point of the sap in the vacuoles we shall have a measure of the osmotic pressure. This cryoscopic method has been applied to determine the osmotic pressures of various fluids of the animal body by numerous investigators. In these cases, comparatively large quantities of the fluids are available, and consequently Beckmann's method for determining freezing-points is suitable.

Beckmann's method of cryoscopy.-This involves the use of a thermometer with a large bulb which must be inmersed in the solution the freezing-point of which is to be determined. The size of the bulb necessitates the use of a considerable quantity of the solution, viz., 12 to 15 c.c. as a minimum. ${ }^{1}$ Such large requirements seemed to preclude the application of the method to the determination of the osmotic pressures of the sap of transpiring organs, of which but small quantities

1 Beckmann thermometers with diminutive bulls have been introduced recently for dealing with small quantities of liquid. 
can be conveniently obtained. This objection applies all the more strongly to the other more elaborate methods of determining the freezing-points of solutions.

Use of thermocouples.-In order to circumvent this difficulty, it was decided to replace the mercurial thermometer by a thermocouple, and to compare directly the freezing-point of water with that of the solution.

It seems surprising that thermocouples have not been in general use for determining the freezing-points of solutions. In the first place, it is evidently possible to make the thermo-electric method a differential one, viz., comparative of the freezing-point of the solution to be examined with that of pure water under the same conditions, and so it would seem most of the corrections necessary in the thermometric method would be rendered needless. Thermocouples have great possibilities of sensitiveness, e.g., it is by no means difficult to obtain by their use a deflection of the light-spot on a galvanometer scale amounting to $1 \mathrm{~mm}$. for a difference of $0.000 \mathrm{I}^{\circ}$. With this sensitiveness they can be made with a very small heat-capacity, and will consequently take up the temperature of their surroundings quickly. Their minute size and ease of manipulation contrast very favourably with the bulkiness of the ordinary freezing-point thermometers. Absence of parallax in reading the scale and the ease with which couples having various ranges may be constructed will also occur as advantages.

Notwithstanding these attractions, I have not been able to find that thermocouples had been used previously in cryoscopy, although in many researches their properties would be of value. This is probably to be explained by the erratic behaviour they exhibit when set up without special precantions. When a sufficiently sensitive galvanometer is used to give a good deflection for small temperaturedifferences, it is found also to be deflected by temperaturedifferences acting on accidental junctions in the circuit. 
Such junctions are usually formed at the binding-screws between brass and copper or between two different samples of copper. Strained places even in the copper leads may also act as thermo-junctions. Another source of trouble is strains in the galvanometer suspension, which lead to continual changes in the position of the zero on the scale. The slowness of the galvanometer needle to take up its final position may also be mentioned as introducing uncertainty in deciding on the true magnitude of the deflection.

In view of these sources of error, it is evidently of great importance to have as few connections in the circuit as possible, and, where the latter are unavoidable, to secure that they are balanced by similar connections kept at the same temperature.

Construction of the thermocouples.-In order to eliminate one usual set of connections from the circuit, i.e., that between the thermocouple and the leads, it was arranged to utilise the ends of the copper leads themselves as one pair of elements in the junctions. These leads, which had a diameter of $0.17 \mathrm{~mm}$., extended right from the junctions to the reversing key (to be described later). The other pair of elements of the couple were formed of the ends of a continuous iron, nickel, german silver, "constantin," or " eureka" wire.

For the work in hand, the eureka-copper junctions were found most suitable. The eureka alloy has a high thermoelectric value when forming a junction with copper, and so is capable of giving a large deflection for a small temperature difference. Its comparatively great resistance enables one to adjust very conveniently the sensitiveness by increasing or diminishing the length of the eureka in the couple. Its low coefficient of variation of resistance with temperature secures that this convenient resistance introduces practically no error; and when, as in the apparatus to be described, it is enclosed in the freezingchamber, the error is so small that it may be disregarded. 
$15^{8}$ TRANSPIRATION AND ASCENT OF SAP cH.

The specific resistance of eureka at $0^{\circ}$ is given as 47.4 microhms; its variation at $20^{\circ}$ per $1^{\circ}$ as 0.0048 per cent.

The construction of the eureka-copper thermocouple is simplicity itself. To each end of the silk-covered piece of

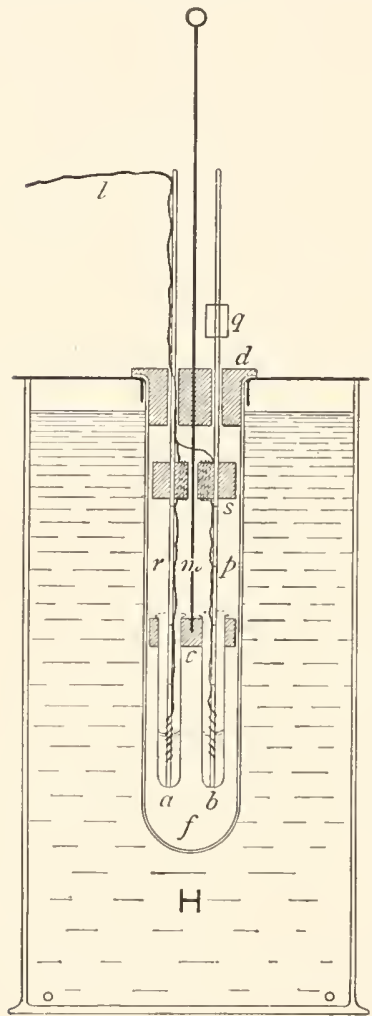

Fit: 25. eureka wire, about $1 \mathrm{~m}$. long, a convenient length of the copper lead is soldered. The eureka wire I made use of had a diameter of $0.19 \mathrm{~mm}$., and a resistance of about $16.5 \mathrm{ohms}$ per metre. The soldered junctions between the eureka and copper may be neatly made by stripping a few millimetres of the ends of each from their silk coverings and dipping the bared tips into a solution of resin in spirit. After this treatment, if the ends in contact with one another are immersed in a tiny drop of molten solder, a very compact and good junction is made.

Description of the apparatus. - To accommodate the couple to the apparatus, the eureka wire before soldering was wound on a cork support (Fig. $25 \mathrm{~s}$ ), leaving some $20 \mathrm{~cm}$. of each end free. This cork support forms a connecting-piece between two drawn pine rods ( $p$ and $r$, Fig. 25) which are destined to carry the junctions and to keep them in position, one in a test-tube $(a)$ containing the fluid to be examined, and the other in a similar tube $(b)$ containing distilled water. ${ }^{1}$

1 If a finer wire is used, the resistance may be disposed of by winding it round the lower end of the rod $p$, so that it remains immersed in the freezing distilled water. This eliminates any change in the resistance due to temperature finctuation. 
'The two test-tubes, each about $1 \mathrm{~cm}$. in diameter, are supported in a perforated cork bung (c), which fits loosely in an outer large test-tube, which in turm is immersed in the freezing-bath, and forms the freezingchamber $(f)$. The perforated bung is held about the middle of the large test-tube by a metal rod $(m)$ - a piece of stout brass wire-fixed into it and passing through another bung which closes the mouth of the outer test tube. The rod is prolonged above the second bung $(d)$, and forms a handle by which both bungs may be removed simultaneously from the freezing-chamber carrying the small test-tubes in the lower bung.

The cork connecting-piece $(s)$ carrying the eureka wire of the couple is fumished with a wide median vertical perforation parallel to the two pine rods. When the pine supports are placed in the small test-tubes, the metal rod is passed through the perforation in the connecting-piece and works loosely in it. Before fixing in the connectingpiece the pine supports are thoroughly impregnated with paraffin-wax by keeping them submerged for some time in melted wax near its boiling-point. The junctions and the wires coming from them are laid along the supporting rods thus prepared and fixed in the connecting-piece, and are bound to the rods, and the whole is waterproofed and insulated with several coats of collodion varnish. 'The supporting rods are continued above the connecting-piece and are produced through corresponding perforations in the upper bung $(d)$, in which they fit loosely. It is convenient that some kind of easily detached stop $(q)$ should be fixed on one of the rods above the upper bung to prevent the rods slipping out of this bung when the test-tubes are removed. The copper leads $(l)$ emerge from the freezing-chamber along one of the supporting rods.

This arrangement, which will be easily understood by reference to Fig. 25, allows the junctions in each of the 
smaller test-tubes to be moved simultaneously by raising and lowering the upper ends of the pine supports, when the upper bung is in position and the freezing-chamber is closed. The double lead may be easily introduced, or withdrawn, from the perforation in the upper bung by means of a narrow slit opening into that perforation from the side of the bung.

From these arrangements it will be seen that the method has been rendered a comparative and differential one, and consequently the corrections necessary for the thermometric methods may be partly or wholly dispensed with here. Botli test-tubes gain the same amount of heat from the stirring. With regard to the loss of heat to the freezing-bath, the water will tend to lose heat more rapidly, owing to its higher temperature. This difference is rendered negligible by the way in which the water freezes. A continuous layer of ice always separates out against the wall of the test-tube, and forms a screen between the bath and the water in which the junction moves.

Again, the velocity with which the ice and the liquids in the tubes come into equilibrium, depends on the amount of ice present, its surface, its fineness of division, and the energy of the stirring.

In the solution less ice will separate than in the water for a given temperature of the freezing-bath; but, at the same time, it is, in practice, found to be more finely divided. These two differences will act in opposite directions.

The calibration-curve given in Fig. 26, which is sensibly a straiglit line, shows that these error's practically neutralise each other, and that in the working of the method the galvanometer-deflection is proportional to the true depression of freezing-point of the solution examined.

Reversing key.--Bearing in mind the desirability of eliminating all needless junctions from the circuit, 
one would like to connect the leads coming from the junctions on the pine supports directly with the terminals of the galvanometer. The importance of reversing the current through the galvanometer owing to shirts in the zero position of the mirror, and the advantages of being able to disconnect the couple readily from the galvanometer during various manipulations, render a key of some form or other necessary in the circuit.

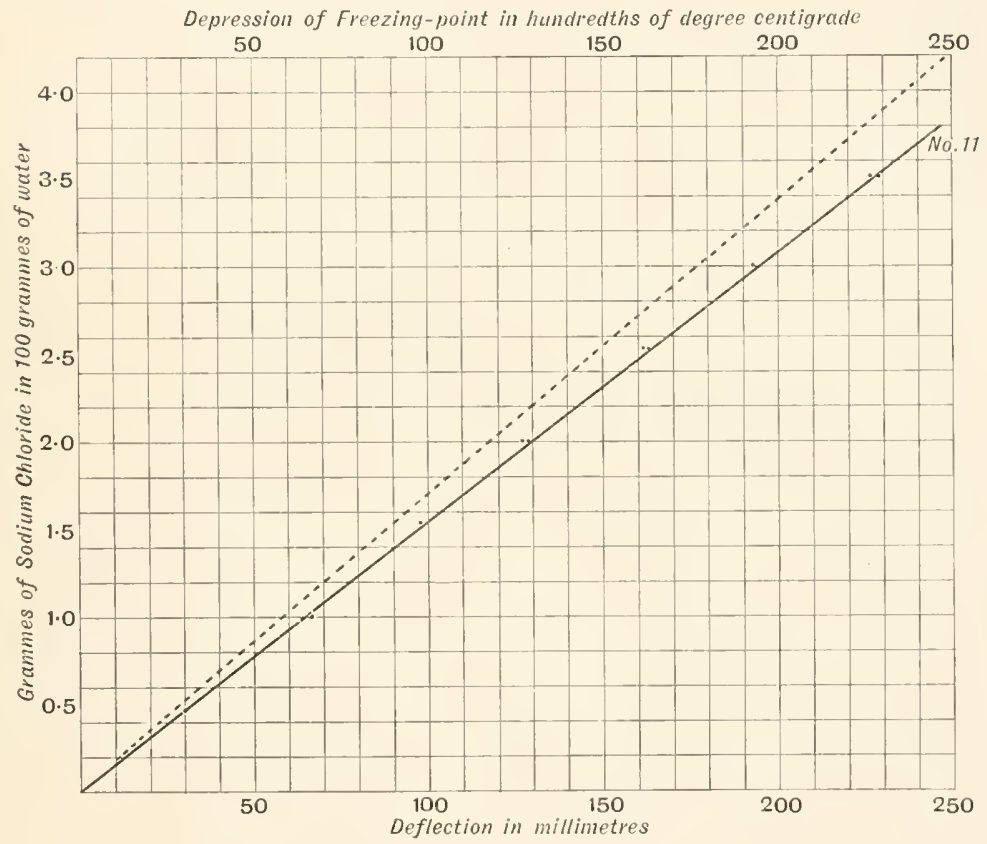

Fir: 26.

Such a break in the continuity of the leads involves a pair of junctions. Experience shows that even when the junctions are between two pieces of the same wire, thermoelectric effects are produced if they are not at the same temperature. In order to keep the two junctions as closely as possible at the same temperature, the following arrangement was adopted:-

The leads coming from the couple are disposed so that 
their naked ends are exposed on opposite sides of a flat vertical support. To effect this they were passed several times through a piece of thin cardboard in such a manner that when the card was bent and folded across the support the stitches made of the two wires lay on opposite sides.

Fig. 27 shows the arrangement. $\mathrm{T}$ is an $\mathrm{H}$-shaped piece of timned iron about $5.5 \mathrm{~cm}$. long. The cross-piece of
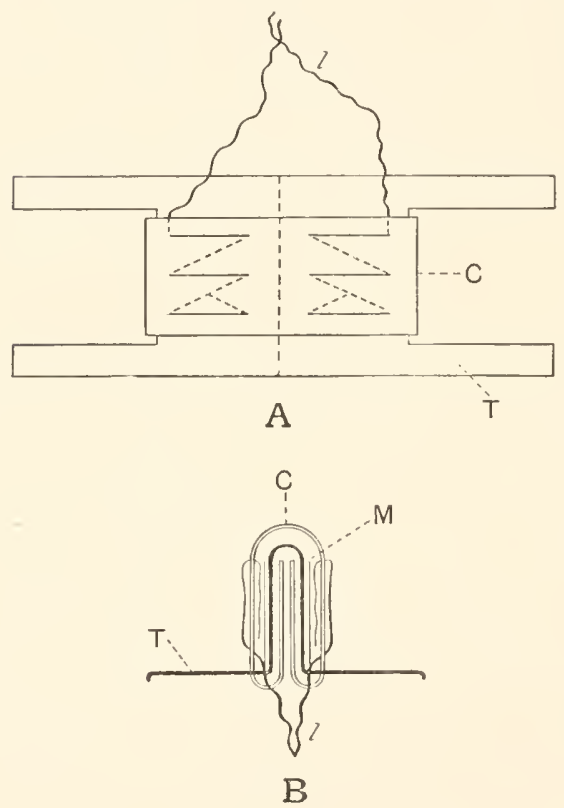

FIt: 27. the $\mathrm{H}$ is represented by a broad band about $3 \mathrm{~cm}$. wide. It is covered by a thin piece of cardboard C about $1 \cdot 2 \mathrm{~cm}$. by $5 \mathrm{~cm}$. This card carries three stitches of the ends of the leads on each side of its middle line. The ends of the card are folded round the crosspiece of the $H$, and the iron is folded in the midclle along the dotted line (Fig. 27A), so that the ends of the card are nipped within the fold. Then the four ends of the $\mathrm{H}$ are bent out at right-angles to the folded middle-piece, so as to form a stand to support this in a vertical position (Fig. 27B). T'o prevent the ends of the leads making contact with the iron, two plates of mica (M, Fig. 27B) are slipped between the leads and the iron-one on each side of the vertical portion. The mica plates are held in position by the carclboard.

Connection between the ends of the leads exposed on this support and those coming from the galvanometer 
was made in the following way: The bare ends of the galvanometer leads were fixed on the inner surfaces of the jaws of a spring wooden clip. When the clip was closed upon the vertical support of the thermocouple leads, connection was established between the two pairs of leads, and the circuit was complete. By releasing the clip and rotating it round a vertical axis through $180^{\circ}$, and clamping it again on the support, the current from the couple may be reversed through the galvanometer.

In this form of reversing key, the junctions being of the same metal and-if clesired-made of the same piece of metal, thermo-electric effects set up by temperaturedifference at the junctions are reduced to a minimum. Notwithstanding this, it was found that these differences of temperature were a source of error. To maintain the junctions on the opposite sides of the support at the same temperature and so eliminate the error, these connections were made underneath liquid petroleum, contained in a beaker, on the bottom of which rested the support of the thermocouple leads. The petroleum was kept stirred during observations.

Arrangements for galvanometer.-It is found convenient to have the galvanometer leads a considerable length, so as to allow a suitable distribution of the parts of the apparatus; consequently, it is essential that they should have a sufficiently large crosssection, so as to offer but a small resistance; otherwise changes in temperature, from which it is impossible to shield them, will alter the sensitiveness of the apparatus. With the key described, there is no objection to having the galvanometer leads of different copper wire and heavier than those coming from the junctions.

Some special precaution is also needed to secure that the junctions at the binding-screws and those in the galvanometer are at the same temperature. In the case of these connections it is all the more necessary, because 
164 'TRANSPIRATION AND ASCENT OF SAP' ch.

elements of the junctions are of different materials-viz., brass and copper. It was found that the different temperatures of the opposite sides of the galvanometer in an ordinary laboratory could cause quite an appreciable deflection. To remove this, the galvanometer was placed in a thermostat, arranged to maintain a temperature of about $21^{\circ}$ (Fig. 28, T). For this purpose one of Hearson's incubators was used. A hole was cut in the wooden door. Through this a beam of light illuminated the galvanometer-

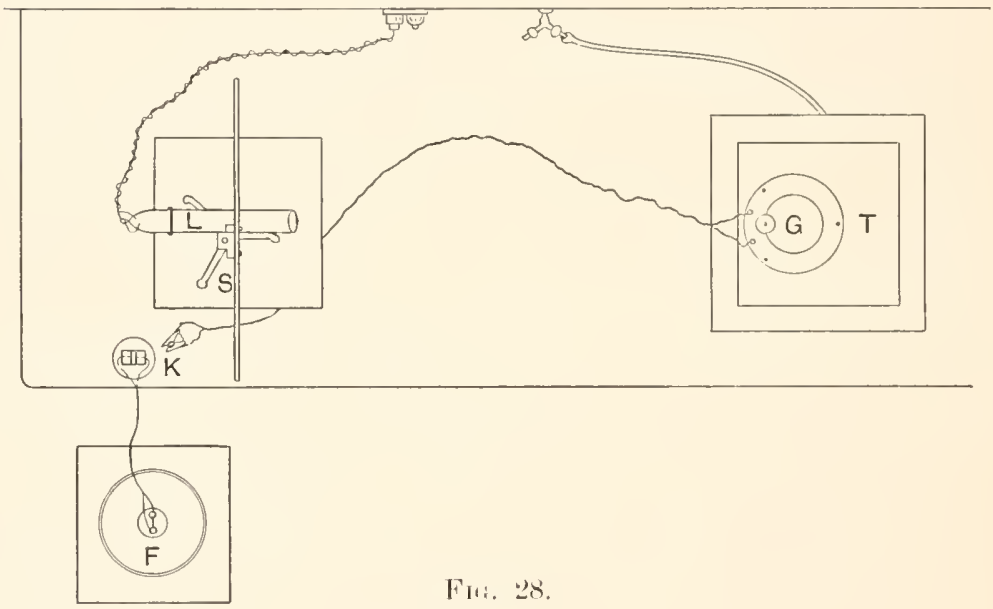

mirror, and was reflected back to the scale (S). The inner glass door was found not to injure the sharpness of the image of the cross-wire sufficiently to be objectionable. It was necessary to stand the galvanometer (Fig. 28, G) on a stout glass plate on the copper floor of the thermostat, which otherwise slowly sagged under the pressure of its feet. The thermostat during observations, extending over a year, was maintained at temperatures which varied very slowly between $20.2^{\circ}$ and $215^{\circ}$, so that at any moment the parts of the galvanometer must have been very closely at the same temperature.

This constancy of temperature was probably also ad- 
vantageous in maintaining the resistance of the galvanometer itself constant.

The galvanometer employed was one of the AyrtonMather pattern, manufactured by the Cambridge Scientific Instrument Company. Its resistance was $20 \cdot 7$ ohms. The deflection of the spot of light for one micro-volt, when the screen was 1 metre distant from the mirror, was $10 \mathrm{~mm}$., and for one nicro-ampere $206 \mathrm{~mm}$. A translucent screen was used to receive the spot of light from the galvanometer-mirror, which was illuminated with a Nernst-lamp (Fig. 28, L).

Where one observer is using the apparatus, it is convenient to have the galvanometer leads so long that the petroleum key may be placed close to the screen, while the freezing-bath and thermocouple, etc. (F), may stand at a level $50 \mathrm{~cm}$. below the screen and somewhat nearer the observer. This disposition brings the key $(K)$, the supports of the thermocomple, and the stirrer of the freezing-bath close to the observer, and he is in a convenient position for reading the position of the image of the cross-wire.

The apparatus should be set up, and the thermostat and galvanometer adjusted, on the day before an observation is made. Once set up, no readjustment should be necessary

'The freezing-bath is contained in the large cylindrical glass vessel, shown in Fig. 25, H, with thick walls. 'To prepare the bath the vessel is about a quarter filled with salt solution, and then finely divided ice is added till the ressel is filled up to within about $3 \mathrm{~cm}$. of the brim. A stout brass wire stirrer of the usual form is used to mix the brine and ice. Salt is added till the desired temperature is attained. This should be about $1.5^{\circ}$ below the freezing-point of the solution to be examined. If the proportion of ice to the liquid is large, this temperature may be maintained constant by occasionally adding a little salt. A brass lid is fitted to the freezing-vessel, and 
supports the large test-tube which forms the freezingchamber. It is also perforated to admit a thermometer into the freezing-bath and to allow the stirrer in the bath to project from it.

Details of procedure.-To make an observation with the apparatus-say, to determine the freezingpoint of a solution-the procedure is as follows: the leads of the thermocouple are slipped through the slit and the pine supports through the holes in the upper cork bung, and the stop is fixed on one of the supports above the cork, to prevent them falling down. The freezing-chamber is then closed with the cork. Meanwhile, two small test-tubes, one containing about 2 c.c. of the solution, and the other the same quantity of distilled water, are being cooled by supporting them in the freezing-bath, making use of the perforation in the lid through which the stirrer works.

When it is judged that they have reached their freezingpoint, a little hoar-frost is detached on a cooled platinum needle from the outside of the freezing-chamber and introduced into the distilled water. Ice crystals are immediately formed, and some adhere to the needle, which is then transferred to the salt solution. Crystallisation is instantaneously started in this, and the needle is withdrawn. The two test-tubes are now put into the holes of the smaller cork, and this is fixed on to the lower end of the wire handle which passes down through the upper cork, which has been removed from the freezingchamber momentarily for the purpose. The junctions on the lower ends of the pine supports are now immersed in the freezing liquids in the test-tubes. 'Thus arranged, the whole, test-tubes and thermocouple, is put into the freezing-chamber and the upper cork tightly adjusted.

Stirring of the contents of the test-tubes is immediately commenced by moving the pine rods up and down. As these are rigidly connected together, the two test-tubes 
are subjected to precisely similar conditions in this respect. The freezing-bath is also kept stirred. The galvanometer may now be put in circuit with the thermocouple by fixing the clip on the support in the petroleum key; and the petroleum is occasionally stirred. Immediately on making the contact the spot of light travels from zero. At first its motion is rapid, but becomes slower and slower till at last it moves with an almost imperceptible creep. It comes to rest about 60 secs. after contact is made. It will be found convenient to allow 75 secs. to elapse before making a reading. During this time the stirring of the test-tubes is actively kept up; for it is surprising how. quickly the ice rising in the solution allows the lower layers round the junction to become supercooled. In the other test-tube the same does not occur, as the ice soon forms a lining lying against the wall of the test-tube, and the junction is supported in water surrounded by ice.

When the first reading is made, the clip is disconnected and the galvanometer nirror swings free. Reversed connection is made when the spot of light is at the limit of its swing on the side on which the first deflection was recorded. In this way the suspension of the galvanometer is kept from any sudden strain which might be produced by suddenly checking its movement. After 75 secs., during which the same active stirring is kept up, a second reading is made. 'This first observation after putting in the solution should be regarded merely as a preliminary one; but still, if too much ice has not been present, it will give the freezing-point within a couple of hundredths of a degree.

The test-tubes are now raised from the freezing-chamber, and the one containing the solution momentarily touched by the finger to give it a little heat. When the upper cork is readjusted and stirring recommenced, it will be noticed that the spot of light retires towards zero. If all the ice is not melted, it will quickly recover its former 
position; and the test-tube should again be touched. When it is certain that almost all the ice is melted in the solution, it is left in the freezing-chamber and allowed to cool. Meanwhile connection is broken by removing the clip from the support in the petroleum key.

When it is judged that radiation has cooled the solution nearly to its freezing-point, connection is again made by the clip, and stirring is recommenced. The spot of light then travels to near its previous resting-place, or possibly beyond it. Supercooling may proceed, and the spot of light will slowly travel indefinitely beyond its previous position, $\mathrm{ol}^{2}$ crystallisation may supervene, and the spot will return somewhat on its path and tend to take up a steady position. In the latter case connection is broken at the clip, and the mirror allowed to swing free. Connection is again made, and, after 75 secs., during which vigorous stirring is kept up, a reading is made. The current is then reversed, and at the end of 75 secs., another reading is made on the other side of the zero point. If, however, supercooling proceeds, and crystallisation does not automatically occur, it is necessary to inoculate the solution with a little hoar-frost. The inoculation should be carried out when the spot of light has definitely passed the limit of the first deflection. If it is allowed to cool too far, much ice will separate, and the concentration of the solution left over will cause too large a depression; if, on the other hand, it is inoculated just at its freezingpoint, so little ice separates that the solution in parts may continue for some time supercooled, and we may get too great a deflection. Experience shows that the smallest depression is obtained if the solution is allowed to cool $0 \cdot 1^{\circ}$ to $0 \cdot 2^{\circ}$ below its freezing-point before inoculation.

It will often be found that the mean of the second pair of readings indicates a larger deflection than that of the first pair by about 1 per cent. This seems to be 
due to the slow cooling of the support of the junction in the solution. It will be found that readings after the junctions have been in the freezing-chamber about $15 \mathrm{~min}$. do not tend to be greater than the preceding ones. In the natural routine the second pair of readings are made about 15 mins. after the junctions have been put in position. A third pair of readings made in a sinilar manner will plainly show whether the apparatus has reached a steady state. If the observations have been satisfactory, they should not diverge from one another by more than one-half per cent., and with care greater accuracy may be obtained.

To calibrate the apparatus, sodium-chloride solutions of known strength are introduced into one of the test-tubes. The deflection produced by the depression of the freezingpoint of each is observed. These depressions being known by the work of Raoult, Loomis, Nernst, and Abegg, we obtain the value of a millimetre deflection of the lightspot in degrees.

Table 19 (p. 170) exhibits the figures of one of these calibrations. The individual readings are recorded to give some idea of the accuracy of the arrangement.

The scale reads continuously from left to right: $250 \mathrm{~mm}$. marks its middle point.

In this table are recorded the two positions of the spiderline in the spot of light on the scale for three successive observations of the freezing-point of each solution. The defiection corresponding to this freezing-point is obtained by subtracting the second from the first, and halving the result. It will be seen that deflections obtained in this way diverge only slightly from the mean, which is given in the last column but one. The greatest divergence is not one-half per cent. In the final column are given the actual freezing-points of the solutions derived from Raoult's results quoted from Hamburger. 
TABLE 1!).

Calibration of Thermocotple.

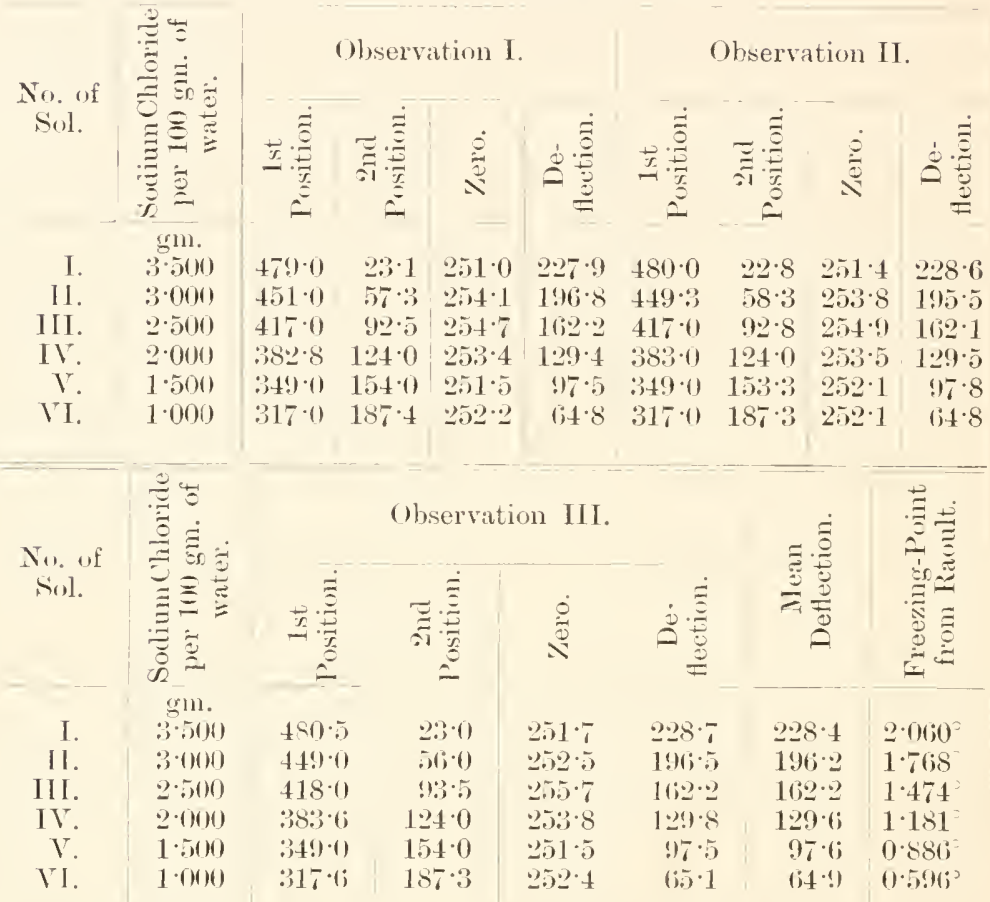

It will be noticed from the numbers recorded in the table that the position of the zero shifted considerably during the observations. In the first series, i.e., those on Solution I, the zero point lay about 251 on the scale, while during the first observation on Solution II it was near 254, These shifts of zero show the importance of being able to reverse the current, and of obtaining the deflection by two readings, one on each side of the zero position.

A graph of these observations is given in Fig. 26 (p. 161). The ordinates correspond to the concentrations of the solutions, and the abscissie to the measures of the deflections in mm., caused by the difference in temperature of the freezing-points of the solutions and that of water. The 
dotted line is a similar graph of Raoult's freezing-point determinations. The concentrations are plotted against the depressions of the freezing-point. In the second graph the abscissa correspond to hundredths of a degree.

The couple on which these observations were made had a length of $126 \mathrm{~cm}$. interposed between the junctions, as it was desired that it should give about $1 \mathrm{~mm}$. deflection for a temperature difference of $0.01^{\circ}$. The actual deflection was found to be $110.9 \mathrm{~mm}$. for $1.00^{\circ}$.

For some time after being made, the thermocouple used in these observations changed its constant considerably, owing probably to some progressive change in the metals of the junction and circuit. After nine months, when the constant was re-determined, it gave a deflection of $130.4 \mathrm{~mm}$. per $1^{\circ}$. It had then become nearly stable, and observations during the next three months showed that its deflection varied between $129.2 \mathrm{~mm}$. and $133.0 \mathrm{~mm}$. per degree. 'The smaller fluctuations are possibly due to changes in the resistance of the circuit comnected with changes of temperature. They show, the need of redetermining the constant of the couple during each series of observations, just as the zero change of the Beckmann thermometer necessitates a control-experiment in the thermometric method.

With regard to the temperature of the freezing-bath, it would at first sight appear of little importance in this differential method, as, no matter what its temperature is, it might be thought that it affects each test-tube similarly. It has, however, been found to have an appreciable effect on the magnitude of the deflection corresponding to the freezing-point of a given solution, as will be seen from the table below, in which are recorded the deflections corresponding to the freezing-point of a solution of $1.5 \mathrm{gm}$. sodium chloride in $100 \mathrm{gm}$. of water, having a freezingpoint of $0.886^{\circ}$, when surrounded with a freezing-bath of different temperatures. 


\section{I72 TRANSPIRATION AND ASCENT OF SAP ch.}

Temperature of Bath.

$$
\begin{aligned}
& -1 \cdot 0 \\
& -1.5 \\
& -2 \cdot 0 \\
& -2 \cdot 5 \\
& -3 \cdot 0 \\
& -4 \cdot 0
\end{aligned}
$$

Deflection.

$113 \cdot 6 \mathrm{~mm}$.

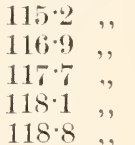

From these figures it appeared that when the freezingbath is less than $1.2^{\circ}$ below the freezing-point of the solution under examination, a small alteration in the temperature produces a greater effect on the deflection than when the bath is about $1.5^{\circ}$ below the solution. It consequently seemed best to adjust the freezing-bath about $1.5^{\circ}$ below the suspected temperature of the freezingpoint.

As has already been pointed out, the influence of the temperature of the freezing-bath on the apparent freezingpoint deffection is due to the difference in the behaviour of water and salt solutions on freezing. In the latter the crystals remain separate and the ice is finely divided. The difference of density between it and the solution causes it to rise up somewhat more rapidly, tends to aggregate it at the upper surface, and so permits the lower layers of the solution to supercool to a small extent. In the distilled water, on the other hand, the ice adheres to the walls of the tube, and forms a lining to it, so that supercooling of the lower layers is less favoured.

The convergence temperature and the velocity of heat exchange between the freezing-bath and the contents of the tubes are dependent largely on the heat-capacity of the solution, and consequently it is of importance that the two test-tubes should contain approximately the same amount of liquid; otherwise the rate of exchange of heat between the solution and the freezing-bath and the water and the freezing-bath will be different. Thus the deflection due to the depression of freezing-point of a solution containing $1.5 \mathrm{gm}$. sodium chloride in $100 \mathrm{gm}$. of water was found to be $115 \cdot 6 \mathrm{~mm}$., when the 
solution and the water stood at a level of $3 \cdot 3 \mathrm{~cm}$. in similar tubes; it was reduced to $115.4 \mathrm{~mm}$., when the depth of the salt solution was increased to $5 \mathrm{~cm}$. Of course it is easy to arrange that both tubes should contain the same amount, and so have practically the same heatcapacity.

Change of resistance of the circuit due to temperature changes is guarded against by completely immersing the eureka or nickel of the couple in the freezing-chamber, while the resistance of the galvanometer is kept constant by its being enclosed in the thermostat. The complete immersion of the connecting-piece of the couple in the freezing-chamber also secures the elimination of thermoelectric effects due to want of uniformity in this wire.

From what has been said, it will appear that the thermoelectric method is capable of considerable accuracy, even when only two junctions are employed. Of course if it were desired to work to greater accuracy, there would be no reason why the number of junctions should not be increased, thus greatly increasing the galvanometer deflection for the same temperature interval. In the work in which we were engaged, however, this would have been undesirable, as a comparatively large range was required.

But even with a pair of junctions, the hundredth of a degree could be measured with certainty. With this accuracy very small quantities of fluid may be dealt with. The small quantities required render the method particularly suitable to physiological work. Its differential character might also be applied with advantage to comparing the freezing-points of different fluids ; for example, in a comparison of jugular and carotid blood.

\section{LITERATIRE.}

Dixon, H. H., "- Observations on the Temperature of the Subterranean Organs of Plants," Trans. Roy. Jiish. Acal. 1903, vol. 32 B, 1. 145.

Id. "A Thermo-electric Method of Cryoscony," Proc. Roy. Dublin Sor. 
1911, vol. xiii (X. S.), 1. 49, and Notes from the Botanical school of Trinit! College, Dublin, wol. ii, p. 121.

Dixon, H. H., and Atkins, W. R. G., "On Osmotic Pressures in Plants; and on a Thermo-electric Method of determining Freezing Points," Prom. Roy. Dublin Soc. 1910, vol. xii (N. S.), p. 275, and Notes from the Botanical School of Trinity College. Dublin, vol. ii, 1). 47.

Hamburger, H. J., "Osmotischer Druck und Ionenlehre (Wieshaden, $1902)$. 


\section{CHAPTER IX}

METHODS OF EXTRACTING SAP FOR CRIOSTOPIC

OBSERTATIONS

Is the earlier experiments with the thermo-electric method, the sap employed was obtained by simply crushing the tissues in linen till they yielded the necessary amount of liquid. In a few cases at the beginning of the investigation, when a difficulty of obtaining sufficient sap was anticipated, a modification of this method was used. A weighed quantity of leaves was broken up to a nearly uniform pulp in a mortar and a measured quantity of water was added. When thorough mixing was effected, the diluted sap was squeezed from the sludge and its freezing-point determined. The correction for dilution was obtained by a separate determination of the percentage of water in the sample of leaves used.

Method of simple pressure.-The method of extraction by simple pressure had always been adopted hitherto in cryoscopic determinations both for animal and vegetable juices.

The sap so obtained has been regarded as a fairly average sample of the sap of the organ pressed. This seemed a reasonable view to take, inasmuch as the pressures applied so completely crushed the cells of the tissues that the sap expressed contained large quantities of protoplasmic fragments, which in the case of green organs were particularly 


\section{I76 TRANSPIRATION AND ASCENT OF SAP ch.}

noticeable, owing to the presence of chlorophyll corpuscles embedded in them. It seemed allowable to assume that, where the component cells are so completely disintegrated as is indicated by this observation, all the sap of their vacuoles must be shed into the expressed fluid; or at least there would be no reason to suspect a difference in composition between the latter and the sap which remained behind in the organ.

Fairly early in this research, however, observations were made which, in the light of subsequent work, might have borne a different interpretation. For example, when leaves were exposed to the vapour of chloroform, it was found that the sap was pressed out with much greater ease, and its freezing-point was very much lower, than that of the sap coming from the untreated leaves.

This may be illustrated by the experiments made on the sap of leaves of Hedera helix, shown in Table 20.

\section{T'ABLE: 20.}

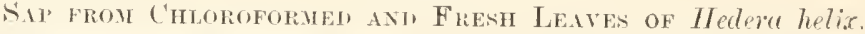

No. of

Expt.

Description of Sap.

\section{$\Delta$.}

0.754

$0 \cdot 9192$

1). .81

$1 \cdot 280$

A comparison of experiment 227 with 229 shows the increase of the depression of freezing-point we may expect from the saturation of the sap with chloroform. Experiment 232 is added by way of comparison to indicate the change in freezing-point which is experienced by the sap of untreated leaves when kept for twenty-four hours in the dark. 'The depression of the sap pressed from the 
chloroformed leaves is evidently much greater than can be assigned to the action of the chloroform on the sap, or to the spontaneous changes in the cells of the leaves, which appear in Experiments 229 and 232 respectively.

Another result which could be interpreted in the same sense was furnished by two experiments on the sap of leaves of Ilex aquifolium. In these it was found that, if the leaves were killed by heat in a saturated atmosphere, they yielded a sap having a much greater depression of freezing-point than that pressed from similar leaves which had not been heated.

TABLe 21.

Sap frou Fresil axi Heated Leaves of llex aquifolim.

No. of

Expt.

$4: 30$

431
Description of Sap.

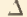

Again, it was found that, if a weighed quantity of leaves be desiccated, reduced to powder, and again made up to the original weight with water, the sap pressed from the mass will have a much greater depression than that pressed from the fresh leaves without passing through this treatment. This point is borne out by the following experiments :-

TABLE 22.

Sap from Fresh and Destcaten Leaves of Ifodera helid.

No. of

Expt.

$4: 34$

435

430

$4: 37$
Description of Sap.

$\Delta$

From fresh leaves . . . . . . . . . 0.728

From similar leaves desiccated

$1 \cdot(): 31$

$0.869^{\circ}$

From fresh half leaves . $\cdot$.
From remaining halves desiccated

$1 \cdot 177^{\circ}$ 
In Experiments 436 and 437 the specific electrical conductivities of the saps at $0^{\circ} \mathrm{C}$. were also determined, and were found to be respectively 0.00485 and 0.00623 . This shows that the quantity of electrolytes in the sap pressed from the desiccated leaves has increased approximately proportionally with the other dissolved substances.

These observations were made primarily with other objects in view. But even then the possibility that the sap pressed from the untreated leaves was not so concentrated as that remaining behind in them presented itself. However, it seemed more probable that the greater concentration of the sap derived from the chloroformed, heated, and desiccated leaves was attributable to changes due to the treatment in each case, and the investigation of the discrepancy was deferred to a later date.

Progressive concentration of pressed sap.Finally a short paper by Marie and Gatin again suggested the necessity of investigating this point. These writers when investigating the cryoscopic value of the sap of Alpine plants note that the sap expressed first from a plant-organ has a smaller depression of freezing-point than that pressed subsequently. They contented themselves however, with adding the successive samples together, and take the freezing-point of the mixture as the freezing-point of the sap of the plant.

This progressive concentration of the sap pressed from plant-organs had been, it was found, very convincingly established some years previously by André, who claimed to show by exhaustive chemical analyses of the plantorgans which he examined that, while the concentration of the sap expressed by increasing pressures rose, the proportion of the constituents remained the same.

The following experiments illustrate this progressive concentration of successive pressings from the same leaves. The leaves experimented upon were made up into a pellet, wrapped in two folds of fine linen and pressed in the jaws 
of a vice. As the vice was screwed up five or six drops of sap were pressed out and caught in a capsule; then the vice was opened and the same leaves re-arranged and pressed again. The sap exuding on this occasion was collected and kept separate from the first sample: similarly a third sample was prepared. Successive pellets of leaves were dealt with in the same manner; and so, from the same set of leaves, three samples of sap were obtained. These were called 1st, 2nd, and 3rd pressings. For each the depression of freezing-point $\Delta$ and, in some cases, the electrical conductivity $\mathrm{C}$, were determined. The latter measurements vere always made at $0^{\circ}$.

TAbLe 23.

Hedere helix: leaves.

Concentration of Sap in Suchestre Preshingis.

\begin{tabular}{|c|c|c|c|c|c|}
\hline \multirow{2}{*}{ No. of Experiment. } & \multirow[t]{2}{*}{ 1st Pressing. } & \multicolumn{2}{|c|}{ and Pressing. } & \multicolumn{2}{|c|}{ sred Pressing. } \\
\hline & & $\Delta$. & C. & $د$. & C. \\
\hline $\begin{array}{l}458,459,460 \\
462,413 ;, 464\end{array}$ & $\begin{array}{l}0.9998 \\
0.6944^{\circ}\end{array}$ & $\begin{array}{l}1.110 \\
0.782\end{array}$ & $\overline{0 \cdot 004 ! 36}$ & $\begin{array}{l}1.579= \\
0.888\end{array}$ & $0 \cdot \overline{0.513}$ \\
\hline
\end{tabular}

These figures show very plainly the increase of concentration in the later samples, and by inference the still higher concentration of the sap remaining behind in the pressed leaves. Hence, the concentration of the expressed sap may be expected, in all cases, to be less than the average concentration in the vacuoles of the tissues before the application of pressure.

The explanation of this increased concentration is not hard to find. When the pressure is first applied, almost pure water is extruded from the intact cells, for the protoplasmic membranes are sensibly semi-permeable, permitting water to pass out under pressure, but resisting, more or less completely, the passage of dissolved substances. 
Even in the first pressing many of the cells are usually burst, and their sap passes out with, and is diluted by, the much more dilute sap coming from the uninjured cells. Subsequent pressings contain the sap of a larger proportion of burst cells, and those which are now burst have had their sap concentrated by the former application of pressure. Hence, later samples must be more concentrated.

Necessity of rendering the protoplasm permeable.-From this consideration it appears that the problem of obtaining an average sample of the sap of a plant-tissue by pressure resolves itself into the problem of rendering the cell-membranes permeable, so that the application of pressure will force out solvent and solutes alike. It need scarcely be said that the method adopted for rendering the membranes permeable must not itself alter the concentration.

Exposure to toluene vapour first suggested itself as a means for rendering the protoplasm permeable. Owing to its extremely small solubility in water, it was hoped that it would not appreciably alter the freezing-point. By experment it was found that $\Delta$ for water saturated with toluene is approximately $0.024^{\circ}$, so that the correction for its vapour going into solution would not be a serious one.

Effect of toluene vapour on protoplasmic permeability.-To test the efficiency of toluene vapour in making the protoplasm permeable, a sample of leaves of Inederr helix was gathered; each leaf was halved, and two lots (A and B) were made, each containing a half of every leaf These two lots were then kept under the same conditions of moisture and darkness in closed glass vessels, the only difference being that in the ressel enclosing lot $\mathrm{A}$ an open capsule containing cotton wool soaked in toluene was placed. After 48 hours the freezing-point and the electrical conductivity of the sap pressed from the two lots were 
examined. In order to see if the increasing concentration which is characteristic of the sap pressed from untreated leaves occurs in the case of the sap pressed from the leaves exposed to toluene vapour, the sap from this lot was divided into first, second, and third pressings.

TABLE 24.

Heleve helix: leaves.

\lrcorner.

C.

Lot I (exposed to toluene), 1st pressing

$\begin{array}{lll},, & , & \text { 2nd pressing } \\ \text { Thd pressing }\end{array}$

Lot B (control). $1.865^{\circ} \quad(1.00521$

$1.875^{\circ} \quad 0 \cdot 00521$

$\left.1.856^{\circ} \quad 1\right) \cdot 005(60$

These results show that, with an exposure to toluene vapour of 48 hours, the protoplasm has become permeable, and no longer tends to keep back the dissolved substances of the vacuoles.

Of course, such prolonged exposure has the objection that during this process enzymes in the cells may considerably alter the nature of the dissolved substances, and so lead to a change in the concentration and constitution of the sap. Accordingly, experiments were made to determine if shorter exposures would be sufficient.

By means of these experiments it was found that shorter exposures, e.g., 1 to 5 hours, caused a marked concentration of the sap expressed when compared with that from the same leaves untreated; but much longer exposures were needed to render all the cells permeable, and so allow the sap obtained to be a fair sample of that of the uninjured leaf. The prolongation of the exposure makes the method objectionable. Accordingly, it was abandoned as unsatisfactory.

Protoplasm rendered permeable by intense cold. - The possibility that the protoplasmic membranes 
might be rendered permeable by exposure to low temperature then suggested itself. At the same time, it was apparent that the low temperature would have the advantage of arresting changes taking place in the tissues experimented upon. To this end the experimental tissues were immersed in liquid air. Tissues thus treated immediately become frozen hard. From the liquid air they were without delay transferred to a stoppered vessel to prevent the condensation of moisture on them from the atmosphere. When they had assumed the temperature of the surroundings, they were pressed in the usual manner.

TABLE 25.

Comparison of SAp' Extracten by Variols Methohs.

\begin{tabular}{|c|c|c|c|c|}
\hline $\begin{array}{l}\text { No. of } \\
\text { Expt. }\end{array}$ & Sap from & $د$. & $\mathrm{C} \times 10^{\circ}$ & $\begin{array}{c}\mathrm{C} \times 10^{3} \\
\Delta\end{array}$ \\
\hline 472 & Thedera heli.r, leaves untreated & $0.767^{2}$ & 40.3 & $5 \cdot 2$ \\
\hline 473 & Simne leaves frozen & 1055 & $(0) 5$ & $4 \cdot 8$ \\
\hline 476 & Part of same sample 19 hours & & & \\
\hline & in toluene vapour . . . . & 1.444 & 5.36 & $3 \cdot 8$ \\
\hline 477 & Hedera helix, leaves frozen . . . & $1 \cdot 239$ & 558 & 4.5 \\
\hline 478 & Same leaves as 477 in toluene & & & \\
\hline & vapour, 2 hours . . . . . . . & 0.747 & 422 & $5 \cdot 6$ \\
\hline $48: 3$ & Ilex riprifolinm, roots untreated & $0 \cdot 5: 31$ & 563 & $10 \cdot(i$ \\
\hline 484 & Same sample as 483 frozen & 0.682 & 629 & $9 \cdot 2$ \\
\hline 486 & Ilex uquifolium, leaves untreated & $0 \cdot 651^{\circ}$ & 433 & $6 \cdot 6$ \\
\hline 487 & Part of sample 486 frozen . . . & $1 \cdot 130$ & (i19) & $5 \cdot 4$ \\
\hline 494 & Iris germanicu, rhizome untreated & $0.450 ?$ & 128 & $2 \cdot 8$ \\
\hline $4 \%$ & Same rhizome as 494 frozen . & $0 \cdot 8: 9$ & 335 & $4 \cdot 0$ \\
\hline 510 & Pyms mulus, fruit untreated. & $1.507^{2}$ & 171 & $1 \cdot 1$ \\
\hline 511 & Same fruit as in 510 frozen & $1 \cdot 919$ & 161 & $0 \cdot 8$ \\
\hline 512 & Citrus ammentium, fruit untreated & $1 \cdot 0+4$ & -- & -- \\
\hline 513 & Sime fruit frozen . . . . & $1.206^{\circ}$ & 208 & 1.7 \\
\hline 518 & Citrus limomm, fruit untreated & $1 \cdot 0: 33$ & 291 & $2 \cdot 8$ \\
\hline 519 & Some fruit frozen . . . . & $1 \cdot 089$ & 345 & $\because 3 \cdot \omega$ \\
\hline 514 & Solremm lubersism, tuber untreated & $0.52: 3$ & 555 & $11 \cdot 0$ \\
\hline 515 & Sime tuber frozen . . . . & $0.588=$ & $58: 3$ & $9 \cdot 9$ \\
\hline illi & T'itis vinifere, fruit untreated & $2: \pi\left(i 7^{2}\right.$ & 132 & 0.5 \\
\hline 517 & Same fruit frozen . . . . & $3 \cdot 185$ & 112 & $11 \% 3$ \\
\hline $5: 38$ & Chumarerops humilis, leaf untreated & $0.365^{\circ}$ & $2 ! 9$ & $8 \cdot 1$ \\
\hline $5: 39$ & Same leaf frozen. . . . . . . & $1 \cdot 5 \cdot 29$ & 752 & $4 \cdot 9$ \\
\hline 5.12 & Chumaprops humilis, leaf untreated & (). 5.99 & 508 & $8 . \overline{5}$ \\
\hline 5.54 & Same leaf frozen . . . . . . & $1.517^{2}$ & $9 \geq 6$ & $6 \cdot 1$ \\
\hline $5+9$ & Bete vulyaris, root untreated & $1 \cdot 473^{2}$ & 570 & $3 \cdot 4$ \\
\hline $5 ., 1$ & Same root frozen . . . & $1.71 ; 1^{\circ}$ & 5.55 & $3 \cdot 2$ \\
\hline
\end{tabular}


It is generally found that after liquid air treatment comparatively small pressure is needed to obtain the sap, which flows easily from the tissues without requiring the disruption of the cells. At the same time the sap is much freer from the débris of broken cells than that from an untreated leaf. 'This sap has always given a greater depression of freezing-point and usually a higher conductivity than that from the same tissues untreated. Furthermore, these determinations differed from similar measurements made on sap of the same tissues exposed to toluene vapour. The results are tabulated on page 182 .

The numbers in that table show conclusively that the concentration of the sap pressed from the untreated tissues seldom approximates to the concentration of that obtained from the same tissues after freezing. It is hard to see how freezing could be supposed to alter the concentration of the sap, whereas, as we have already seen, it is certain that the sap pressed from living tissues may be considerably less concentrated than that which remains behind, and consequently less concentrated than that which was originally in the cells of the tissue before the pressure was applied.

Sap unaltered by liquid air.- It is well known that chemical changes are arrested at such low temperatures as that of liquid air; however, it seemed just possible that changes might take place in the proteids or in the protoplasm just as the cold was being applied, and that these changes might lead to an increase in the quantities of dissolved substances in the sap.

To set this doubt at rest, determinations were made of the freezing-points of the sap pressed from the untreated roots of Beta vulgaris and from the leaves (also untreated) of Chamaerops humilis before and after freezing in liquid air ; also of the fluids of an egg and of bull's blood under the same conditions. These liquids were not cleared in any way of the matter suspended in them, so it is certain 
that they contained ample amounts of proteids and of protoplasm to test the point. The results were as follows:

TABLE 26.

Effect af Ligeid Air an Tegetale axt Aximal Fluins.

\begin{tabular}{|c|c|c|c|}
\hline $\begin{array}{l}\text { No. of } \\
\text { Explt. }\end{array}$ & - & $\Delta$. & $\mathrm{C} \times 10 \%$ \\
\hline $5+9$ & Untreated sap of root of Beta & $1.473=$ & 570 \\
\hline 550 & Same sap frozen in liquid air . . & 1.47 & 574 \\
\hline 52 & Entreated sap of leaf of Chamaerojs & $0.599^{2}$ & 508 \\
\hline 5.53 & Same saj frozen in liquid air . . & $0.575=$ & 502 \\
\hline 479 & White of egg untreated . . & 0.445 & 一 \\
\hline 480 & White of egg frozen in liquicl air . & 0.445 & -- \\
\hline 481 & Bull's blood untreated . . . . & $0 \cdot 616^{3}$ & - \\
\hline 482 & Bull's blood frozen in hiquid air & $0.584^{\circ}$ & - \\
\hline
\end{tabular}

In no case was a sensibly greater depression detected after exposure to liquid air. The diminution in the depression observed in the experiments 553 and 482 appears to be due to the expulsion of dissolved gases. The frothing of the sap of Chamaerops on thawing after treatment with liquid air was very marked. This was not looked for in the case of the bull's blood.

Hence it appears that there is no reason to believe that the application of liquid air leads to a concentration in solutions in contact with proteids and protoplasm.

Again, the sap extracted from plant-organs after exposure to liquid air does not cause plasmolysis of the cells in these organs. This was demonstrated both for the sap of the root of Beta and for the leaf sap of Chamaerops. In the case of the latter the demonstration is particularly convincing. Sap from the frozen leaf was found to have a depression of $1.517^{\circ}$, while the value of $\lambda$ for that of the untreated organ was $0.599^{\circ}$. Yet the former caused no plasmolysis in the cells of a section of the leaf mounted in it, even after twenty minutes. The difference in concentration indicated by these two freezing-points would of 
course rapidly produce plasmolysis. This clearly shows that no appreciable concentration has been effected by the treatment, and that the sap pressed from the untreated organ is not isotonic with that in the vacuoles of its cells.

Of course the application of liquid air cannot stop changes taking place while the sap is being pressed, as is evidenced by the production of colour in the sap of many tissues during the process.

The cells treated with liquid air seem to be rendered completely permeable. This appears from the fact that the sap is so easily pressed from the tissues after the exposure, often without any disruption of the cells. Also the concentration of successive pressings from these frozen tissues remains sensibly the same, as is shown in Table 27:-

TABLE 27.

Medera holix: leaves.

No. of

Expt.

$47: 3$

4.4

Exposed to linguid air, 1st pressing

$1 \cdot 255$ 2nd pressing .

$\Delta$.

$\mathrm{C} \times 10^{5}$.

$1 \cdot 261$

606

597

Hence we may assume that the sap so obtained is a fair sample of that of the uninjured tissues.

It will be noticed that in most instances the difference in conductivity between the sap of organs treated with liquid air and that of those untreated is not so marked as the difference in freezing-point. Comparison of the ratio $\mathrm{C} \times 10^{3}$

$\Delta$ for the pairs of experiments will make this clear.

This, perhaps, may be largely attributed to the greater permeability of the protoplasm to electrolytes, so that the sap pressed from the untreated organs is relatively richer in them. 
The result, however, was not anticipated, as from Andrés work it appeared that the proportions of the solutes present in the sap were not altered by their passage out of the organs under pressure. Hence it was to be expected that the ratio of the electrolytes to the other solutes would remain sensibly the same for the sap pressed from the living tissues and for that from tissues rendered permeable by liquid air.

The results for the rhizome of Iris germanica and for the fruit of Citrus limonum are exceptions, for in their case the sap extracted after freezing appears to contain a larger proportion of electrolytes to other solutes. This may very probably be assigned to actual differences in the sap from two apparently similar portions of the same massive organ. It is also possible that part of this effect is due to the greater viscosity of the sap from the treated organ.

These two factors probably also account for the anomalous fall in conductivity noticed in the sap of the fruit Pyrus malus and of Vitis vinifera obtained by means of liquid air.

It is certain that a much less extreme cold than that of liquid air would render the protoplasm permeable; but where this is available, it has the advantage of being very rapid in its application, and reduces the chances of change in the sap to a minimum.

Use of heat and chloroform vapour for the extraction.-. A few experiments were made with the object of finding out if the application of heat in a saturated atmosphere, or the exposure to chloroform vapour, might be used as a substitute for exposure to liquid air.

First, with regard to the application of heat, a quantity of leaves of Tlex aquifolium were divided down the midrib, and two samples, $A$ and $B$, were formed, each containing half of every leaf used. A was wrapped in moist bibulous 
paper, enclosed in a metal box, and placed for ten minutes in a water-oven at $95^{\circ}$. The half-leaves were then cooled on ice and pressed, the sap flowing out easily. Sample B was immersed in liquid air, and then pressed. The results of two pairs of comparative experiments on different sets of leaves were as follows:

TABLE 28.

Ilex aquifolimm: leaves.

No. of

Expt.

500

501

502

503
Sample $A$ from heated half-leaves Sample B from frozen half-leaves Sample A from heated half-leaves Simple B from frozen half-leaves s. $\quad \mathrm{C} \times 10^{\circ}$.

$1 \cdot 152^{3}$

677

$1 \cdot 2+14^{3}$

696

(1) $816^{3}$

504

$1 \cdot 30.5$

844

From these numbers it is evident that ten minutes' exposure to $95^{\circ}$ is not sufficient to render the membranes permeable with certainty. Owing to the likelihood of serious changes taking place in the sap, it woukd not be feasible to expose the leaves for longer to so high a temperature.

A similar objection was found to apply to the use of chloroform. For this test, samples A and B were prepared in the same way as in the foregoing experiment. A was then exposed to the vapour of chloroform for thirty minutes, pressed, and to the sap obtained a few drops of chloroform were added to ensure saturation. ' The freezingpoint was then determined in the usual way, except that the control-tube of the apparatus which usually contained pure water was charged with distilled water, saturated with chloroform. This change was, of course, not made when examining sample $B$, which before pressing had been immersed in liquid air. The conductivities were determined in the usual manner. 
TABLE 29.

Hedera helin: leares from s. aspect.

No. of

Expt.

49:2 Sample A, half-leaves exposed to chloroform

4!:3 Sample 13 , half-leaves exposed to liquid air
ง. $\quad(1 \times 10)^{5}$.

$1 \cdot 063 \quad 485$

$1: 315 \quad 51 \%$

Here again it appears that the exposure to chloroform vapour has not been sufficient, and it is evidently inadvisable to prolong the opportunity for spontaneous changes beyond thirty minutes.

It appears from the experimental work detailed in this chapter that the liquid pressed from untreated vegetable tissues is not an average sample of the sap contained in the cells of those tissues. However, exposure to intense cold, as may be conveniently effected by treatment with liquid air, renders the cells permeable and secures that the sap yielded up under pressure is not altered in concentration during its passage from the cells. Exposure to heat, tohene or chloroform vapour cannot be recommended for securing this end.

\section{Literatike.}

André, G., "Sur la composition des liquides qui eirculent dans le régétal," Compt. rend., 19ki, 142, p. 106;.

Id., "Sur la composition des sucs régétaux extraits des racines," Compt. rent., 1904; 143, p. 972.

Id., "Sul la composition des sues végétaux extraits des tiges et des feuilles," fompt. innd., 1907, 144, p. 270 .

ld., "Sur la migration des principes solubles dans le régétal," Commpt. icnd., 1907, 144, 1. :383.

Atkins, II. R. 1;., "Cryoseopic Determinations of the Osmotic Pressures

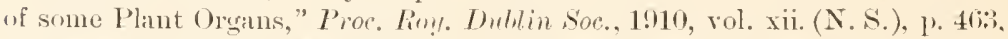
and Notes form the Buturical schos of Trinit" Colloge, Dublin, vol. ii, 1. 84.

Dixon, II H., and Atkins W. R. G., "On Osmotie Pressures in Plants ; and on a Thermo-electric Method of Determining Freezing Points," Proc. Roy. Mublin soc., 1910, vol. xii. (N. S.), p. 275.

ld., "()motic Pressures in Plants. I. Methods of Fxtracting Sap from 
Plant Or.gans," Proc. Roy. Dublin śre. 1913, vol. xiii. (N. S.), p. 422, and Notes from the Botanical Show of Trinity College, Dublin, vol. ii, 1. 152.

Id., “ Osmotic Pressures in Plants. If. Cryoscopic and Conductivity Measurements of some Vegetable Silps," Pror. Roy. Dublin Sor., 1913, vol. xiii. (N. S.), p. 434, and Notes form the Boteniond Sthend of Trinity Golloge, Inblin, vol. ii. p. 173.

Marie, C. H., and Gatin, C. I., "Déterminations cryos opiques effectuées sur les sucs régétaux." (191:2).

Maximow, N. A., "Chemische Schutzmittel der Pflanzen gegen Erfrieren," ber. d. Deulsth. But. Gesell., 1912, Bd. 30 s. 52, 29:3, and 504. 


\section{CHAPTER X}

OSMOTIE PRESSERES IN PLANTS

IIAving determined the freezing-point of the unaltered sap, it remains to calculate from it the osmotic pressure developed in the cells. The relation connecting these two quantities has been determined experimentally and also deduced theoretically. Nernst gives the equation :-

$\Delta \times 12 \cdot 03=0$ smotic pressure in atmospheres at 0 .

In Table 30 (p. 192), the depression of freezing-point and the calculated osmotic pressures are given under $\Delta$ and $\mathrm{P}$ respectively.

Factors tending to lower results.--It should here be mentioned that the osmotic pressure recorded is probably in no case so ligh as that obtaining in the cells of the leaves at the moment when they were collected; for when the leaves are plucked the tension in the water columns is destroyed and the cells of the leaves are free to gorge themselves with water from the tracheie. The dilution may be considerable if the cells were not fully distended when the leaves were gathered, and if they were severed from the branch with a considerable mass of the conducting tracts.

Even when this dilution may be neglected the osmotic pressure of the sap of the fresh leaf does not represent the maximum tension the osmotic substances in the cells can 
exert; ${ }^{1}$ for the fully distended cells of a leaf may be considerably reduced in size before wilting takes place. The variation in pressure which may be occasioned by this change of volume can be judged by comparing the osmotic pressure of the sap extracted from freshly plucked turgid leaves with that of the sap from part of the same sample when the first signs of wilting are apparent. An experiment of this nature was made on a sample of leaves of Fraximus oxyphylla. The sap from the fresh leaves had an osmotic pressure of $15.15 \mathrm{~atm}$., while that from the same sample just beginning to wilt had a pressure of 24.09 atm. A similar experiment with the leaves of

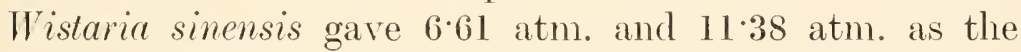
pressure in the turgid and wilting leaves respectively.

Again the osmotic pressures, calculated from the freezing points of the saps, should, when applied to the leaves at air temperatures be raised 10-15 per cent.

We may conclude, then, that the tensions developed on the upper ends of the water columns are usually at least as great as the pressures recorded in the table; but that inasmuch as fresh leaves were always examined, the pressures indicated in the table are by no means equal to the maximum tensions which may be exerted on the rising sap.

Determinations.-The majority of the determinations have been made on sap extracted by the liquid-air method, while some, which are marked in the table " untreated," have been made on sap simply pressed from the tissues. It is highly probable that, if the samples which yielded these measurements had been treated with liquid-air before pressing, higher values for the osmotic pressures would have been obtained. A similar criticism is applicable in a less degree to those marked "crushed and diluted." In these an extract

1 It may be pointed out that in low-growing plants high tensions are probably only developed when the supply of water to the roots is restricted. 


\section{TRANSPIRATION AND ASCENT OF SAP ch.}

of the crushed leares was examined and the osmotic pressure of the original sap was calculated, allowing for dilution, as before described.

Although the determinations made on sap extracted by these last two methods can only be regarded as minor limits, it appears that they also have a relative significance. Thus the sap yielded without treatment from three samples of leaves plucked simultaneously from three separate branches of Syringa vulgaris growing under similar conditions had freezing-points respectively $-1.570^{\circ}$, $-1.581^{\circ}$, and $-1.576^{\circ}$. Furthermore, the increase in concentration of the sap of the parenchymatous tissues from the root upwards to the leaf, which is always observable in the saps extracted by the liquid-air method, is paralleled by a similar gradient from below upwards in the saps extracted from these tissues without treatment.

Table :30.

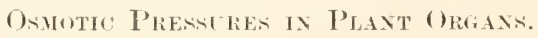

\begin{tabular}{|c|c|c|c|c|}
\hline $\begin{array}{c}\text { No. } \\
\text { of } \\
\text { Expt. }\end{array}$ & & $\begin{array}{l}\text { Ditte of } \\
\text { Obs. }\end{array}$ & $د$. & l'. \\
\hline 648 & Arep psoudoplutumus leaves. & $26 ; 8,13$ & $1 \cdot 207$ & $14 \cdot 52$ \\
\hline $5(j)$ & Agetioe americana & 11113 & $0.840^{\circ}$ & $10 \cdot 11$ \\
\hline $5(i 6 ;$ & Aloe plicutile & $11 / 13$ & $(1) \cdot 29 \cdot 2$ & $\because 5 \cdot 5$ \\
\hline 574 & Anthurinm curtrenum," leaves & 2713 & $0 \cdot 623$ & $7 \cdot 49$ \\
\hline $57 \div$ & .. mistullimum ". & 2713 & 0.727 & 8.73 \\
\hline 2 & $\begin{array}{r}\text { Cutulpu bignominides, leares (crushed and } \\
\text { diluted). . . . . }\end{array}$ & :3) $8,(19)$ & 1.905 & $2 \cdot 2 \cdot 92$ \\
\hline$: ;$ & ,, speciosit leares (crushed and diluted) & 30809 & $1 \cdot 724$ & $20 \cdot 73$ \\
\hline $5: 1 ;$ & Cerasus laurocerasus, leaves. . . . . & 281113 & $1 \cdot 522$ & $18 \cdot 31$ \\
\hline 5i3:; & Chamaerops humilis , & $29,111: 3$ & $1 \cdot 598^{2}$ & $19 \cdot 2 \cdot 2$ \\
\hline$\therefore 28$ & Condigline anstralis & $26,11,13$ & $1 \cdot 116$ & $13 \cdot 4: 3$ \\
\hline $1 \%$ & $\begin{array}{r}\text { Equisetrem telmutein, lateral branches (un- } \\
\text { treated) . . . . }\end{array}$ & $129(199$ & $0 \cdot 9+46^{2}$ & $11: 38$ \\
\hline 6011 & $,, \quad, \quad \quad$ main stems . . . . & 11913 & 0.878 & $10 \cdot 56$ \\
\hline $5: 3: 2$ & $\begin{array}{ccc}\text { Eucalmptus globulus, horiz. leaves } \\
.,\end{array}$ & $\begin{array}{lll}2 ! & 11 & 12 \\
2: 3 & 10 & 09\end{array}$ & $\begin{array}{l}0.970^{\circ} \\
0 \cdot 4: 33^{\circ}\end{array}$ & $\begin{aligned} 11 \cdot 68 \\
5 \cdot 33\end{aligned}$ \\
\hline 679 & Fugus silcutich var. pupumer, leaves. & $+101: 3$ & $1 \cdot 119^{\circ}$ & $13 \cdot 45$ \\
\hline 11 & Frurinus excolsior (untreated) . . . . & 2900 & $2 \cdot 097^{3}$ & $25 \cdot 2 \cdot 2$ \\
\hline 17 & ,, ax!lyhllu, fresh leaves (untreated) & 11,09 & $1 \cdot 239$ & $15 \cdot 15$ \\
\hline 18 & $\begin{array}{c}\text { leaves begimning to } \\
\text { wilt (untreated) }\end{array}$ & $1190 !$ & $2 \cdot 009$ & $24 \cdot 09$ \\
\hline
\end{tabular}


T'ABLE 30-(contd.).

Onhotic T'ressures in Plant Oruanis-(contd.).

\begin{tabular}{|c|c|c|c|c|c|}
\hline $\begin{array}{c}\text { No. } \\
\text { of } \\
\text { Expt. }\end{array}$ & & & $\begin{array}{l}\text { Dite of } \\
\text { Obs. }\end{array}$ & د. & $\mathrm{P}$. \\
\hline (i14 & Hederr helir, N. aspect, leaves . & . & $19 / 313$ & $1 \cdot 468$ & $17 \cdot 6 ;$ \\
\hline 615 & ,, ,, S. asprect, leaves. & . & $19: 31: 3$ & $1.55 \%$ & $18 \cdot 70$ \\
\hline 673 & Helianthus multiflores , , . . & & 21013 & 0.764 & $9 \cdot 18$ \\
\hline 617 & Ilex apuifolimm, mature ultimate leaves & & 19,313 & 1.572 & $18 \cdot 91$ \\
\hline bibio & $, \quad, \quad$ roots . . . . . & . & 10913 & $1 \cdot 156^{\circ}$ & $13 \cdot 91$ \\
\hline 498 & Tris yermunira, leaves . . . . & . & $1511 / 12$ & $1 \cdot 085$ & $1: 3 \cdot 05$ \\
\hline $4 ! 5$ & $, \quad,, \quad$ rlizome . . . . . . & . & $15 / 11 / 12$ & $0 \cdot 829$ & $9 \cdot 97$ \\
\hline 496 & 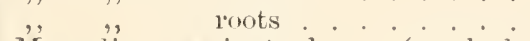 & & $15 / 11 / 12$ & $0 \cdot 764^{3}$ & $9 \cdot 20$ \\
\hline 7 & $\begin{array}{l}\text { Mammolia acuminata, leaves (crushed } \\
\text { diluted). }\end{array}$ & and & & & $2 \cdot 2 \cdot 34$ \\
\hline 548 & Monstera deliciosa, leaves . . . . . & & & & $6 \cdot 64$ \\
\hline 546 & Musa sapientum ,, . . . & & & & $9 \cdot 44$ \\
\hline 545 & Pussiflora quudrungularis, leaves & & $1012 / 12$ & $62^{3}$ & $13 \cdot 98$ \\
\hline 677 & Pinus laricio & & $3,10,13$ & $1 \cdot 174$ & $14 \cdot 13$ \\
\hline 573 & Platycerium alcicone & & (1, 13 & $0 \cdot($ & $7 \cdot 51$ \\
\hline 576 & Polipodium irioides , & & $7 / 1 / 13$ & $0 \cdot 886$ & $10 \cdot 65$ \\
\hline 651 & Populus albu, spring leaves . . & . & $8 / 8,13$ & $1: 326$ & $15 \cdot 95$ \\
\hline 652 & $,, \quad,$, summer leaves & & & $1 \cdot 487^{\circ}$ & $17 \cdot 88$ \\
\hline 653 & , bark at $40 \mathrm{ft}$. level & & & $1 \cdot 2$ & $14 \cdot 6 \cdot$ \\
\hline 65 &,$"$, of root . . . . & & & $1 \cdot 101$ & $13 \cdot 23$ \\
\hline 1 & $\begin{array}{r}, \quad \text { balsamifera, leaves (crusherl } \\
\text { diluted). }\end{array}$ & and & & & \\
\hline 96 & Pteris aquilima, leaves (untreated) & & & $19^{\circ}$ & $7 \cdot 44$ \\
\hline 547 & Sacharmm officina & & 10 & & $5 \cdot 8: 3$ \\
\hline 572 & Selaginella mertensii, leaves and stems & & $1 / 3$ & & $10 \cdot 16$ \\
\hline 634 & Syringa vulgaris, leaves . . . . . . . & & & $2 \cdot 119=$ & $25 \cdot 50$ \\
\hline$\overline{5}$ &, (crushed and dilu & uted) & & $2 \cdot 234^{\circ}$ & $26 \cdot 87$ \\
\hline 39 & ,, $,, \quad,$, (untreated). & & 13 & $2 \cdot 1$ & $25 \cdot 68$ \\
\hline 24 & Ulmus campestris, leaves (untreated) & & & $1.550^{\circ}$ & $18 \cdot 64$ \\
\hline 27 & Vitis veitchii, leaves (untreated). . . & & $6 / 9,09$ & $0.783^{3}$ & $9: \because 4$ \\
\hline 84 & $\begin{array}{r}\text { Wisturin sinensis, leaves beginning to } \\
\text { (untreated). }\end{array}$ & wilt & & & \\
\hline 665 & leaves fresh . . & & 30913 & $0.709^{\circ}$ & $8 \cdot 52$ \\
\hline
\end{tabular}

Tension in tracheæ indicated by osmotic pressures in leaves.-In the foregoing table, as a rule, only the maximum pressure observed in the leaves or the roots of each species is recorded. As a matter of fact, wherever sought, great variations were found between different individuals of the same species, and in the same individuals in different positions and under different conditions. In every case, 
the osmotic pressure of the leaf cells (ranging as it does from 5 to $27 \mathrm{~atm}$.) was such that it was well able to sustain the tension necessary to lift the water current in the plant and to keep the cells turgid during normal transpiration. Renner's figures obtained by a different method are in accordance with this result. He compared the flow due to the tension set up by the leaves, with that caused by a known difference of pressure, in branches in which the resistance had been artificially increased. The tension thus indicated varied between 10 and 20 atmospheres.

Variations in osmotic pressure.-With regard to the causes of the variations in pressure much still has to be found out, but the results obtained up to the present may be of interest.

In the first place, a series of experiments was designed to test the possibility that the osmotic pressure of the sap of the leaves on any region of the branches is defined by the resistance which has to be overcome in drawing the transpiration current from the roots to that part. Ewart had previously looked for such a difference by means of the plasmolytic method, but he seems to have encountered difficulties and left the question undecided. In the following experiments sap was pressed from leaves taken at a considerable height above the ground; and its freezing-point was compared with that of leaves from near the groundlevel. The results of pairs of experiments bearing on this question are shown in Table 31 (p. 195).

It there appears that, on the whole, taking the experiments in pairs, the leaves at the lower level contained sap with a lower (sometimes considerably lower) osmotic pressure than that of higher leaves. But experiments are far from satisfactorily bearing out this view; for it has been noted that the osmotic pressures of the sap from leaves at the same level, but at different times and under different conditions, by no means correspond in each case, although they are often higher than those of leaves at a lower 
level. 'The reverse, however, is sometimes found, as in Experiments 6 and 7, where the pressure in the lower is much greater than in the higher leaves.

'T.IBLE 31.

()smotic Pressure ann Height above Grounil Comparil.

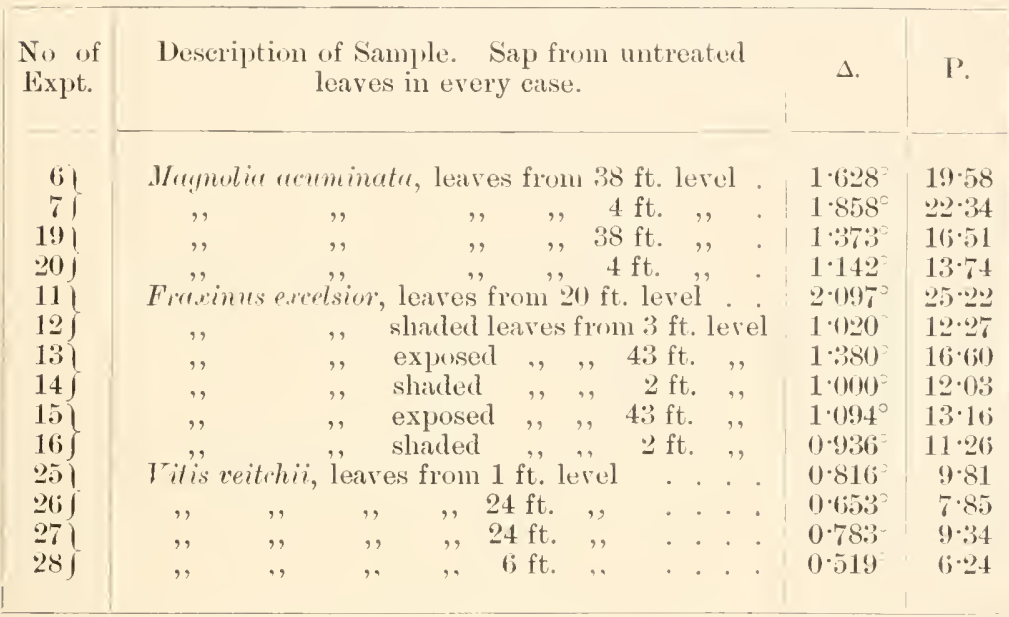

The possibility that these discrepancies might be due to resistance in the conducting tracts apart from that offered by the hydrostatic head had to be examined, and Experiments 80, 81, 82, 83 on Wistaria sinensis and 21, 22, 23, 24 on Ulmus campestris (recorded in Tables 32 and 33 respectively) were carried out.

Table 32.

Wistaria sinensis: sap from untreated leares.

\begin{tabular}{|c|c|c|c|c|}
\hline $\begin{array}{l}\text { No. of } \\
\text { Explt. }\end{array}$ & Deseription of Sample. & $\Delta$. & P. & M. ${ }^{1}$ \\
\hline 80$)$ & Shaded, from $3 \mathrm{ft}$. level on basal sloot . . & $0.412^{\circ}$ & 4.95 & 149 \\
\hline $81 j$ & $\begin{array}{l}\text { Exposed, from } 3 \mathrm{ft} \text {. level at distal end of } \\
\text { horizontal branch } 65 \mathrm{ft} \text {. long . . . . }\end{array}$ & $0.4: 37$ & $5 \cdot 25$ & 169 \\
\hline 821 & Fxposed, from $27 \mathrm{ft}$. level . . . & 0.550 & $6 \cdot 61$ & $1(i=$ \\
\hline $8: 3 i$ & Shaded, from : $\mathrm{ft}$. level . . . . . . & 0.443 & $5 \cdot 53$ & 169 \\
\hline
\end{tabular}

1 Under M are given the mean molecular weights of the solutes calculated from the dry weight and freezing-point of the solutions. 
Experiments 80 and 81 were made on sap from the leaves of an old Wistaria trained on a low wall. One sample of leaves was gathered from short branches near the base of the main stem. The leaves were about three feet over the ground. The second sample of leaves was taken from the terminal branches of a stem running 65 feet approximately horizontally along the wall at a level of about three feet. Here again we find a slight difference in pressure in favour of the distal leaves.

Table: 3:3.

Ulmus compest,is: sap from untreated leaves.

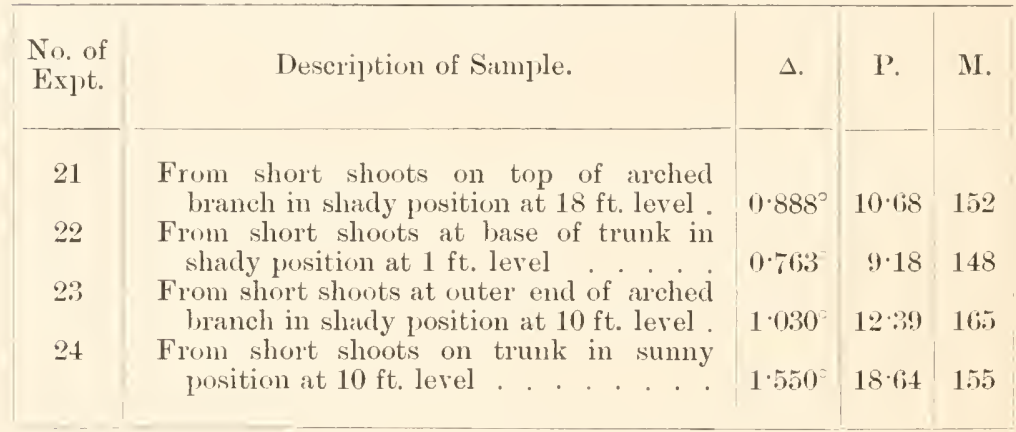

The numbers in Table 33 show the real meaning of the results which had apparently indicated that the level was the controlling factor in determining the osmotic pressure. If the hydrostatic head defined the pressure of the leaves, it is evident that the pressure in the leaves examined in Experiment 21 should have been the greatest; if the resistance of the water-tracts were the controlling factor, those of Experiment 23 should have had the maximum pressure, which should have been much greater than those of 22 and 24. The actual order is $24,23,21,22$. From this it is clear that the resistance of the water-tracts was not the controlling factor of the pressure; accordingly some other cause for its variation must be sought. This cause seems to be principally the fluctuations in the sugarcontent of the leaves due to difference in illumination. 
In Experiments 21 and 22, the leaves of which are from shaded positions, smaller pressures are found than in Experiment 24, which was performed on sap from leaves in a sunny position. Experiment 23, on leaves coming from the outside of the crown facing a clear north sky, and being consequently better illuminated than the other two samples, used in 21 and 22 , reveals a higher pressure than they, though this pressure is considerably lower than that found in 24 .

This effect of illumination in raising the osmotic pressure in the cells of leaves appeared in a great number of experiments. Conversely it was also found that the pressure gradually falls when they are cut off from light. 'The difference thus produced may amount to $14 \cdot 11 \mathrm{~atm}$.

These experiments, taken in conjunction with observations on the mean molecular weight of the solutes, amply show that conditions favouring the formation of soluble carbohydrates are those which raise the osmotic pressure; and vice versa, the osmotic pressure falls when conditions are unfavourable to the formation of these substances, while not preventing their consumption. It was only to be expected then that the cells in organs where these substances are normally stored should have high osmotic pressures. This point is well illustrated by the high pressures found in the fruit of Vitis vinifera $(38 \cdot 3 \mathrm{~atm}$. $\left.\Delta=3 \cdot 185^{\circ}\right)$, and of Pyrus malus $\left(23 \cdot 1\right.$ atm. $\left.\Delta=1.919^{\circ}\right)$, and in the root of Beta vulgaris $\left(21 \cdot 2\right.$ atm. $\left.\Delta=1 \cdot 761^{\circ}\right) .^{1}$

1 Another point of interest with regard to the distribution of osmotic pressure in plants may be mentioned.

In almost every case it was found that the older leaves, cuteris paribus, had a higher osmotic pressure than the younger leaves on the same plant. This was observed in Syringa vulgaris, Vitis veitchii, Eucelyptus globulus, Hedera helix, and especially in Ilex aquifolinm. The leaves of the last named evergreen persist through four or five periods of growth, and it is generally found at any time that the osmotic pressure of the sap of the leaves of each successive growth is lower than that of those which precede it. 'Thus taking the mean of many observations made throughout the year on the sap from untreated leares, the osmotic pressure of the sap of the ultimate three 
Inasmuch as the conditions favouring the formation and storage of soluble carbohydrates are generally best realised in the higher levels of trees, it is not surprising to find that the greater pressures are often developed there, while smaller pressures usually occur in leaves, etc., near the ground level. But as in every case the pressure observed is much greater than the force required to overcome the resistance of the water-tracts; it is evidently in no way defined by that resistance.

Relation of osmotic pressure to the breaking stress of the cell-walls. - The presence of these high pressures, amounting to about $30 \mathrm{~atm}$. in the mesophyll, naturally raises the question as to how far the tensile strength of the cell-walls is taxed by their distending action.

When these cells are inadequately supplied with water it is evident that their walls may be barely distended and there will be no tension in them. On other occasions when the supply is sufficient their walls may be stretched by nearly the whole osmotic pressure of their vacuoles.

The actual tenacity of cell-walls has been determined by various investigators. The following determinations are quoted from Pfeffer. Schwendener found that sclerenchymatous fibres could support from 15 to 25 kilo. per sq. mm. before breaking, Weinzierl estimated the tenacity of the fibrous cells in the leaves of Phormium tenax at 20.33 kilo. per sq. mm., and those of Allium porro at 14.71 kilo. per sq. mm. Ambronn gives the breaking strain for the walls of collenchymatous cells at 8 to 12 kilo. per sq. mm.

More recently the author estimated the tenacity of

leaves on the last growth was 8.88 atm. $\left(\Delta=0.738^{\circ}\right)$; of the penultimate three leaves on the last growth was 9.26 atm. $\left(\Delta=0.750^{\circ}\right)$; of the leaves on the penultimate growth, $10 \cdot 61 \mathrm{~atm} .\left(\Delta=0 \cdot 882^{\circ}\right)$, and of the leaves on the antepenultimate growth, $11.76 \mathrm{~atm} .(\Delta=0.978)$. If these observations had been made on sap extracted by the liquid-air method considerably higher pressures would have been obtained. But observations made by this latter method fully confirm the rise in pressure with age. 
cellulose by loading very gradually a single fibre, detached from the seed of Gossypium, until it broke. By observing the breaking weight and the area of the cross-section where the break occurred, the tenacity was obtained.

Different fibres gave tenacities of 37 kilo. to 60 kilo. per sq. mm. The cell-walls of these fibres are of pure cellulose, and having been taken from fresh seeds and soaked in water, were in the imbibed condition, and consequently resembled in their properties the imbibed cellulose walls of the mesophyll cells. As in no case can the fibre support a stress greater than its tenacity we must regard the lower results as due to flaws in the fibres, and the highest figures as giving the actual tenacity of cellulose.

The cells of the leaf approximate in form more or less to cylinders; they are seldom, if ever, spheres. Therefore the stress in the cellulose wall will never exceed the internal pressure $P$ acting over an area $\pi r^{2}$ divided by the sectional area of the cell-wall $2 \pi i t$, where $t$ is the thickness of the wall, and $r$ the radius of the cylindrical or spherical cell.

$$
\text { Stress per sq. mm. of celluluse }=\frac{P \pi r^{2}}{2 \pi r t} .
$$

In Cytisus laburnum, for example, the palisade cells are approximately $0.06 \mathrm{~mm}$. long, $0.0175 \mathrm{~mm}$. in diameter, and their cell-walls are $0.001 \mathrm{~mm}$. thick. The osmotic pressure may rise to $30 \mathrm{~atm}$., or about $300 \mathrm{gr}$. per sq. mm.

$$
\text { Stress }=\frac{300 \times 0.0087}{2 \times 0.001}=1305 \mathrm{gr} . \text { per sq. } \mathrm{mm} \text {. }
$$

The observations quoted above show that the breaking stress of cellulose is more than $50,000 \mathrm{gr}$. per sq. mm. Consequently an osmotic pressure of $30 \mathrm{~atm}$., even if entirely borne by the cell-wall, will not tax it to near its limit.

Probably the greatest value for the diameter of any of 
the cylindrical cells of the leaves is under $0.05 \mathrm{~mm}$, but even in cells having this diameter and having a thickness of wall equal to $0.001 \mathrm{~mm}$. only, it would require a pressure of $100 \mathrm{~atm}$. to tax the cell-wall to its breaking point. Consequently we may take it that the osmotic pressures of the leaves never seriously tax the tensile strength of the cell-walls.

\section{Literattre.}

Dixon, H. H., "The tensile Strength of Cell-walls," Ann. of Butany, 1897, vol. xi, p. 585 .

Id., "O) the Physics of the Transpiration Current," Notes from the Buteniral Sichool of Trinity Colley Dublin, vol. i, p. 57.

Id., "Transpiration and the Ascent of Sap," Progressus Rei Botunicue, 1909, Bd. iii, s. 1.

Dixon, H. H., and Atkins, W. R. G., "()n Osmotic Pressures in Plants ; and on a Thermo-electric Methol of Determining Freezing Points," Proc. Roy. Dublin Soe, 1910, vol. xii (N.S.), p. 275.

Id., "Changes in the Osmotic Pressure of the Sap of the Developing Leaves of Syringu inlgaris," Proc. Roy. Duhlin Soc., 1912, vol. xiii (X.S.), 1. 219, and Notes from the Botanical School of Trinity College, Dublin, vol. ii, p. 90.

Id., "Tariations in the Osmotic Pressure of the Sap of Ilex aquifolium," Proc. Romy. Dublin Soc., 1912, vol. xiii (N.S.), p. 229, and Notes from the Butanical School of Trinity College, Dublin, vol. ii, p. 111.

Id., "Variations in the Osmotic Pressure of the Sap of the Leaves of Hederce helin," Proc. Roy. Dublin Sre., 1912, vol. xiii (N.S.), p. 239, and Notes from the Protenical Siherel of Trinity College, Dublin, vol. ii, p. 103.

Il., "()smotic Pressures in Plants. I. Methods of Extracting Sap from Plant Organs. II. Cryoscopic and Conductivity Measurements on Some Vegetable Saps," Proc. Roy. Dublin Soc., 1913, vol. xiii (N.S.), pp. 422, 434, and Notes from the Butenical sichool of Trinit! College. Dublin, rol. ii, pp. 152, $17: 3$.

Pfeffer, W., "Physiology of Plants," Translated by A. J. Ewart (Oxford 1903.)

Renner, ()., "Experimentelle Beiträge zur Kenntniss der Wasserbewegung," Flore, 1911, Bil. 19:3, Hft. 3, 171. 


\section{CHAPTER XI}

ENERTY AVAIIABLE FOR RAISING THF SAP

Energy available for secretion.-It has been pointed out earlier that, under normal conditions of transpiration, water is probably extracted from the mesophyll cells and exposed on the outside of these cells to evaporation by a secretory action. Hence the lifting force of the transpiration current in these cases may be attributed to the expenditure of energy by the protoplasm of the leaf-cells. For this the energy entering the cells at the moment, and that stored as energetic compounds in the protoplasm, are available.

Energy entering the leaf.-With regard to the former the data determined experimentally by Brown and Escombe are applicable.

By use of a Callendar radiometer they found that the maximum amount of energy incident on leaves of plants in Kew in full sunshine amounted to 1.0 to 0.5 cal. per sq. cm. per minute. Had the observations been made in a higher position, and in one free from the veil of smoke hanging over Kew, this amount would have been greater. The coefficient of absorption of the leaves experimented upon averaged about $0^{\cdot} 7$. Consequently each square centimetre should absorb at least $0.5 \times 0.7$ cal. per minute of radiant energy. Of this it was found about 0.25 cal. might be required for the vaporisation of the water given off (allowing $42 \times 10^{-5} \mathrm{gr}$. to be transpired per sq. 
cm. per minute), while less than 1 per cent. or 0.0035 cal. was used in photosynthesis, leaving more than 0.0965 cal. available for carrying out other processes in the leaf and for raising its temperature above the surroundings.

External energy of this nature may not be available for secretion when the temperature is high and the sunshine is veiled; for then vaporisation lowers the temperature of the evaporating surfaces, and these possibly absorb the energy before available. Thus in an experiment on a leaf of Helianthus annuus under such conditions Brown and Escombe found :-

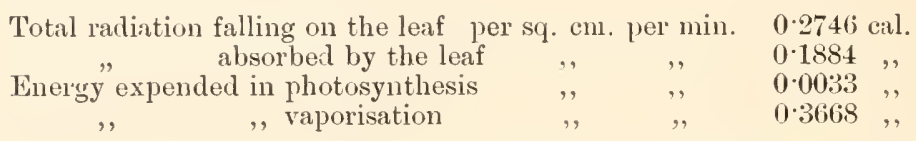

In this case 0.1817 cal. must have been derived from the surroundings, and hence very probably the cells of the leaves drawing forward the water lost rather than gained energy in the process.

Energy set free by respiration.--With regard to the stored energy set free by respiration and at least partially available for secretory processes, precise figures are not to hand; but we may infer from certain observations the order of the amounts available.

Aubert records that $1 \mathrm{gr}$. of leaves of Hedera helix rises in respiration $252 \cdot 1$ c.mm. of oxygen per hour. Assuming a hexose is oxidised according to the equation

$$
\mathrm{C}_{6} \mathrm{H}_{12} \mathrm{O}_{6}+6 \mathrm{O}_{2}=6 \mathrm{CO}_{2}+6 \mathrm{H}_{2} \mathrm{O}+677 \cdot 2 \times 10^{3} \mathrm{cal} .
$$

we find that the respiration of $1 \mathrm{gr}$. of these leaves generates $1 \cdot 27$ cal. per hour. 1 gr. of leaf has about $45 \mathrm{sq}$. cm. under surface. Therefore the respiration of $\mathrm{I}$ sq. cm. of Hedera leaf would generate 0.0282 cal. per hour. The amount of water vapour exhaled from $1 \mathrm{sq}$. cm. will probably not exceed, under normal conditions, 0.0252 gr. per hour. Consequently for every gramme of water vapour given off there may be as much as a calorie available for raising it 
through the water tracts and secreting it on the outside of the leaf-cells.

No energy need be spent in separating the water from the solution in the cells, inasmuch as there is a constant supply of water on the inner side bordering on the trachex, and the water passing out to the seat of evaporation is immediately replaced by that coming in from the vascular bundles.

Hence, taking into account only respiratory energy, we have available for raising the water in a tree and exposing it for evaporation something approximating to one calorie for every gramme of water given off.

It has previously been shown that the resistance to be overcome in moving the transpiration current through the stems of trees is not much more than equivalent to a head of water equal to the length of the stem. Hence, as each cubic centimetre of water given off from the leaves of a tree $100 \mathrm{~m}$. high requires an expenditure of work to the extent $100 \times 100 \mathrm{gr}$. $\mathrm{cm}$. to lift it, we must add the same quantity of work to overcome the resistance of the conducting tracts; and the total work for raising a cubic centimetre in the tree will be about $2 \times 10^{4} \mathrm{gr}$. $\mathrm{cm}$., or in calories $\begin{gathered}2 \times 10^{4} \\ 428 \times 10^{2}\end{gathered}$, i.e., about 0.5 calorie.

As we have seen, the respiratory energy of the leat supplies something of the order of one calorie for each cubic centimetre of water given off and hence would be quite adequate to do the raising of the sap from the root to the leaves.

Raising of sap by evaporation:-We have already seen that under certain conditions, e.y., when evaporation from the transpiring cells removes water faster than their secretory powers can provide it, the menisci formed in the substance of their walls must support the tensile columms of water in the plant. Evaporation from these menisci must provide the traction to raise the 
water. The tension is transmitted downwards through the roots to the absorbing cells. In these cells the actions which occur must be the converse of those occurring in the mesophyll. At the root the entry of water depends on the gradient of pressure on passing from the outside of the root to the inside of the trachere. The fall of pressure due to the tension in the water is continuous all the way up the stem to the leaf. Thus we may regard the flow of water up the highest tree as due to the evaporation and condensation produced by the difference between the vapour pressure in the soil spaces and that obtaining round

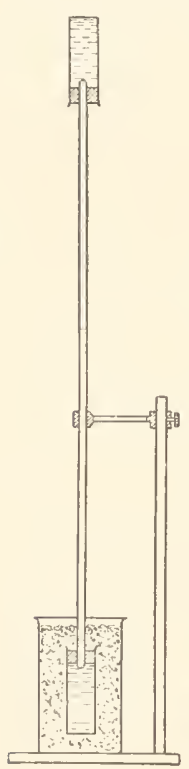

Fir. 2!). the leaves. The column of tensile water flows under the action of this difference from end to end of the plant.

Model.-The relations in these respects of the leaves to the roots may be illustrated by two porous pots connected hermetically by a glass tube about a metre long, the pots and the tube being completely filled with water (Fig. 29). If one is immersed in damp earth and the other supported above it, the difference in the state of saturation of the spaces surrounding each will be sufficient to cause condensation to take place on the surface of the lower pot and evaporation to proceed from the surface of the upper one. Motion of the water upwards may be demonstrated by the introduction of a mercurial index into the tube. If evaporation from the upper pot eliminates more water than condensation on the lower pot supplies, and if the liquid in the apparatus is in a state capable of standing tension, the stress developed by the reduction of the volume of water will drag in the menisci in the interstices of the walls of both porous pots, and make them more concave. This will have a twofold effect. The rendering of the upper menisci more 
concave tends to bring them into equilibrium with a lower vapour pressure, and consequently reduces evaporation, whilst the increased concavity of the lower menisci for the same reason renders them more ready to condense water vapour.

When this model has been in action for some time it will be noticed that the lower pot is at a higher temperature than the upper one. This difference of temperature is to be attributed to the "sorting demon" action progressing at the two surfaces. The lower menisci form a trap for more energetic water vapour molecules in the soil spaces, the upper retain the less energetic, while those which are more energetic escape into the surrounding space. Hence there is a gain of heat to the lower menisci, and a loss of heat by molecular convection from the upper. This cooling of the upper menisci maintains a regular flow of heat into the evaporating surfaces, which is constantly being abstracted again by the escaping molecules. As they escape, fresh molecules are drawn into their places from the water beneath by the attractions of those remaining in the menisci, and these mutual attractions find expression in the tensile strength of the liquid which joins the whole column to the evaporating menisci. Thus the loss of molecules from the menisci, kept up by the inflow of heat, is able, by calling into play the mutual attractions of the water molecules, to set up a stress in the water which may be transmitted to the lower menisci.

If we suppose, in order to imitate the conditions in the plant more closely, the outer surfaces of the two pots in the model to be covered with osmotic cells, we can readily see that the conditions are not essentially altered. The osmotic pressure in these cells need not change the gradients of pressure in the water. The osmotic pressure is the pressure which the dissolved substance exerts against the membranes of the cells, while the tension is in the solvent 
and is transmitted unaltered across the space in which the pressure of the solutes is also exerted.

In this respect the osmotic pressure acts just in the same way as a number of internal supports, keeping the cell turgid and preventing it from collapsing under the tension of the solvent which drags the water across the cell.

An evaporation engine.-The suitability of evaporating menisci as a mechanism for doing work may be

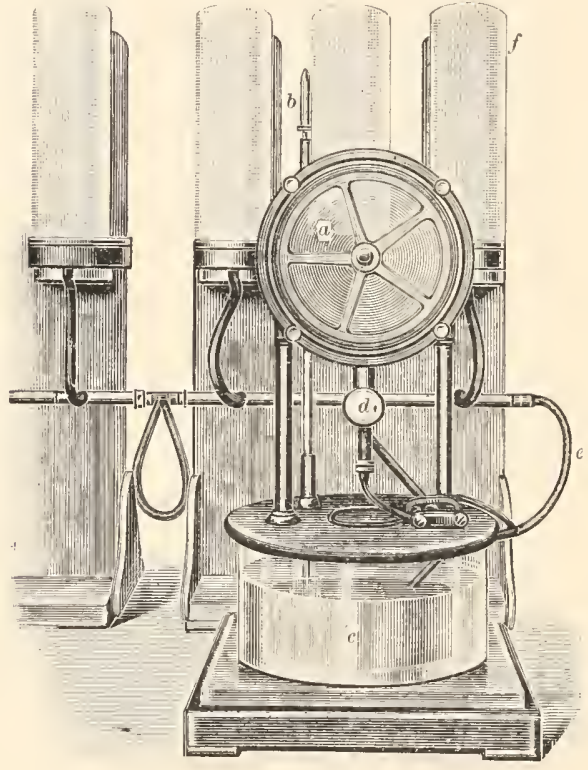

FIt: 30. illustrated by a model designed by Dr. Joly (see Fig. 30). A light fly-wheel is delicately hung in an air-tight chamber $(a)$. The short limb of a $\mathrm{J}$-shaped glass tube $(b)$ enters the upper part of this chamber from above, and its end, which is drawn to a fine nozzle, is vertically over the edge of the wheel. The longer limb of the tube dips into a well of water formed by a glass vessel (c) beneath the chamber. In the lower part of the chamber, beneath the wheel, is a small cistern $(d)$ also containing water, and from this cistern leads a branching tube (e) which distributes the water to twelve porous pots $(f)$, some of which are seen in the background.

Evaporation from the surface of the pots removes the water from the cistern. 'This diminishes the air pressure in the air-tight chamber, and the atmosphere, pressing on the surface of the water in the well beneath, urges 
water up the glass tube and through the fine nozzle. A series of drops is thus delivered on the edge of the wheel, and keeps it in constant rotation so long as there is water in the well beneath. In order to prevent the drops running round the edge of the wheel, this latter is covered with a thin coating of paraffin wax. By this means the drops remain fixed on the edge of the wheel just like the bucketfuls of water on the rim of an overshot wheel. Lest the drops should not readily detach themselves immediately on reaching their lowest position on the edge of the wheel, a camel's-hair brush, projecting out of the water in the cistern, is brought sufficiently close to the wheel to be able to drink the drops off its edge.

The arrangements adopted in setting up this model are shown in the accompanying illustration. The pots used were $16 \mathrm{~cm}$. in length and $5 \mathrm{~cm}$. in diameter, and thus the twelve expose a total effective evaporating surface of $3200 \mathrm{sq} . \mathrm{cm}$. With these arrangements the wheel might be kept in rotation apparently for an indefinite time, were it not that the paraffin surface on the edge of the wheel ceases to preserve its water-repellent character after a certain amount of wear, and then the drops from the nozzle run down round the wheel without causing its rotation. Notwithstanding this, the wheel may be easily kept in rotation for several days.

When the pots are replaced by a leafy branch the wheel is kept in lively rotation by the evaporation from the leaves. Variations in the speed of rotation of the wheel mark the variations in the amount of evaporation from the leaves. Thus, exposure to a draught or to a higher temperature, as in the case of the pots, accelerates the rate of rotation. In addition to this, the influence of light upon the stomata may be observed in the increased rate by day; while conversely darkness diminishes the rate of rotation.

It is interesting to trace in this model how the molar work of maintaining the wheel in rotation is derived from 
the molecular action at the evaporating surface. The molecules of the liquid with most vis viva emerge from the superficial layers of the liquid and, escaping by reason of their momentum from the attractions of their fellows, dash into the adjacent unsaturated space. Those with less energy cannot free themselves from the bonds of their neighbours and, if they get beyond the surface at all, they must needs fall back again into the body of the liquid. In this manner, from the surface of an evaporating liquid there is a constant sorting out of these molecules which possess the greatest amount of energy, while those with less remain behind. In consequence of this selective action, the unevaporated liquid, being composed of those which possess least energy, is maintained at a lower temperature, and therefore heat continues to flow into it from its surroundings. It becomes, in fact, a sink of energy. The heat, which is continually entering at the evaporating surface, prevents the liquid under ordinary conditions falling to a temperature much below that of the surrounding objects, and so increases the vis viva of the remaining molecules and enables evaporation to continue. This inflow of heat at the seat of evaporation is the ultimate source of the energy which raises the water to turn the wheel. This is true both for the evaporating surfaces of the porous pots and those of the leaves when secretion is not taking place.

In the model, the evaporating menisci do work raising the water, which in its passage turns the wheel; in an intact plant the work is done against the weight of the tensile transpiration stream and the resistance of the conducting tracts. The capillary forces of the menisci serve to hold the upper surface of the water in position whilst the inflowing heat, by discomnecting and removing molecules in these menisci, tends to shorten the water columns. The bonds cast off by the escaping molecules are transferred to others within the liquid, which are thus 
drawn to the menisci, and the tension is generated and maintained in the liquid. It is clear that the capillary forces of the menisci must be sufficiently great to support the tension needed to raise the water; hence the fine grain of the walls of the transpiring cells forms an essential link in the mechanism which utilises the energy entering at the evaporating surfaces in the leaves.

\section{Effect of tension in sap on evaporation.-} When the heat entering at the evaporating surfaces is, as just described, the source of the energy which raises the transpiration current, it is evident that less water will be evaporated from these surfaces than from similar surfaces under similar conditions, but relieved of the work of drawing the water through the conducting channels. Accordingly it is of interest to inquire what propcrtion the work of raising the sap bears to that of evaporation, or, in other words, how will the tension in the sap retard evaporation from the transpiring cells.

As was shown previously, each cubic centimetre of water given off from the leaves of a tree $100 \mathrm{~m}$. high requires an expenditure of work amounting to $0.5 \mathrm{cal}$. for transporting in the conducting tracts one cubic centimetre from the roots to the leaves.

To evaporate a cubic centimetre of water at $20^{\circ} \mathrm{C}$. requires $592.5 \mathrm{cal}$. Therefore the work done in transporting the water from the roots to the leaves of a $100 \mathrm{~m}$. tree will not require more than the one-thousandth part of the energy required for the evaporation of the water. Hence to obtain the energy needed to raise the water in a $100 \mathrm{~m}$. tree the amount evaporated will only be diminished by one-thousandth part. Even taking the highest and certainly excessive estimate of the resistance, the amount evaporated will only be reduced by one-thirtieth, if, in addition to evaporation, the energy absorbed by the leaf has to do the work of transporting the water from the roots. 


\section{IO TRANSPIRATION AND ASCENT OF SAP сн.}

Summary.-In bringing to a close this description of researches on Transpiration and Ascent of Sap, it seems suitable to summarise br efly the principal conclusions which they have established.

The transpiration stream is raised by secretory actions taking place in the leaf cells, or by evaporation and capillarity (imbibition) at their surfaces drawing water from the tracheæ. The state of saturation surrounding these cells determines which of these agencies is effective.

The configuration, physical properties, and structure of the wood render the conducting tracts of plants highly inefficient if regarded as a system for conveying water urged upwards by pressure or drawn upwards in the substance of the woody walls. The distribution of living cells in these tracts is such that their actions cannot account for the rise of water observed, and there is no reason to believe that the elimination of these activities, if attended by no secondary changes in the conducting tracts or transpiring leaves, will arrest the transpiration stream.

While thus structural and physiological evidence prevent us from accepting any of the previous physical or vital theories, the same configuration, physical properties, and structure of the wood compel us to admit that the water in the conducting tracts, when not acted upon by a vis a tergo, must pass into a state of tension. This state is necessitated by the physical properties of water when contained in a completely wetted, rigid and permeable substance which is divided into compartments. Therefore when root pressure is not acting and when the leaves of trees are transpiring, the cohesion of their sap explains fully the transmission of the tension downwards, and consequently explains the rise of the sap.

Resistance to a current of water moving through wood at the velocity of the transpiration stream is approximately equivalent to a head of water equal in length to 
the wood traversed. Hence the tension applied to the upper end of the water columns, which will be able to raise the transpiration stream in a tree, must equal the pressure produced by a head of water twice the height of the tree. In a tree $100 \mathrm{~m}$. high, therefore a tension of $20 \mathrm{~atm}$. must be produced.

The cohesion of sap amounting, as it does, to at least $200 \mathrm{~atm}$. is in no way taxed by this tension.

The transpiring cells of the mesophyll normally remain turgid during transpiration; accordingly we would expect, if our line of reasoning is correct, that in high trees the osmotic pressure keeping them distended must correspond in magnitude to the tensions necessary to raise the sap.

This surmise has been confirmed by determinations of the osmotic pressures of the saps of various leaves. These pressures have always been found adequate to resist the transpiration tension; but in many cases other factors enter in, and the pressures developed are much in excess of those demanded by transpiration.

Finally, it has been shown that the stored energy set free by respiration in leaves is quite sufficient to do the work of secretion against the resistance of the transpiration stream; while, when the vapour pressure of water in the surrounding space is low, and when evaporation is doing the work of raising the sap, the expenditure of energy in this process will reduce the quantity of water evaporated only by an imperceptible amount.

\section{Literature.}

Aubert, E., "Recherches sur la respiration et l'assimilation des plantes grasses," Revue général de Botanique, 1892, Tom. 4, p. 373.

Brown, H. T., and Escombe, F., "On the Physiological Processes of Green Leaves," Proc. Roy. Sor. London, 1905, vol. 76 B, p. 29.

Dixon, H. H., "On the Physies of the Transpiration Current," Notes from the Botanicul School of Trinity College, Dublin, 1897, vol. 1, p. 57.

Id. "Transpiration and the Ascent of Sap," Progressus Rei Botrnicae, 1909, Bd. iii, s. 1. 



\section{INDEX}

A

Air dissolved in tensile water, $103 \mathrm{ff}$

Air in conducting tracts, $91 \mathrm{ff}$

Air-pressure balancing osmotic pressure, 153

Air-pressure in traclee, 48,49

Ambronn, 198

Anæsthetics and transpiration, $9 \mathrm{ff}$

André, 178, 186, 188

Atkins, 52, 59, 188

Aubert, 202,211

Beckmanx, 155

Berthelot, 103, 114, 117

Biot, 50, 79

Boehm, 28, 29, 45, 95, 99

Bordered pits, Mechanism of, 98

Boucherie, 49, 79

Brown and Escombe, 2, 25, 201, 211

Bubbles in tensile water, $87,90,91,92$, 93

Bubbles in trachee, 91

CAlILLARITY AND TRANSPIRATION, $4 \mathrm{ff}$ $91,203 \mathrm{ff}$

Carbon dioxide, Effect of, on leaves, $144 \mathrm{ff}$

Influence of, on osmotic pressure, 150

Influence of, on transpiration, $11 \mathrm{ff}$

Cell-wall, Breaking strength of, $19 \mathrm{~s}$

Menisci in, 4, 203, 204, 205

Centrifuge for extracting wool-sap, 44, 57

Chloroform, Influence of, on transpiration, $11 \mathrm{ff}$

Clogging of cut surface, Elimination of, 134

falsifies resistance, 125,126
Cohesion of soap film, 106 of water, $84 \mathrm{ti}, 101 \mathrm{ff}$ containing dissolver air, 10:3 ff Theory, $87 \mathrm{ff}$

Collapse of protoxylem, 97

Colocusia antiquorum, Secretion by, 8,9

Concentration of sap by pressure, $178 \mathrm{ff}$ 183

Concentration of wood-sap, $39,45,58$

Condensation of water on roots, 204

Conducting tracts, Changes in, due to lieat, $54 \mathrm{ff}$

Structure of, 51, 52

Conductivity of sap, Electrical, 17s, 179,185

Contamination of sap due to heat, $55 \mathrm{ff}$ removed, $65 \mathrm{ff}$

Copeland's suction theory, 28, 45

Cotter, 106, 108

Cryoscopy, Beckmann's method, 155

Thermo-electric method of, $156 \mathrm{ff}$

D.RWIN, 123, 138

Dead stems, Rise of water through, 50 if 'Transmission of water through, $53 \mathrm{ff}^{\prime}$

Diffusion through stomata, 2, 3

Dissolved air in tensile water, $103 \mathrm{ff}$

Dixon, 25, 45, 79, 99, 100, 114, 138, $154,173,200,211$

Dixon and Atkins, 174, 18s, 1s9

Jixon and Joly, 26, 45, 114, 154

Donny, 101, 114

Drop experiment, 49

ELETTRICAL CONAUCOIVITY OF SAP, 178, 179,185

of secreted fluid, 9

Theory, 8.3 
Electrolytes in sap, 178, 186

Elf ving, $29,45,95,97$

Energy absorberl by leaf, 201 available for raising sap, $201 \mathrm{ff}$ secretion, 201

relations of leaves and roots, 204 set free by respiration, 202

Errera, 29, 46

Ether, Influence of, on transpiration, $9 \mathrm{ff}$

Evaporation and tension il sap, 209 and transpiration compared, 1 engine, 206

Function of, in transpiration, $+\mathrm{tt}$ in raising sap, 25,203

Evaporation into various gases, $15 \mathrm{ff}$ Raising sap, 25, 203

Ewart, 52, 69, 70, 79, 94, 100, 114, 116, $118,119,122,125,127,131,138$

Extraction, see sap-extraction

Fadivg of leaves indicating a change in water tracts, $54,56,57,62 \mathrm{ff}^{\circ}$

Freezing point and osmotic pressure, relation of, 155, 190.

G.AS GENERATED IN LUMINA, 37

pressure balanced against osmotic pressure, $142 \mathrm{ff}$

Pressure theory, 28

Gases, Transpiration into various, $9 \mathrm{ff}$

Gelatine, Penetration of, into walls, $29 \mathrm{ff}$

Plugging of lumina by, $29 \mathrm{ff}$

Godlewski, 47, 79

Gravitational theory, 81

HALES, 27, 46

Hamburger, 174

Hartig, 28, 46, 48, 49, 79, 93, 100

Heat causing changes in conducting tracts, $54 \mathrm{ff}, 62 \mathrm{ff}$

Heat causing changes in sap of stems, $53 \mathrm{ff}, 62 \mathrm{ff}$

used for extraction of sap of lcaves, 177,186

Henslow, 16, 26

ICE IN LUMINA, effect of, 38 if

Illumination and osmotic pressure, 196

Inbibition, Function of, in transpiration, $4 \mathrm{ff}$

Theory, 29 ff 84

JAMN's CnAN, 20

Janse, 48, 51, 5:2, 5t, 79, 10:2, 117, 118

Johomot, 106, 114

Joly, 81, 87, 100, 119, 206
KAMMERLiNG, 90, 100

Key, Reversing, for thermocouples, 160

LAPLACE, 101, 115

Larmor, 2, 44, 46

Leaf-cclls, Osmotic pressure of, 139

Pressure and tension in, 140

Tensile strength of walls of, $198 \mathrm{ff}$

Liquid air for sap-extraction, $181 \mathrm{ff}$

Lumina blocked with gas, 37 gelatine, $29 \mathrm{ff}$

ice, $38 \mathrm{ff}$

paraffin, $32 \mathrm{ff}^{\circ}$

water vapour, $41 \mathrm{ff}$

of cells and Trachex compared, 52

Transmission in, 29 ff, 53

Marie axd Gatis, 178,189

Maximow, 189

Medullary rays, $47,48,51$

Nodel of transpiring plant, 204

Osuosis, Function of, in transpiration, $4 \mathrm{ff}$

Osmotic pressure and freezing point, 155,190

in plant organs, 192

of leaf cells, t, 139

a measure of tension in tracher, 141, 193

and age, 197

lieight, 195

illumination, 196

resistance, 195

tenacity of cellulose, 198

Effect of carbon dioxide on, 150

measured by external gas pressure, $142 \mathrm{ff}$

measured by freezing point, $190 \mathrm{ff}$

plasmolysis, 142

Variations in, 194

Osmotic theory of Larmor, $t \cdot$

Overton, 80

Oxydase in sap, 58

Oxygeu, Influence of, on transpiration, 9 if

Pappenleim, 98, 100

Paralfin casts of trachece, 35 for plugging trachei, $32 \mathrm{ff}$ Pfeffer, 198

Pliysical Theories, $27 \mathrm{ff}, 81 \mathrm{ff}$

Pits, Bordered, Mechanism of, 98

Plasmolytic method for measuring osmotic pressure, $1+2$ 
Poisonous substances in condncting tracts after lieating, $56 \mathrm{ff}, 60 \mathrm{ff}$

Poynting and Thomson, 115

Pressure concentrates sap of tissues, $178 \mathrm{ff}$

for sap extraction, 175

Velocity of flow in stcms, proportional to, $135 \mathrm{ff}$

Protoplasm, Semi-permeability of, 4, $179 \mathrm{ff}$

Protoplasmic streaming and transmission of water in stems, 52, 5.3

Protoxylem, Collapse of, 97

Quincke's Theory, 83

RENNER, 194, 200

Resistance and osmotic pressure, 195 of walls to flow, 42, 95

of water-tracts, $116 \mathrm{ff}, 124 \mathrm{ff}, 195$

Fffect of temperature on, 70

Ewart's estimates of, 116 ff

falsitied by clogging, 125, 126

Respiration, Energy set free by, 202 necessary for transpiration under water, 24

Root-l'ressure, Function of, 95

Roots, Condensation of water on, 204

Osmotic pressures of, 45, 182, 184, 192,193

SACHS, von, 29, $46,49,83,100$

Siap-extraction, $175 \mathrm{ff}$

by centrifuge, 44,5 ;

chloroform, 176,186

lesiccation, 177

heat, 177,186

liquid air, $181 \mathrm{ff}^{\circ}$

pressure, 175

toluene, 180

Sap of conducting tracts changed by heat, $5.5 \mathrm{ff}$

concentration of, $39,45,58$

contaminated by heat, $56 \mathrm{ff}$

contamination of, renoved, $65 \mathrm{ff}$

extracted by centrifuge, $4 \frac{1}{2}, 57$ oxydase in, 58

raised by evaporation, 203 secretion, $7 \mathrm{ff}, 210$

sugars in, 59

temsile strength of, $110 \mathrm{ff}$.

tissues, concentrated by pressure, $178 \mathrm{ff}$

leaves, osmotic pressure of, 139 , $190 \mathrm{ff}$

Schultz, 50, 80

Schwendener, $49,80,93$, I9S
Secretion and trauspiration, 7 of water, $S$ ff raising sap, 2(1), 210

scmipermeability of protoplasm, 4 , 179

Soap-film, cohesion of, 106

Stephaı, '2

Sitomata, arca of, 1

Diffusion through, 2, 3

Strasburger, 6, 26, 29, 46, 50, s0, sl, $93,94,9 \%, 100,117,138$

Structure of wood and cohesion theory, $91 \mathrm{ff}, 210$

vital theory, 51,210

subdivision of conducting tracts, $91 \mathrm{ff}$, 210

T'enshle Film Theory, $\mathrm{S} 3$

strength of sap, $110 \mathrm{ff}$ water, $103 \mathrm{ff}$

water, Bubbles in, 87,89 rupture of, 86,113

Tension in sap, measured by osmotic pressure in leaf-cells, 141, 193 by flow, 194 retards transpiration, 209

Tension theory, $8 ;$ if

Thermo-couples, Calibration of, 169 Change in constant of, 171

Construction of, 157

Use in Cryoscopy of, $156 \mathrm{ff}$

Thermo-clectric method of cryoscopy, $156 \mathrm{ff}$

Trachea, Contents of, $9 \mathrm{l} \mathrm{fi}$ plugged by effects of heating, jt, 60

Structure of, $96 \mathrm{ff}$

without semi-permeable membranc, 4,44

Transmission of water in walls, $29 \mathrm{ff}$

through dead stems, $53 \mathrm{ff}$ stems as rapour, 42 proportional to pressmre, 13.

Transpiring plant, model of, 204

Transpiration, a physical phenomenon, 6

and anesthetics, $9 \mathrm{ff}$ evaporation, compared, 1 sccretion, $7 \mathrm{ff}$. turgor, 6 controlled by supply, 122 -current, velocity of, 52,132

Function of evaporation, osmosis and imbibition in, 3 fr

Function of living cells in, $7 \mathrm{ff}, 201$

influenced by solutes, i

into saturated spaces, $17 \mathrm{ff}$ into various gases, $9 \mathrm{ft}$ under water, 2.3 
UNGER, 1, 26

Ursprung, 54, 5€, 80, 115

VAPOUR BLOCKING LUMINA, $41 \mathrm{ff}$

Influence on transpiration of, $9 \mathrm{ff}$

Water transmitted as, $42 \mathrm{ff}$

Vesque, 29, 46, 54, 56, 80

Vital actions in transpiration, $7 \mathrm{ff}$

lifting water in stems, Assumed, 47 if

lifting water in stems, looked for, $69 \mathrm{tf}^{\mathrm{t}}$

Vital theories, 47,54

Evidlence from structure regarding, 51
WaLLS OF CELLS, Breaking strength of, $198 \mathrm{ff}^{\prime}$

of trachere, Resistance of, to moving water, 95,96

of tracheer, thickenings on, 96

Weber, 5t, 5.5, 80

W einzierl, 198

Weslermaier, 48, 80

Wilting of leaves indicating changes in water tracts, $54,56,57,6 i 2 \mathrm{ff}$

Wolti, 27

Woorl-sap, Concentration of, $39,45,58$ extracted by centrifuge, 44,57

Wood, Section of elements in, 52

Worthington, 115 


\section{Macmillan's Science Monographs}

HE aim of these volumes is to provide a medium through
which investigators who have made substantial contributions to the advance of Science in particular directions may bring together their results and conclusions and discuss them in connexion with the related work of others.

Scientific research of to-day is essentially specialised; and though investigators may make excursions into various parts of the field of natural knowledge, their names are usually associated most closely with studies of specific areas. Surveys thus carried on are described in papers presented to Scientific Societies during a period which may extend over a number of years; so that the student or the original researcher who desires to know the position of a subject as represented by the work of a leading authority upon it, has to refer to many volumes of Transactions or Proceedings of possibly different Scientific Societies. Occasionally, in an address or an article in a scientific journal, an investigator gives a sketch of the outstanding points of his studies of a subject; but the limitations of space prevent him from doing justice to himself or his work.

Macmillan's Science Monographs afford to authorities upon definite aspects of science a means by which an adequate statement of their work may be madè available to the scientific world within a volume of reasonable dimensions and at a moderate price. The monographs are not intended to be exhaustive records of all the researches that have been carried out in particular subjects, but the expression of the original work of the individual authors, with such consideration of related contributions by others as is demanded of a scientific publication. Each volume is, therefore, unique; and the series forms a collection of authoritative works which claims a place in every scientific library and is of prime value both to the student and the original investigator. 


\title{
Macmillan's Science Monographs
}

Svo.

\author{
TOLUIIES ALREADY PUBLISHED
}

CRYSTALLINE STRUCTURE AND CHEIMICAL CONSTITUTION. By A. E. II. TUTTON, D.Sc., M.A. (Oxon.), F.R.S., A.R.C.Sc. (Lond.), President of the Mineralogical Society; Member of the Councils of the Chemical Society and the British Association for the Advancement of Science. 5s. net.

STABILITY IN AVIATION. An Introduction to Dynamical Stability as applied to the Motions of Aeroplanes. By G. H. BRYAN, Sc.D., F.R.S., Professor of I'ure and Applied Mathematics in the University College of North Wales, formerly Fellow of Peterhouse, Cambridge. 5s, net.

\section{STUDIES IN TERRESTRIAL MAGNETISIM.}

By C. CHREE, M.A., F.R.S., Sc.D. (Camb.), LL.D. (Aberdeen), Superintendent of Kew Observatory; Late Fellow of King's College, Cambridge; Ex-President Physical Society of London. 5s. net.

STUDIES IN RADIOACTIVITY. By W. H. BRAGG, M.A., F.R.S., Cavendish Professor of Physics in the University of Leeds; formeriy Elder Professor of Mathematics and Physics in the University of Aclelaide. 5s, net.

\section{THE COTTON PLANT IN EGYPT : STUDIES}

IN PHYSIOLOGY AND GENETICS. By W. LAIVRENCE BALLS, M.A., Fellow of St. Joln's College, Cambridge ; Membre de l'Institut Egyptien ; Botanist to the Department of Agriculture, Egyptian Government. 5s. net.

\section{RESEARCHES IN MAGNETO - OPTICS. With}

Special Reference to the Magnetic Resolution of Spectrum Lines. By P. ZEEMAN, Sc.D., Ph.D., D.Sc., Nobel Laureate; Professor of Experimental Physics in the University of Amsterdam. $6 s$, net.

STUDIES IN WATER SUPPLY. By A. C. HOUSTON, I.Sc., M.B., C.M., Director of IVater Examination, Metropolitan Water Board. 5s. net.

\section{STELLAR MOVEMENTS AND THE STRUC-} TURE OF THE UNIVERSE. By A. S. EDDINGTON, M.A. (Cantab.), M.Sc. (Manchester), B.Sc. (Lond.), F.R.S., Plumian Professor of Astronomy, University of Cambridge. 6s, net.

\section{TRANSPIRATION AND THE ASCENT OF SAP}

IN PLANTS. By IIENRY H. DIXON, Sc.D., F.R.S., University I'rofessor of Botany in Trinity College, Dublin; Director of Trinity College Botanic Gardens.

$$
\text { IN THE PRESS }
$$

\section{THE MUTATION FACTOR IN EVOLUTION;} WITH PAR TICULAR REFERENCE TO CENOTHERA. By Dr. R. R. GATES, Lecturer in Biology, St. Thomas's Hospital.

$$
\text { LONDON: MACMILLAN AND CO., LTD. }
$$







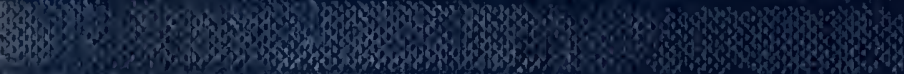

W.

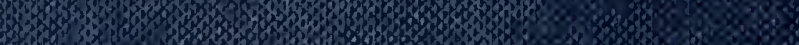

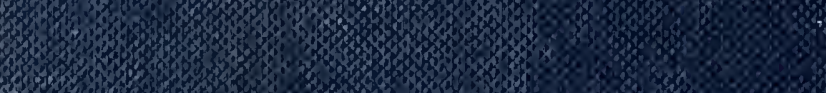

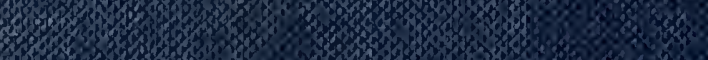

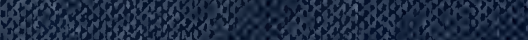

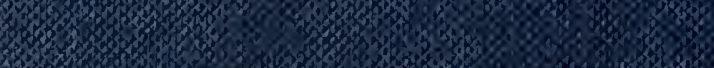

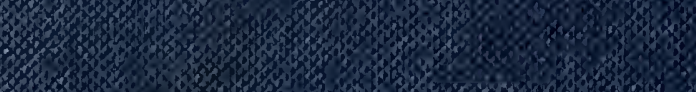

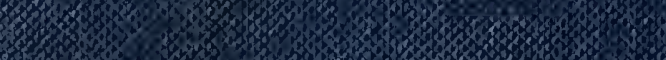

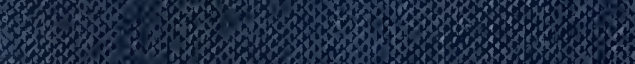

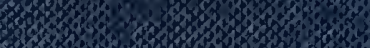

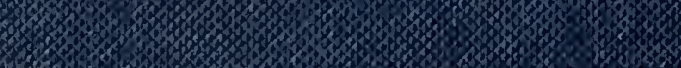

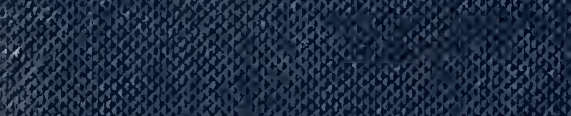

35,30

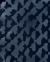

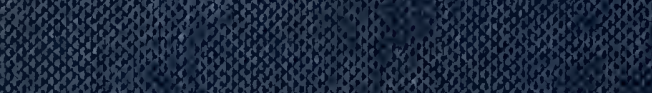

3.

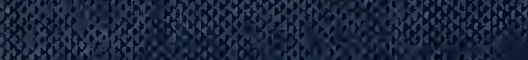

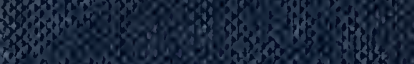

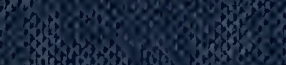

Soly

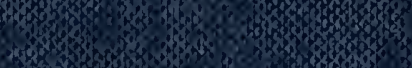

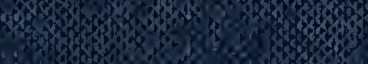

3.

Q3 $30,6,5$

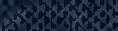

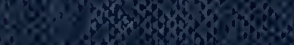

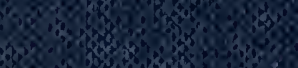

3.

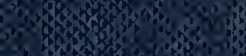

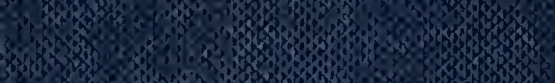

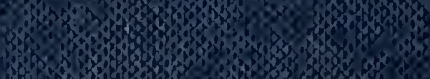

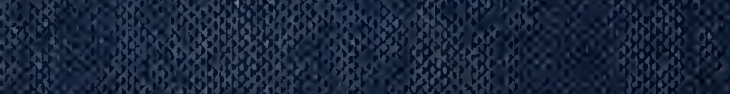

